NBER WORKING PAPER SERIES

\title{
ON THE RELATIONSHIP BETWEEN QUALITY AND PRODUCTIVITY: EVIDENCE FROM CHINA'S ACCESSION TO THE WTO
}

\author{
Haichao Fan \\ Yao Amber Li \\ Stephen R. Yeaple \\ Working Paper 23690 \\ http://www.nber.org/papers/w23690 \\ NATIONAL BUREAU OF ECONOMIC RESEARCH \\ 1050 Massachusetts Avenue \\ Cambridge, MA 02138 \\ August 2017
}

We gratefully acknowledge the financial support from the Natural Science Foundation of China (No.71603155), the Shanghai Pujiang Program (No.15PJC041), the Research Grants Council of Hong Kong, China (General Research Funds and Early Career Scheme GRF/ECS Project No.646112), and the self-supporting project of Institute of World Economy at Fudan University. Yeaple's research was funded in part by the National Science Foundation, grant SES-1360209. The views expressed herein are those of the authors and do not necessarily reflect the views of the National Bureau of Economic Research.

NBER working papers are circulated for discussion and comment purposes. They have not been peer-reviewed or been subject to the review by the NBER Board of Directors that accompanies official NBER publications.

(C) 2017 by Haichao Fan, Yao Amber Li, and Stephen R. Yeaple. All rights reserved. Short sections of text, not to exceed two paragraphs, may be quoted without explicit permission provided that full credit, including $(\subset$ notice, is given to the source. 
On the Relationship Between Quality and Productivity: Evidence from China's Accession to the WTO

Haichao Fan, Yao Amber Li, and Stephen R. Yeaple

NBER Working Paper No. 23690

August 2017

JEL No. F1,F10,F14,O3

\section{ABSTRACT}

This paper presents an analysis of the effect of China's entry into the WTO on the quality choices of Chinese exporters in terms of their outputs and their inputs. Using highly disaggregated firmlevel data, we show that the quality upgrading made possible by China's tariff reductions was concentrated in the least productive Chinese exporters. These firms, which had been laggards in terms of quality prior to the tariff reduction, were the most aggressive in increasing the quality of their exports and their inputs and in redirecting their exports toward high income markets where demand for high quality goods is strong. Our empirical results are consistent with a simple model featuring scale effect and non-Hicks' neutral productivity that disproportionately affects the efficiency with which firms use intermediate inputs. This latter feature does not appear in workhorse models of firm heterogeneity and endogenous quality choice which provide a distorted view of the impact of trade liberalization on quality upgrading.

Haichao Fan

School of Economics

Fudan University

fan_haichao@fudan.edu.cn

Yao Amber Li

Department of Economics

Hong Kong University of Science and Technology

1 University Road, Clear Water Bay, Kowloon

Hong Kong SAR

yaoli@ust.hk
Stephen R. Yeaple

Department of Economics

The Pennsylvania State University

520 Kern Building

University Park, PA 16802-3306

and NBER

sry3@psu.edu 


\section{Introduction}

Firms from developing countries historically have failed to break into developed country markets. Much of their difficulties stem from an inability to produce at sufficiently low cost the high quality goods that these markets demand. One of the reasons proposed for the competitive disadvantage of developing country firms is that government efforts to protect domestic intermediate input producers artificially raise the cost of the high quality intermediate inputs necessary to produce high quality goods.

This paper presents an analysis of the effect of China's entry into the WTO on the quality of Chinese exports. We use highly disaggregated firm-product-level data and the shock of China's entry into the WTO to trace through in detail the mechanisms through which trade liberalization contributes to quality upgrading by Chinese firms. We find that the chief beneficiaries of liberalized intermediate input tariffs are not the initially most productive firms but are instead the less productive firms that are operating in industries in which the scope for quality variation is the most pronounced. It is these lower productivity firms that are most likely to upgrade the quality of their exports, increase the quality of their imported intermediates, and upgrade their workforces. In so doing, these firms are better able to break into markets with high demand for product quality and reduce the gap in their quality performance relative to initially more productive firms.

China's entry into the WTO in 2001 provides an excellent opportunity to identify the causal effect of trade liberalization on quality upgrading. First, the tariff reductions imposed on China, viewed as unilateral trade liberalization, were largely outside of China's control. ${ }^{1}$ Second, China's imports are mostly dominated by intermediate inputs with tiny share of final consumption goods, and so the impact of import tariff reductions is largely operating on imported intermediate inputs. ${ }^{2}$ Third, the effect of tariff reductions on the cost of Chinese production is highly heterogeneous across industries and across

\footnotetext{
${ }^{1}$ As a condition for WTO accession, the reduction in import tariffs by China is largely viewed as the unilateral trade liberalization, because the WTO accession does not require corresponding changes in its trading partners' import barriers (Ju, Shi and Wei, 2012). It is also well known that its major trading partners had already granted MFN treatment to China long before China joined the WTO (Fan, Li and Yeaple, 2015). The summary statistics of the export tariff reductions also supports the fact of unilateral liberalization: between the sample period of 2001 and 2006, the export tariff reductions imposed on China's exports by trading partners are around $1 \%$. In contrast, the average import tariff reductions by China are around $6 \%$ during the same period.

${ }^{2}$ Based on product classification by BEC (Broad Economic Categories), intermediate goods and capital goods account for $74 \%$ and $19 \%$, and final consumption goods account for only $4 \%$, of total import values for China during 2000-2006. A fourth "uncertain" category accounts for approximately $3 \%$. If we view capital goods also as "intermediates", then intermediates account for $93 \%$ of total imports in China. In contrast, the share of intermediate goods in total imports for US is approximately $47 \%$ during the same period. To show the comparison of import composition between China and other developed countries, we present the share of the four categories of goods, namely, capital goods, consumption goods, intermediate goods, and uncertain goods, in total imports for China, US, EU, and Japan in Figure A.1 in the online appendix (see Appendix D).
} 
firms within industries. We carefully calculate total factor productivity of Chinese firms just prior to the trade liberalization and provide the following stylized facts: low TFP exporters were most likely (i) to increase their export prices to foreign destinations, and (ii) to increase the wages they pay their workers and the prices they pay for their inputs. Importantly, these outcomes were only present in those industries in which quality heterogeneity across products is high. Moreover, the evidence at the extensive margin shows that low TFP exporters were most likely to expand into high income country markets where demand for high quality goods is strong.

We develop a simple model of output and input quality choice to flesh out the mechanisms at work. In the model, firms differ in their productivity and maximize profits by choosing the quality of their output and inputs. As in many models of innovation, our model features scale effects whereby a larger market share induces more quality innovation and more productive firms charge higher export prices. Additionally, higher quality output requires higher quality (and more expensive) inputs. As a result, more productive firms pay higher prices for their inputs and sell at higher prices for their outputs. This mechanism induces firms to upgrade their quality in response to a reduction in import tariffs since productivity and low cost inputs are in a sense substitutable. More importantly, firm productivity is not Hicks' neutral and disproportionately affects the efficiency with which firms use intermediate inputs. As initially more productive firms are less affected by cost of inputs, the return to quality upgrading for high productivity firms is less sensitive to tariffs on imported inputs. Consequently, our model makes it possible to explain why more productive firms produce higher quality output using higher quality inputs, but gain less from tariff reductions than less productive firms.

We use the first-order conditions of our model to devise an econometric strategy to estimate the size of mechanism at work in our model. The model's predictions prove to be robust to a wide range of econometric specifications, to alternate methods of calculating tariff reductions enjoyed at the firm level or industry level, and to alternative measures of initial firm productivity. More importantly, we provide support to the interpretation of the data as quality upgrading through input prices of both labor input and imported intermediate inputs as well as through the share of imported inputs in total intermediate inputs. In addition, we present evidence at the extensive margin that the change in export price and destination markets' income is more pronounced for less productive firms who aggressively respond to input tariff reductions by shifting their exports from countries with relatively weak demand for high-quality goods to countries with strong demand for high-quality goods.

Our paper is linked to a large literature on firm heterogeneity in performance. We show how firm heterogeneity in productivity maps into firm heterogeneity in quality and how shocks to the economic environment caused by trade liberalization alters this map- 
ping. Our theoretical model shows and our empirical estimates confirm that the role of productivity is not as simple as the standard heterogeneous-firm models that have followed from the canonical Melitz (2003) framework. In particular, our results show that firms demonstrating high productivity in highly protected developing countries are relatively well adapted for an environment in which high quality intermediates are expensive to procure. In this way, our results provide nuance to the results of Halpern, Koren and Szeidl (2015) who show asymmetric effects across Hungarian firms' measured productivities following a trade liberalization. Improved access to intermediate inputs favors relatively low productivity exporters who were less efficient in handling intermediate inputs before trade. ${ }^{3}$

Our paper also contributes to a growing literature on the impact of greater access to imported intermediate inputs on firm-level performance, especially on export quality. ${ }^{4}$ Highly related, recent examples include Fan, Li and Yeaple (2015) and Bas and StraussKahn (2015). Fan, Li and Yeaple (2015) focus on cross industry heterogeneity. They show that export price increases were present only in those industries in which quality variation was initially high and that firms tended to migrate toward markets and toward products in which quality heterogeneity is most important. Our current paper digs deeper into crossfirm heterogeneity within industries. We show that, both theoretically and empirically, the chief beneficiaries of the tariff reduction with respect to trade liberalization is not the most productive firms who were initially producing relatively high quality goods from high quality inputs but was rather the least productive of the set of exporters. Indeed, the most productive firms may respond little to tariff cuts on their imported intermediates and to the extent that they did, they simply passed cost savings on to consumers. Bas and Strauss-Kahn (2015) explore the link between tariff cuts that hit Chinese exporters asymmetrically and the prices paid by firms for their imported inputs and received for their exports. This paper also differs from Fan, Li and Yeaple (2015) and Bas and Strauss-Kahn (2015) by examining extensive margin effect that firms set different prices for their outputs in different markets and how the extensive margin relates to a firm's initial productivity under trade liberalization.

Much of the literature on the effect of trade liberalization on quality (e.g. Verhoogen, 2008) relies on variation in access to foreign markets following a fall in foreign tariffs or a real exchange rate shock. The interpretation given in these papers tends to be one

\footnotetext{
${ }^{3} \mathrm{Feng}, \mathrm{Li}$ and Swenson (2016) provide evidence that private Chinese firms derived a greater benefit from imported foreign intermediates relative to foreign invested firms, which is consistent with the interpretation given by Halpern, Koren and Szeidl (2015).

${ }^{4}$ For instance, Amiti and Konings (2007) and Kasahara and Rodrigue (2008) for the impact on productivity. Antràs, Fort and Tintelnot (2017) estimate a model in which profits are supermodular in productivity and imports. Goldberg et al. (2010) show that access to greater intermediate inputs induced Indian firms to expand their product scope. Manova and Zhang (2012a) focuses on cross sectional data in trying to infer the relationship between export quality and productivity. We take the further step to look at the effect of trade liberalization on the relationship between input/output quality and productivity.
} 
of scale effects: more productive firms enjoy large sales which tilts innovation decisions toward higher variable profits at the expense of higher fixed costs. Our paper shows this mechanism alone is insufficient to understanding the heterogeneous quality upgrading that is actually observed: the impact on scale effects for the most productive firms needs to be moderated by some form of decreasing variable returns. ${ }^{5}$

The remainder of this paper is organized in five sections. In Section 2, we describe the data and generate a series of stylized facts on the link between firms' initial productivity, export and import prices, and the subsequent adjustment of export and input prices following the trade liberalization. In Section 3, we introduce a model that shows how input and output quality and firm initial efficiency map into a firm's choice of export and input prices and how this mapping is altered by falling input tariffs. In Section 4, we specify a simple econometric model and describe the construction of the data and measures used to estimate the model. Section 5 provides the main results and robustness exercises concerning the link between a firm's initial productivity, the size of the tariff reduction experienced, and the resulting impact on export prices, input prices (such as imported input prices and wage payment) and export destinations. The final section concludes.

\section{Data and Stylized Facts}

Data. - To capture firms' productivity and import/export prices, we merged two databases: (1) the firm-product-level trade data from Chinese customs, and (2) the firm-level production data, collected and maintained by the National Bureau of Statistics of China (NBSC). Our sample period is between 2001 and $2006 .^{6}$

The transaction-level trade data, provided by China's General Administration of Customs covers the universe of all Chinese exports and imports in 2001-2006 at the HS 8-digit level. For each trade transaction, it records detailed information including import and export values, quantities, products, source or destination countries, contact information of the firm (e.g., company name, telephone, zip code, contact person), type of enterprises (e.g. state owned, domestic private, foreign invested, and joint ventures), and customs regime (e.g. "Processing and Assembling" and "Processing with Imported Materials"). As firms under processing trade regime are not subject to import tariffs, we focus on firms under ordinary trade regime. Then we aggregate transaction-level data to firm-HS6 product-level or firm-HS6-country trade data. ${ }^{7}$ For each HS 6-digit product, we use ex-

\footnotetext{
${ }^{5}$ Our framework shares much in common with Feenstra and Romalis (2014) who focus primarily on aggregate provision of quality across markets, but do not explore the differential impacts of quality across firms and the heterogeneous response within industry.

${ }^{6}$ We do not include the year 2000 because the WTO tariff data at HS 8-digit level are not available.

${ }^{7}$ China changed HS- 8 codes in 2002, and the concordance between the old and new HS- 8 codes (before
} 
port/import values and quantities to compute unit value export/import prices by each firm. ${ }^{8}$ Our empirical analysis for product/variety therefore refers to either HS6 product category or HS6-country combination.

To characterize firms' attributes such as TFP and capital intensity, we also use the NBSC firm-level production data from the annual surveys of Chinese manufacturing firms, covering all state-owned enterprises (SOEs), and non-state-owned enterprises with annual sales of at least 5 million Renminbi (RMB). The NBSC database contains firmlevel production and accounting information of manufacturing enterprises in China, such as employment, capital stock, gross output, value added, and firm identification (e.g., company name, telephone number, zip code, contact person). Due to some mis-reporting, we follow Cai and Liu (2009) and use General Accepted Accounting Principles to delete the unsatisfactory observations. ${ }^{9}$

Then we merge the firm-product-level trade data from the Chinese Customs Database with the NBSC Database using the contact information of manufacturing firms. ${ }^{10}$ Our matching procedure is done by company name first, and next by both zip code and telephone number, and lastly by telephone number and contact person name together (see detailed description of the matching process in Fan, Lai and Li, 2015). Our merged sample covers $52.4 \%$ of total export value and $42 \%$ of total import value reported by the Customs Database. ${ }^{11}$

We use the NBSC firm-level production data to measure revenue TFP in our main results. To overcome known issues in revenue TFP, we also show that our main results are robust to physical TFP measures by merging the firm-level revenue-based production data with another newly obtained dataset on firms' quantity output from the NBSC for the same sample period (see Section 4.3 for more detailed discussion on various TFP measures and their estimation methods). ${ }^{12}$

and after 2002) is not available. To ensure the consistency of the product categorization over time (20012006), we choose to adopt HS-6 codes maintained by the World Customs Organization (WCO) and use the conversion table from the UN Comtrade to convert the HS 2002 codes into the HS 1996 codes.

${ }^{8}$ We use two measures to compute unit value export/import prices: (1) the export/import prices of each HS 6-digit goods by each firm, and (2) the export/import prices of the HS 6-digit goods shipped to/from different countries by each firm, i.e., we view the same HS 6-digit goods exported to/imported from different countries as "different" varieties.

${ }^{9}$ We use the following rules to construct our sample: (i) the total assets must be higher than the liquid assets; (ii) the total assets must be larger than the total fixed assets; (iii) the total assets must be larger than the net value of the fixed assets; (iv) a firm must have a unique identification number; and (v) the established time must be valid.

${ }^{10}$ This merging has to be done using the contact information of firms due to the lack of consistent firm identification between the two databases. The NBSC Database uses the corporate representative codes to identify firms while the Customs Database adopts another set of corporate custom codes as firm identity. These two firm identity coding systems are not transferable between each other.

${ }^{11}$ When merging the Customs Database with the NBSC data, we exclude intermediaries and/or trading companies.

${ }^{12}$ This quantity output database contains information on each product, defined by the Chinese product classification $(\mathrm{CPC})$ at the 5-digit level, produced by the firm, and in particular, output quantity. We 
Finally, the Chinese import tariff data are obtained from the WTO website, available as MFN (most-favored nation) applied tariff at the most disaggregated level, the HS 8digit level, for the period 2001-2006. ${ }^{13}$ As our product is defined at HS6 level, we compute average tariff at HS6 level by using each HS8 tariff line within the same HS6 code. We then calculate firm-specific and industry-specific tariffs in empirical investigation (see more details in Section 4.2). The summary statistics of key variables in our firm-product(country) sample for regression analysis are reported in Table 1.

Table 1: Summary Statistics of Key Variables and Sample

\begin{tabular}{|c|c|c|c|c|c|}
\hline Variable & Mean & Median & S.D. & Min & $\operatorname{Max}$ \\
\hline \multicolumn{6}{|c|}{ Sample: Firm-HS6-country } \\
\hline$\Delta \ln ($ price $)$ & 0.13 & 0.09 & 0.90 & -7.64 & 9.94 \\
\hline$\Delta$ Duty & -0.06 & -0.05 & 0.05 & -1.11 & 0 \\
\hline$\Delta \ln (\mathrm{TFP})$ & 0.43 & 0.38 & 0.95 & -9.08 & 5.76 \\
\hline $\ln (\text { price })_{2001}$ & 1.51 & 1.26 & 2.18 & -9.07 & 12.76 \\
\hline $\ln (\text { price })_{2006}$ & 1.63 & 1.38 & 2.16 & -6.54 & 12.49 \\
\hline $\ln (\mathrm{TFP})_{2001}$ & 4.34 & 4.30 & 1.05 & -0.62 & 8.36 \\
\hline $\ln (\mathrm{TFP})_{2006}$ & 4.77 & 4.78 & 1.10 & -5.41 & 8.53 \\
\hline \multicolumn{6}{|c|}{ Sample: Firm-HS6 } \\
\hline$\Delta \ln ($ price $)$ & 0.15 & 0.11 & 1.01 & -9.26 & 9.96 \\
\hline$\Delta$ Duty & -0.06 & -0.06 & 0.05 & -1.11 & 0 \\
\hline$\Delta \ln (\mathrm{TFP})$ & 0.42 & 0.36 & 0.97 & -9.08 & 7.35 \\
\hline $\ln (\text { price })_{2001}$ & 1.53 & 1.30 & 2.08 & -9.07 & 13.27 \\
\hline $\ln (\text { price })_{2006}$ & 1.68 & 1.45 & 2.05 & -7.55 & 14.20 \\
\hline $\ln (\mathrm{TFP})_{2001}$ & 4.26 & 4.25 & 1.05 & -0.62 & 8.36 \\
\hline $\ln (\mathrm{TFP})_{2006}$ & 4.68 & 4.67 & 1.10 & -5.41 & 8.53 \\
\hline
\end{tabular}

Notes: The summary statistics of key variables for the continuing firm-HS6-country triplets are reported in the top panel. The number of continuing firm-HS6-country combinations is 16907 and the number of correspondent firms is 2600 . The summary statistics of key variables for the continuing firm-HS6 combinations are reported in the bottom panel. The number of continuing firm-HS6 combination is 8971 and the number of correspondent firms is 2889. Key variables is consist of $(\log )$ price and TFP at year 2001 and 2006, their log change from 2001 to 2006 as well as firm-specific tariff reduction.

Stylized Facts. - Now we document three stylized facts concerning the relationship between output/input prices and productivity during trade liberalization. In this section we use unit-value price as coarse proxy for quality because quality differentiation is often viewed as the main determinant of variation in export unit values (Hallak, 2006; Feenstra and Romalis, 2014), and also because of its simplicity and easy availability in the data. We acknowledge that, apart from quality, there exist other determinants of export unit are able to merge this quantity database with the NBSC production data as the two databases adopt the same firm identification code. We will focus on single-product firms in estimating physical TFP.

${ }^{13}$ The data are available at http://tariffdata.wto.org/ReportersAndProducts.aspx. 
values (see a more explicit and detailed discussion in Hallak, 2006). As a result, unit value prices are not perfect proxies for quality. The development in the literature proposes a solution using price and market share data to estimate quality (see a seminal work by Khandelwal, 2010). In the later part of this paper we will also estimate quality as residual from a demand equation. Nonetheless, here we document stylized facts using data on unit values.

The key message from those facts is the closing gap between less and more productive firms following the initial differences in terms of their output and input prices under trade liberalization. As China joined the WTO in December of 2001, we use the data from 2001 to represent the pre-liberalization period and data from 2006 to represent the post-liberalization period. All firms we examine are incumbent exporting/importing firms that are present in both pre- and post-liberalization periods. We focus on incumbent twoway traders that conduct both exporting and importing because of their importance in the productivity distribution and data availability. Since a product is defined at either HS6 or HS6-destination level, it is convenient to compare the changes in export prices at different levels of aggregation that can uncover how changes in the composition of destination markets affect average export prices.

Fact 1: Levels and changes of export prices with respect to firm initial productivity.Table 2 reports the changes in (log) export prices by less and more productive firms via the levels of export prices in both 2001 and 2006. Firms are divided into two groups high- and low-productivity firms based on whether their labor productivity (value added per worker) is above or below the median in the pooled sample in 2001. ${ }^{14}$ Within each group, the median and mean (log) export prices per firm-product in 2001 and in 2006 as well as the percentage changes (in parentheses) are reported.

Table 2 shows that firms with lower initial productivity increase export prices more than those with higher initial productivity, at both firm-product and firm-product-country levels. It is also interesting to note that the price increases are greater at HS6 product level than at HS6-country level due to a composition effect, i.e., firms would charge higher average export prices by entering more destination markets where demand for high quality goods is strong after trade liberalization. To better illustrate the difference between low- and high-productivity firms regarding the change in their export prices of both HS6-country or HS6 products, we also plot the distributions of export prices (in natural logarithm) in 2001 and 2006 in Figure 1. The left panel of Figure 1 refers to firms with initial productivity lower than median productivity; the right panel refers to firms

\footnotetext{
${ }^{14}$ Using estimated total factor productivity (TFP) to group the data yields similar patterns. Note that when using value added per worker or revenue based TFP measures, prices might pollute the measured TFP cutoff used to construct two groups of firms. Then a simple mean-revision pattern would occur to yield higher price growth for initially low-price firms. To eliminate this concern, we also use physical productivity measures and show the robustness of our results to the use of physical TFP (see later discussion in Section 5.1.2 "Robustness for Main Results").
} 
Table 2: Export Prices in 2001 and 2006 and Price Changes from 2001 to 2006

\begin{tabular}{ccccc}
\hline \hline & \multicolumn{2}{c}{ Firm productivity $\leq 50$ th } & \multicolumn{2}{c}{ Firm productivity $>50$ th } \\
\cline { 2 - 5 } & $(1)$ & $(2)$ & $(3)$ & $(4)$ \\
& 2001 & 2006 & 2001 & 2006 \\
\hline $\begin{array}{c}\text { Export Price (HS6-County) } \\
\text { Per Firm-product-country, median }\end{array}$ & 1.04 & $1.22(11.93 \%)$ & 1.33 & $1.38(5.86 \%)$ \\
$\quad$ Per Firm-product-country, mean & 1.11 & $1.28(17.53 \%)$ & 1.59 & $1.68(9.05 \%)$ \\
Export Price (HS6) & & & & \\
$\quad$ Per Firm-product, median & 1.13 & $1.33(14.48 \%)$ & 1.38 & $1.51(8.92 \%)$ \\
Per Firm-product, mean & 1.18 & $1.37(19.65 \%)$ & 1.64 & $1.75(11.78 \%)$ \\
\hline \hline
\end{tabular}

Notes: Prices are in logarithm. Export prices are unit values, computed by dividing deflated export values by the physical quantity. Price changes are presented in parentheses.

Figure 1: Distributions of Export Prices by Initial Firm Productivity in 2001 and 2006

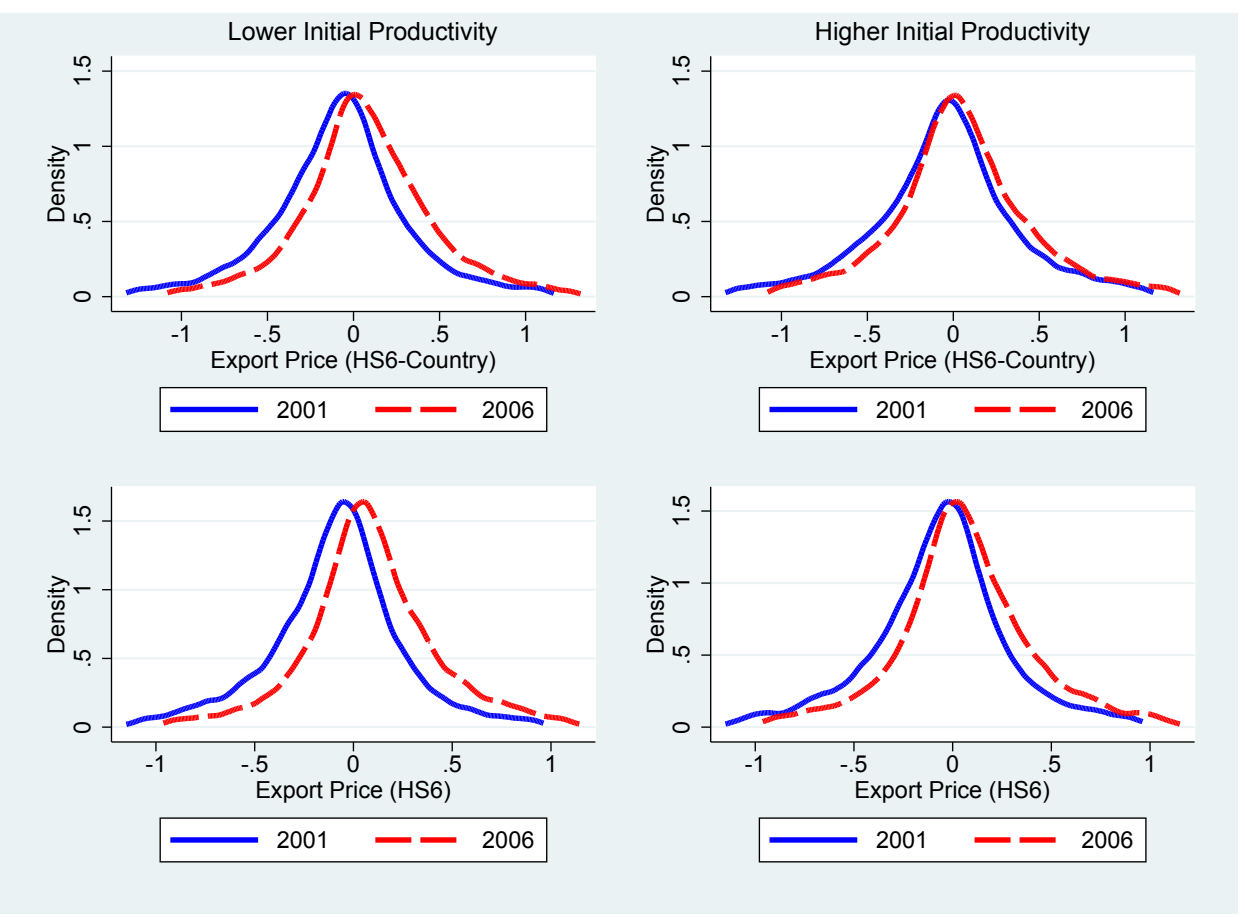

Notes: Prices for continuing firm-HS6-country triplets (see the top panel) and for continuing firm-HS6 combinations (see bottom panel) are in logarithm. Graphs in the left panel refer to firms with lower initial productivity (i.e., productivity lower than the median) and graphs in the right panel refer to firms with higher initial productivity (i.e., productivity above the median). Price distributions are drawn by regressing export prices on firm-HS6-country (see the top panel) and firm-HS6 (see the bottom panel) fixed effects and then plotting the residuals, as in De Loecker et al. (2016).

with productivity higher than the median. In the two graphs in the top we include firmHS6-country triplets that are present in both years for the distribution of prices, while in the two graphs in the bottom we focus on firm-HS6 products. Then we compare export prices over time by regressing them on firm-HS6(-country) fixed effects and plotting the 
residuals. To ensure that our results are not driven by outliers, we remove outliers in the bottom and top 2nd percentiles. The distributions of export prices for both HS6 product and HS6-country move to the right in 2006, and this shifting pattern is more profound for low-productivity firms. We summarize the first stylized fact as follows:

Stylized fact 1. During trade liberalization, firms with lower initial productivity raise export prices more than those with higher initial productivity.

Table 3: Change in Export Prices for Differentiated Goods and Homogeneous Goods

\begin{tabular}{|c|c|c|c|c|c|c|}
\hline & \multicolumn{2}{|c|}{ Whole Sample } & \multicolumn{2}{|c|}{ Differentiated goods } & \multicolumn{2}{|c|}{ Homogeneous goods } \\
\hline & $(1)$ & $(2)$ & $(3)$ & $(4)$ & $(5)$ & $(6)$ \\
\hline & $\leq 50 \mathrm{th}$ & $>50 \mathrm{th}$ & $\leq 50$ th & $>50$ th & $\leq 50$ th & $>50$ th \\
\hline \multicolumn{7}{|l|}{ Change in Export Price (HS6-Country): } \\
\hline Per Firm-product-country, median & $11.93 \%$ & $5.86 \%$ & $13.23 \%$ & $7.24 \%$ & $0.34 \%$ & $-0.16 \%$ \\
\hline Per Firm-product-country, mean & $17.53 \%$ & $9.05 \%$ & $18.67 \%$ & $10.35 \%$ & $0.81 \%$ & $0.95 \%$ \\
\hline \multicolumn{7}{|l|}{ Change in Export Price (HS6): } \\
\hline Per Firm-product, median & $14.48 \%$ & $8.92 \%$ & $16.12 \%$ & $11.56 \%$ & $1.16 \%$ & $-2.74 \%$ \\
\hline Per Firm-product, mean & $19.65 \%$ & $11.78 \%$ & $20.96 \%$ & $13.45 \%$ & $5.39 \%$ & $2.33 \%$ \\
\hline
\end{tabular}

Notes: $\leq 50$ th indicates the firms associated with lower initial productivity (i.e., the bottom 50 th percentile); $>50$ th indicates the firms associated with higher initial productivity (i.e., the top 50th percentile).

Fact 2: Export price changes depend on product quality differentiation. - To explore whether the effect of trade liberalization on export prices depends on quality differentiation, we report in Table 3 export price changes for all goods, differentiated goods, and homogeneous goods, according to Rauch's product classification (Rauch, 1999). ${ }^{15}$ It is usual practice in the trade-and-quality literature that adopts differentiated goods and homogeneous goods to roughly represent heterogeneous-quality products (i.e., goods with large scope for quality differentiation) and homogeneous-quality products (i.e., goods with small scope for quality differentiation), respectively. There are two observations in Table 3. First, for all goods and differentiated products, the firms with lower initial productivity always raise their export prices more than those with higher initial productivity (see column 1 vs. 2 and column 3 vs. 4), while for homogeneous goods this pattern is less pronounced (see column 5 vs. 6). Second, for firms with similar productivity (see low-productivity firms in odd columns and high-productivity firms in even columns), the export price increases show the greatest changes in differentiated goods, the medium changes in all goods, and the least changes in homogeneous goods. Figure 2 also presents the differential effect of product differentiation on price distributions by firm productivity: the export prices of differentiated goods significantly increase from 2001

\footnotetext{
${ }^{15}$ Here homogeneous goods include both goods traded on organized exchanges and reference-priced goods. When we use a narrower definition of homogeneous goods with only organized-exchanged goods, the fact still remains.
} 
Figure 2: Price Distributions for Differentiated Goods and Homogeneous Goods (HS6Country)

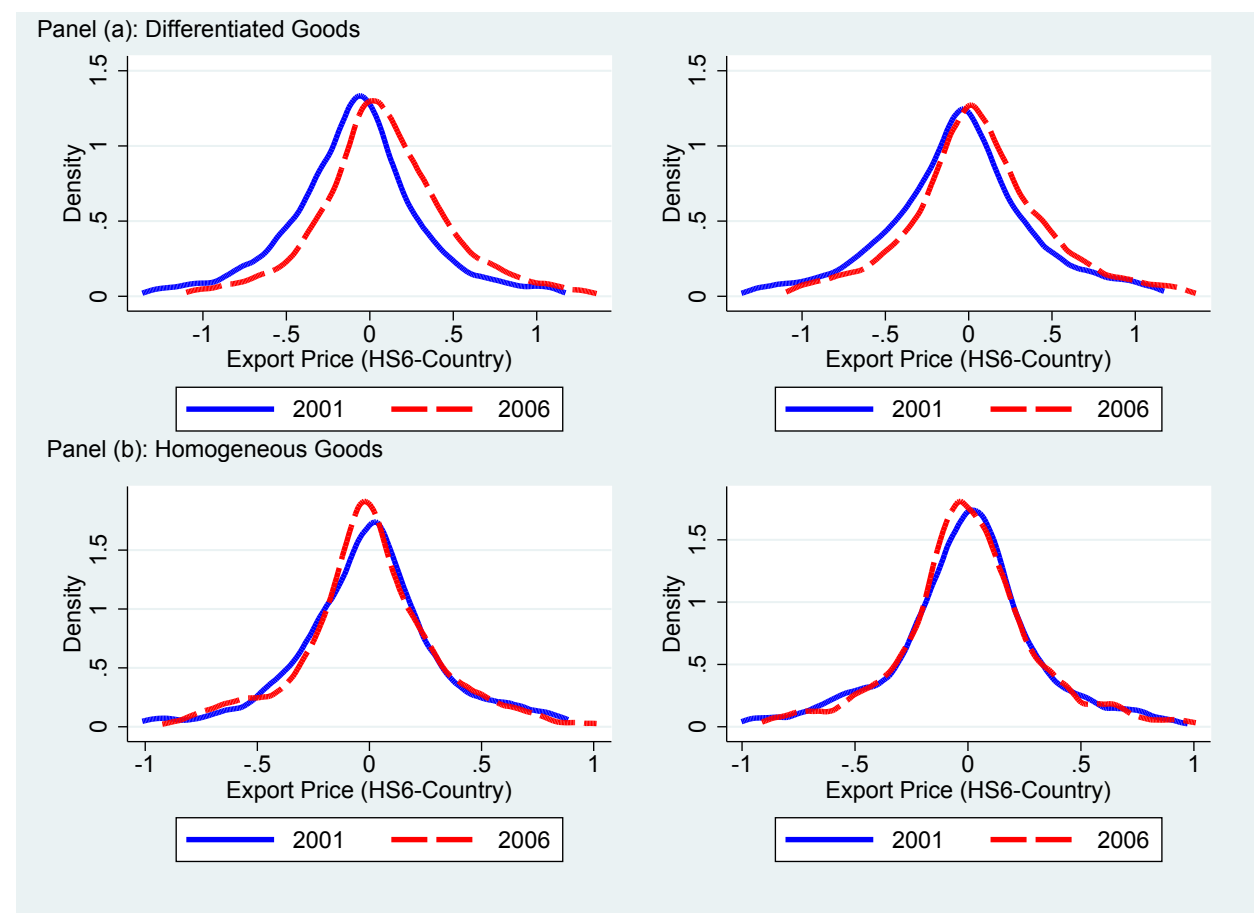

Notes: Prices of continuing firm-HS6-country triplets are in logarithm. Panel (a) presents price distribution for differentiated goods (see the top panel) and Panel (b) presents price distribution for homogeneous goods (see the bottom panel). Graphs in the left panel refer to firms with lower initial productivity (i.e., productivity lower than the median) and graphs in the right panel refer to firms with higher initial productivity (i.e., productivity above the median). Price distributions are drawn by regressing export prices on firm-HS6-country fixed effects and then plotting the residuals, as in De Loecker et al. (2016).

to 2006 in Panel (a) where the low-productivity firms (in the left graph) raise export prices more than high-productivity firms do (in the right graph), i.e., the gap between the solid line and the dashed line is larger for low-productivity firms; while the export prices of homogeneous goods nearly remain unchanged over time (see Panel (b)) regardless of firm productivity. ${ }^{16}$ This suggests that the effect of tariff reduction on export prices conditional on firms' initial productivity also depends on the scope for product quality differentiation. The finding is summarized as follows:

Stylized fact 2. During trade liberalization, firms with lower initial productivity raise export prices of heterogeneous-quality products more than those with higher initial productivity, while the changes in export prices of homogeneous-quality products are less pronounced regardless of firm productivity.

\footnotetext{
${ }^{16}$ Figure 2 is based on HS6-country products. We also present the distributions of export prices for HS6 products in Figure A.2 in the online appendix and find similar patterns.
} 
Table 4: Changes in Wages \& Import Prices from 2001 to 2006 and Their Initial Values

\begin{tabular}{|c|c|c|c|c|c|c|}
\hline & $\begin{array}{c}\quad(1) \\
\leq 50 \text { th }\end{array}$ & $\begin{array}{c}(2) \\
>50 \text { th }\end{array}$ & $\begin{array}{c}\quad(3) \\
\leq 50 \text { th }\end{array}$ & $\begin{array}{c}(4) \\
>50 \text { th }\end{array}$ & $\begin{aligned} & (5) \\
\leq & 50 \mathrm{th}\end{aligned}$ & $\begin{array}{c}(6) \\
>50 \text { th }\end{array}$ \\
\hline & \multicolumn{2}{|c|}{$\begin{array}{c}\text { Change in Wage Payment } \\
\text { (Firm Level) } \\
\text { Per Firm }\end{array}$} & \multicolumn{2}{|c|}{$\begin{array}{l}\text { Change in Import Price } \\
\text { (HS6-Country Level) } \\
\text { Per Firm-HS6-Country }\end{array}$} & \multicolumn{2}{|c|}{$\begin{array}{c}\text { Change in Import Price } \\
\text { (HS6 Level) } \\
\text { Per Firm-HS6 }\end{array}$} \\
\hline Median & $\begin{array}{c}48.07 \% \\
{[1.91]}\end{array}$ & $\begin{array}{c}40.18 \% \\
{[2.24]}\end{array}$ & $\begin{array}{c}10.54 \% \\
{[2.65]}\end{array}$ & $\begin{array}{l}6.92 \% \\
{[3.08]}\end{array}$ & $\begin{array}{c}12.63 \% \\
{[2.62]}\end{array}$ & $\begin{array}{l}6.26 \% \\
{[3.11]}\end{array}$ \\
\hline Mean & $\begin{array}{c}57.53 \% \\
{[1.80]}\end{array}$ & $\begin{array}{c}44.74 \% \\
{[2.22]}\end{array}$ & $\begin{array}{c}19.54 \% \\
{[2.94]}\end{array}$ & $\begin{array}{c}13.43 \% \\
{[3.21]}\end{array}$ & $\begin{array}{c}23.41 \% \\
{[2.93]}\end{array}$ & $\begin{array}{c}15.20 \% \\
{[3.30]}\end{array}$ \\
\hline
\end{tabular}

\footnotetext{
Notes: The initial values (in logarithm) refer to wage payment and import prices in 2001 (presented in brackets underneath). <50th indicates the firms associated with lower initial productivity (i.e., the bottom 50 th percentile); $>50$ th indicates the firms associated with higher initial productivity (i.e., the top 50th percentile).
}

Fact 3: Changes in input prices. - Table 4 shows that the changes in labor input prices through wage payment per firm and the percentage changes in import prices for intermediate inputs per firm-product between 2001 and 2006 indeed depend on initial firm productivity. Columns 1 and 2 present the results for wage payments; columns 3-4 and 5-6 show the results for import prices at HS6-source country and HS6 level, respectively. Table 4 clearly shows that the increases in wages and import prices are greater for initially low productivity firms (see the odd columns vs. even columns). Also, the initial values in brackets show that more productive firms pay higher input prices at the beginning. Hence, we have the following stylized fact:

Stylized fact 3. More productive firms pay higher input prices for both its primary and intermediate inputs. During trade liberalization, firms purchase more expensive labor and intermediate inputs. This effect is more pronounced for less productive firms.

\section{Model}

In this section, we develop a simple model to rationalize the stylized facts presented in the previous section. There are two mechanisms at work in the model. First, more productive firms charge higher prices for their output and pay higher prices for their inputs because large scale production induces productive firms to dramatically upgrade their output quality and high output quality requires high quality inputs. This mechanism also induces firms to upgrade their quality in response to a reduction in import tariffs. The second mechanism makes the model's predictions consistent with the stylized fact that quality upgrading's effects are larger for initially less productive firms. This mechanism arises from the assumption that firm productivity disproportionately affects the efficiency 
with which firms use intermediate inputs. Hence, a reduction in the cost of imported intermediates acts as a relatively less powerful impact on the initially more productive firms.

\subsection{Assumptions}

As we are interested in how firms behave both within and across industries, we consider the following system of preferences:

$$
U=\sum_{i}^{I} \nu_{i} \ln \left[\int_{\omega \in \Omega_{i}} q(\omega)^{\frac{\eta_{i}}{\sigma_{i}}} x(\omega)^{\frac{\sigma_{i}-1}{\sigma_{i}}} d \omega\right]^{\frac{\sigma_{i}}{\sigma_{i}-1}},
$$

where $\nu_{i}$ is the share of industry $i$ in total expenditure, $q(\omega)$ is a measure of quality of variety $\omega, x(\omega)$ is the quantity of variety $\omega$ consumed, $\sigma_{i}>1$ is the elasticity of substitution across varieties of $\operatorname{good} i, \eta_{i}>0$ is a measure of the scope for quality differentiation, and $\Omega_{i}$ is the set of varieties available of good $i$. These preferences imply that in a market in which aggregate expenditure is $E$, the demand for variety $\omega$ in industry $i$ is

$$
x_{i}(\omega)=\nu_{i} E P_{i}^{\sigma_{i}-1} q(\omega)^{\eta_{i}} p(\omega)^{-\sigma_{i}}
$$

where $P_{i}$ is the industry-level price index that is exogenous from the point of view of individual firms.

Producing a higher quality product raises firm profitability directly through its effect on demand but it is more costly to the firm for two reasons. First, product design incurs fixed costs and these fixed costs depend on the number of attributes that the firm chooses to build into the variety. We assume that these fixed costs, measured in terms of bundles of the primary inputs is given by $f q^{\beta_{i}}$. The industry subscript on $\beta_{i}>0$ indicates that given the nature of goods in some industries, designing products with a large number of attributes desired by consumers differs. The higher is $\beta_{i}$ the more difficult it is to design products that consumers value more. Hence, a large value of $\beta_{i}$ or a low value of $\eta_{i}$ indicates that the scope for quality differentiation is limited.

Second, producing higher quality output requires firms to use higher quality inputs. The production function for output of quality $q$ for a firm of productivity $\varphi$ takes the following form:

$$
x_{i}(q)=\varphi\left(\frac{V(q)}{1-\mu_{i}}\right)^{1-\mu_{i}}\left(\frac{M_{i}(q)}{\mu_{i}}\right)^{\mu_{i}}, \mu_{i} \in(0,1)
$$

where $V(q)$ is a bundle of primary factors of quality $q, M_{i}(q)$ is a composite intermediate input of quality $q$ that is used in industry $i$, and $\varphi$ is firm productivity. The price facing 
the firm for a bundle of primary factors of quality $q$ is given by $w(q)=w g(q)$, where $g(q)$ is a strictly increasing function of quality. The price of a bundle of intermediate inputs of quality $q$ is given by $P_{i M}(q)$. The composite intermediate input is produced via a Leontief production function over a unit interval of individual intermediates, indexed by $m \in[0,1]$. The price of any input $m$ of quality $q$ in China is $p_{d} g(q)$, where $p_{d}$ is a constant. A firm may also source an intermediate input from abroad. The imported price of that intermediate input $m$ of quality $q$ is $\tau p_{f}(m) g(q)$, where $\tau$ is one plus the ad valorem tariff on the input and $p_{f}(m)$ is strictly decreasing and continuous in $m .{ }^{17}$ We assume that $\tau p_{f}(0)>p_{d}$ and $\tau p_{f}(1)<p_{d}$ so that there exists a cutoff intermediate that is not imported that is solution to

$$
\tau p_{f}\left(m^{*}\right)=p_{d}
$$

Hence, the price of the composite intermediate input of quality $q$ is given by

$$
P_{i M}(q ; \tau)=\widetilde{P}_{i M}(\tau) g(q), \text { where } \widetilde{P}_{i M}(\tau)=\left(m^{*} p_{d}+\tau \int_{m^{*}}^{1} p_{f}(m) d m\right)
$$

It follows from these assumptions, that the cost of production of a firm of productivity $\varphi$ for a level of quality $q$ is given by

$$
c_{P}(q ; \varphi, \tau)=\frac{w^{1-\mu_{i}}\left(\widetilde{P}_{i M}(\tau)\right)^{\mu_{i}}}{\varphi} g(q) .
$$

In addition to production costs, we assume that firms also face a variety of additional costs of handling of their outputs. Those costs possibly span all stages of production, including prior, post, and during production services, such as services of product design, advertisement, production monitoring, product quality control, distribution, etc. It is natural to think that higher quality goods require better all-around production services given by $S(q)=s w g(q) .{ }^{18}$ In the similar spirit of a per unit shipping charge in Hummels and Skiba (2004), the specific transport costs in Feenstra and Romalis (2014) and the distribution cost in Chatterjee, Dix-Carneiro and Vichyanond (2013), we assume that these costs are per unit of output sold so that the total cost of providing a unit of final

\footnotetext{
${ }^{17}$ In the online appendix, we develop a simple microfoundation for the price setting given here (see Appendix A).

${ }^{18}$ The assumption that all-around production services vary in quality is realistic but is made primarily for convenience. It is realistic because, according to Chinese data, firms that produce high quality outputs are also high-productivity firms that indeed disproportionately hire more highly-educated workers. Meanwhile, it is safe to believe that those all-around production services usually require hiring nonproduction workers to conduct management related tasks, and highly-educated workers often conduct management related, non-production tasks.
} 
output to its final consumers is given by

$$
C_{i}(q ; \varphi, \tau)=\left(s w+\frac{w^{1-\mu_{i}}\left(\widetilde{P}_{i M}(\tau)\right)^{\mu_{i}}}{\varphi}\right) g(q) .
$$

Henceforth, we parameterize the quality premium schedule as $g(q)=q^{\alpha}$.

As the assumption of an additional component of marginal cost that is not subject to a firm's productivity is not common in the literature, it is worth discussing its role in the model. As both all-around production services and production itself are required in fixed proportion within a firm we have essentially adopted a Leontief production function in which firm productivity disproportionately affects the cost of the activity using intermediate inputs. This means the marginal cost effect of changes in intermediate input prices is relatively smaller for more productive firms than for less productive firms. ${ }^{19}$

\subsection{Implications}

We now explore the implications of our model for firms' choices of quality of inputs, outputs, and prices as a function of firms' productivities and the input tariffs that they face. We consider a particular industry and drop the industry subscript $i$, henceforth.

Conditional on its cost-minimizing choice on the source of intermediate inputs, the firm chooses its price, $p$, and its quality, $q$, to maximize its export profits of the firm, which are given by

$$
\pi(\varphi)=\max _{p, q}\left((p-C(q ; \varphi, \tau)) x(q, p, \omega)-f q^{\beta}\right),
$$

Substituting (1) and (5) and solving for the first-order conditions for the choice of quality of outputs and inputs and the price of the final good, we find that the optimal quality choice is given by

$$
q=\left((\eta-\alpha(\sigma-1)) \frac{A}{\beta f}\left(s w+\frac{w^{1-\mu}\left(\widetilde{P}_{M}(\tau)\right)^{\mu}}{\varphi}\right)^{1-\sigma}\right)^{\frac{1}{\beta-\eta+\alpha(\sigma-1)}}
$$

where $A=\frac{1}{\sigma}\left(\frac{\sigma}{\sigma-1}\right)^{1-\sigma} \nu E P^{\sigma-1}$ is the mark-up adjusted demand level common to all firms

\footnotetext{
${ }^{19}$ More generally, a model that features concavity of the profit function with respect to productivity where more productive firms respond less to a cost reduction on high-quality foreign inputs would generate the similar predictions as in the current model. In the online appendix we present a more general formulation with wider interpretations (see Appendix B).
} 
in the same industry, and the optimal price is given by

$$
p=\frac{\sigma}{\sigma-1}\left((\eta-\alpha(\sigma-1)) \frac{A}{\beta f}\right)^{\frac{\alpha}{\beta-\eta+\alpha(\sigma-1)}}\left(s w+\frac{w^{1-\mu}\left(\widetilde{P}_{M}(\tau)\right)^{\mu}}{\varphi}\right)^{\frac{\beta-\eta}{\beta-\eta+\alpha(\sigma-1)}}
$$

Note that an interior solution requires that $\beta>\eta-\alpha(\sigma-1)>0$, which we assume holds henceforth.

We first consider the variation across firms in their choices of the quality of inputs, outputs and price as a function of variation across firms in their productivities given a tariff on intermediate inputs. Differentiating equations (6) and (7), yield the elasticities of quality and output price with respect to firm productivity. This yields after substitution,

$$
\begin{aligned}
\frac{d q}{q} & =\frac{\sigma-1}{\beta-\eta+\alpha(\sigma-1)} \frac{\left(\widetilde{P}_{M}(\tau) / w\right)^{\mu}}{s \varphi+\left(\widetilde{P}_{M}(\tau) / w\right)^{\mu}} \frac{d \varphi}{\varphi}, \text { and } \\
\frac{d p}{p} & =\frac{\eta-\beta}{\beta-\eta+\alpha(\sigma-1)} \frac{\left(\widetilde{P}_{M}(\tau) / w\right)^{\mu}}{s \varphi+\left(\widetilde{P}_{M}(\tau) / w\right)^{\mu}} \frac{d \varphi}{\varphi}
\end{aligned}
$$

Given that an increase in quality of output implies an increase in the quality of inputs, the following propostion is immediate from equations (8) and (9):

Proposition 1. More productive firms always produce higher quality output than less productive firms and so use inputs (local and foreign) that feature higher prices than less productive firms. In industries in which the scope for quality differentiation is high ( $\eta>$ $\beta)$, more productive firms also charge higher prices for their output than less productive firms while the opposite is true in industries in which the scope for quality differentiation is small $(\eta<\beta)$.

The prediction is consistent with the stylized fact that more productive firms pay higher wages and buy higher quality inputs. The result is driven by the scale effects associated with quality innovation. More productive firms produce at larger scale and so benefit more from increases in demand induced by quality innovation relative to less productive firms.

We now consider the effect of a reduction in the tariff on intermediate inputs such as followed China's accession to the WTO. Totally differentiating equations (6) and (7), we obtain 


$$
\begin{aligned}
\frac{d q}{q} & =-\frac{\mu(\sigma-1)}{\beta-\eta+\alpha(\sigma-1)} \frac{\left(\widetilde{P}_{M}(\tau) / w\right)^{\mu}}{s \varphi+\left(\widetilde{P}_{M}(\tau) / w\right)^{\mu}} \frac{\tau \int_{m^{*}}^{1} p_{f}(m) d m}{\int_{0}^{m^{*}} p_{d} d m+\tau \int_{m^{*}}^{1} p_{f}(m) d m} \frac{d \tau}{\tau} \\
\frac{d p}{p} & =-\frac{\mu(\eta-\beta)}{\beta-\eta+\alpha(\sigma-1)} \frac{\left(\widetilde{P}_{M}(\tau) / w\right)^{\mu}}{s \varphi+\left(\widetilde{P}_{M}(\tau) / w\right)^{\mu}} \frac{\tau \int_{m^{*}}^{1} p_{f}(m) d m}{\int_{0}^{m^{*}} p_{d} d m+\tau \int_{m^{*}}^{1} p_{f}(m) d m} \frac{d \tau}{\tau} .
\end{aligned}
$$

The following propositions are immediate from equations (10) and (11):

Proposition 2. A reduction in tariffs on intermediate inputs induces firms to upgrade their quality. This effect is smaller in absolute magnitude for high productivity firms. The differential effect between low-vs. high-productivity is most pronounced in industries in which the scope for quality differentiation is higher (high $\eta$ or small $\beta$ ).

Proposition 3. In industries in which the scope for quality differentiation is high $(\eta>$ $\beta$ ), a reduction in tariffs on intermediate inputs induces firms with lower productivity to raise the price of their final output more than those with higher productivity. The differential effect between low-vs. high-productivity is most pronounced in industries in which the scope for quality differentiation is higher (high $\eta$ or small $\beta$ ); while the opposite is true in industries in which the scope for quality differentiation is small $(\eta<\beta)$.

The above propositions are consistent with Fan, Li and Yeaple (2015), but extend the implications to the differential effect between low- vs. high-productivity and to the choice of input qualities. The key mechanism driving the heterogeneous response of firms of different productivity is driven by the assumption that firm productivity is not Hicks' neutral and disproportionately affects a subset of inputs that includes imported intermediate inputs. ${ }^{20}$

Now, the impact of the tariff reduction on the payment for both primary factors and foreign intermediate inputs satisfy

\footnotetext{
${ }^{20}$ Note that firms use both a bundle of primary factor inputs (e.g., labor inputs) and composite intermediate inputs to product outputs. As aforementioned, we find in Chinese data that high-productivity firms do tend to be more skill intensive as they disproportionately hire more highly-educated workers (see footnote 18 for more details).
} 


$$
\begin{gathered}
\frac{d w(q)}{w(q)}=-\frac{\mu \alpha(\sigma-1)}{\beta-\eta+\alpha(\sigma-1)} \frac{\left(\widetilde{P}_{M}(\tau) / w\right)^{\mu}}{s \varphi+\left(\widetilde{P}_{M}(\tau) / w\right)^{\mu}} \frac{\tau \int_{m^{*}}^{1} p_{f}(m) d m}{m_{d}^{*} d m+\tau \int_{m^{*}}^{1} p_{f}(m) d m} \frac{d \tau}{\tau} \\
\frac{d\left[p_{f}(m) g(q)\right]}{p_{f}(m) g(q)}=-\frac{\mu \alpha(\sigma-1)}{\beta-\eta+\alpha(\sigma-1)} \frac{\left(\widetilde{P}_{M}(\tau) / w\right)^{\mu}}{s \varphi+\left(\widetilde{P}_{M}(\tau) / w\right)^{\mu}} \frac{\tau \int_{m^{*}}^{1} p_{f}(m) d m}{\int_{0}^{m^{*}} p_{d} d m+\tau \int_{m^{*}}^{1} p_{f}(m) d m} \frac{d \tau}{\tau}
\end{gathered}
$$

Upgrading of input qualities, induced by a reduction in tariff on intermediate inputs, increases the payment for primary factors.

Proposition 4. A reduction in tariffs on intermediate inputs, $\tau$, induces firms with lower productivity to increase their payment for both primary and intermediate inputs more than those with higher productivity. The differential effect between low-vs. high-productivity is most pronounced in industries in which the scope for quality differentiation is higher (high $\eta$ or small $\beta$ ).

The above predictions show that our model of scale effects and non-Hicks neutral productivity differences across firms can generate the broad set of stylized facts presented in the previous section. The model is novel in establishing a mechanism through which more productive firms produce higher quality and sell at higher prices but respond less to a reduction in the cost of imported intermediates. That more productive firms produce higher quality and sell at higher prices in any given environment is driven by the scale effects. The less sensitive response of high-productivity firms to tariff reductions is due to the fact that productivity and low cost inputs are in a sense substitutable so that a reduction in tariffs on intermediate inputs has a bigger impact on the costs of less productive firms.

Before concluding this section, we describe a simple extension of the model that would allow analysis of the extensive margin. By observation of equation (6), it is immediate that firms sell higher quality products in countries with high demand, $A$, which in some extent reflects GDP per capita since higher quality products are consumed in these countries. Suppose that countries with high levels of demand $(A)$ involve very high upfront investments in distribution and advertizing. If these investments are sufficiently costly, only the most productive firms would sell there. As a reduction in input tariffs lowers the variable costs of less productive by a larger percentage, it is the less productive firms that are most likely to upgrade the set of markets in which they operate. Specifically, those less productive firms will start exporting to countries with higher demand $A$ and, as a result, to raise export prices more, while more productive firms have already been operating in those higher demand markets before trade liberalization. We will show in 
Section 5.3 "Evidence of Extensive Margin of Exports" that this is exactly what happens in the data.

In summary, we have shown that understanding the data require the standard model regarding the relationship between quality upgrading and firm productivity to be amended in such a way that firm productivity is non-Hicks neutral. Moreover, the model makes predictions over the logarithmic changes in tariffs to logarithmic changes in the price of inputs and the price of outputs at the firm level where the effect of tariff changes is heterogeneous across firms of different initial productivities. In the next section, we devise a simple econometric model that captures exactly these predictions.

\section{Empirical Strategy}

In this section we specify our main estimating equation and describe the measures of the key components of the econometric model, namely, tariff reductions and productivity.

\subsection{Baseline Specification}

Our empirical investigation is guided by the propositions of our model regarding the changes in output and input prices with respect to firm productivity during trade liberalization. To test how the effect of tariff reductions on export prices depends on firm productivity, we estimate the following equation:

$$
\Delta \ln \left(p_{f h(c)}\right)=\beta_{1} \Delta \text { Duty }_{f}+\beta_{2} \Delta \text { Duty }_{f} \times \ln (T F P)_{f}+\beta_{3} \Delta \ln (T F P)_{f}+\boldsymbol{\beta}_{f} \Delta \boldsymbol{\chi}_{f}+\beta_{i} \Delta H H I_{i}+\varphi_{s}+\epsilon_{f h(c)},
$$

where $\Delta$ denotes a change in any variable during a five-year period between 2001 and 2006, i.e, $\Delta x=x_{2006}-x_{2001} ;^{21} \Delta \ln \left(p_{f h(c)}\right)$ denotes the change in log unit value export price of HS6 product $h$ exported by firm $f$ (to destination country $c$ ). The specification can represent a firm-product-destination-level $(f h c)$ regression or one at the firm-product level $(f h)$, in which case the optional $c$ subscript is omitted. $\Delta D_{u t y}$ is the change of import tariff faced by firm $f$ which is firm-specific (see detailed description on the construction of firm-specific tariff measures in Section 4.2); ${ }^{22} \Delta D u t y_{f} \times \ln (T F P)_{f}$ is the interaction term of the change of import tariffs and the firm's initial productivity;

\footnotetext{
${ }^{21}$ We use long difference because the adjustment to the shock of trade liberalization may be slow (e.g., Fan, Li and Yeaple, 2015) and there may also be issues of autocorrelation when estimating the model in levels (Trefler, 2004). We also experiment with shorter difference estimators using various periods, including four-year, three-year, and two-year difference. The results remain qualitatively similar and are reported in the online appendix (see related discussion of baseline results in Table 5 in Section 5.1.1 "Main Results").

${ }^{22}$ We also report results using conventional industry-level input tariffs in robustness checks (see Section 5.1.2) and obtain qualitatively similar results.
} 
$\Delta \ln (T F P)_{f}$ controls for the change in firm productivity (estimated TFP) that affects price change. ${ }^{23}$ The vector $\Delta \boldsymbol{\chi}_{f t}$ consists of other firm-level observables that potentially affect export prices, including the change of capital intensity (capital to labor ratio), the change of total employment, and the change of total wage bill. We also add $\triangle H H I_{i}$ to control for the change in competition effect through Herfindahl index, computed at the 4-digit CIC (Chinese Industrial Classification) industry level. In addition, we control the 2-digit CIC industry-fixed effect $\varphi_{s}$. Finally, $\epsilon_{f h(c)}$ is unobserved demand and cost shocks that affect export prices. When we examine input prices, the dependent variable will be replaced by import prices at firm-HS6(-country) level or wage payments at firm level.

Our theory predicts that the coefficient of $\Delta D u t y_{f}, \beta_{1}$ and, in particular, the coefficient of the interaction term $\Delta$ Duty $_{f} \times \ln (T F P)_{f}, \beta_{2}$, should be negative and positive, respectively in the industries where the scope for quality differentiation is large. As the scope for quality differentiation decreases, the aforementioned effect becomes weaker, i.e., $\beta_{1}$ increases and even becomes positive, $\beta_{2}$ decreases and may also becomes negative such that the differential effects of tariff reduction on price change for low productivity and high productivity firms would attenuate or even reverse. We now turn to the construction of the variables used to estimate (14).

\subsection{Tariff}

As the main focus of this paper is to explore the relationship between prices and productivity under trade liberalization, it is important to measure properly the effective tariff reductions that are actually faced by firms. As in Fan, Li and Yeaple (2015), we focus on firm-specific measures of tariff reductions due to their consistency with our theory: those firm-specific measures use information on the exact initial bundle of intermediates imported by firms and provide high resolution to the firm-specific intensive margin effects of tariff reduction within the same industry. ${ }^{24}$ In robustness checks we also construct conventional industry-level input-output table based measures that would be more comprehensive in capturing the potential to import more intermediates if firms obtain some of the foreign intermediate inputs from other importing firms, but may miss much of the variation of the impact of tariff reductions across firms within the same industry. Our empirical results are not sensitive to alternative measures of tariff cuts.

\footnotetext{
${ }^{23}$ In an alternative specification, we experimented with including initial TFP level (rather than the change in TFP) along with other initial firm and industry characteristics, and obtain largely similar results.

${ }^{24}$ For example, the Input-Output sector, automobile manufacturing (Chinese I-O classification code 37074), includes the HS4 products, "motor cars \& vehicles for transporting persons" (HS4 code 8703), and "special purpose motor vehicles" (HS4 code 8705). Within the same I-O sector, some products enjoyed substantial import tariff reduction from $80 \%$ in 2001 to $28 \%$ in 2006 (e.g., HS 8 product "other vehicles", code 87033390), while others remain the same tariff level at 3\% between 2001-2006 (e.g., HS8 product "fire fighting vehicles", code 87033390).
} 
Our main measure of firm-specific tariff reduction is $\Delta D_{u t y_{f}}=\sum_{h \in Z} w_{h} \Delta D u t y_{h}$, where the weight $w_{h}$ is the import share of product $h$ in the total import value by the firm in the initial year, and $\Delta D u t y_{h}$ is the tariff change at HS6 product level. ${ }^{25}$ This firm-specific input tariff reduction measure reflects changes in effective tariffs faced by each firm and is not subject to the problem of the weight change from 2001 to 2006.

To assess robustness, we adopt three alternative firm-specific measures of tariff reductions. The first is the arithmetic mean of product-level tariff reductions across all imported varieties both before and after the trade liberalization. The formulation is $\Delta$ Duty $_{f}=\left(\sum_{h \in Z \cup Z^{\prime}} \Delta\right.$ Duty $\left._{h}\right) /\left|Z \cup Z^{\prime}\right|$, where $Z$ is the set of varieties imported before the tariff reduction (intensive margin), $Z^{\prime}$ is the set of newly imported varieties after the tariff reduction (extensive margin), and $\left|Z \cup Z^{\prime}\right|$ denotes the total number of imported varieties by the firm over the whole sample period. This measure includes tariff changes relevant to both the intensive margin and the extensive margin. ${ }^{26}$ The second measure is the weighted average tariff reductions only to goods that are clearly intermediate inputs, according to the Broad Economic Categories (BEC) classification.

The third measure attempts to connect individual tariff reductions on intermediate inputs to specific goods in the firm's export portfolio of products. We follow Manova and Zhang (2012b) to focus on foreign inputs in the same broad industry classification as the output product. For example, if a firm buys brakes and seat belts and sells cars, both its exports and imports would be recorded in the motor vehicles industry. If the company also manufactures cell phones, tariff reduction in SIM cards would enter the measure of import tariff change of its cell phones but not that of its cars. Therefore, we construct the weighted average tariff change across all the inputs imported by the firm (e.g. brakes, seat belts) in a given HS4 category (e.g. motor vehicle) and assign this average tariff change to all products exported by this firm in the same HS4 category. Using this method we eventually compute the firm-product specific tariff change $\Delta D u t y_{f h}$ for each product $h$ exported by firm $f .{ }^{27}$ Among all the firm-specific tariff reduction measures,

${ }^{25} \Delta$ Duty $_{h} \approx \Delta \ln \tau_{h}$ since $\tau>1$ is one plus the tariff rate, and the HS6 product index $h$ is the empirical counterpart of intermediate type $z$ in the model. When constructing the weighted average change in input tariffs, we use a product's imports in total import value by the firm as weights, because this measure has been widely employed in the literature (e.g., Fan, Li and Yeaple, 2015; Yu, 2015). It is also because we lack precise data on domestic intermediate inputs: the value of total intermediate inputs in the NBSC firm production survey data is denominated in Chinese currency, while the imports in the customs data are denominated in US dollar. Nonetheless, we also use an alternative weighting scheme where the weight is computed as the import share of product $h$ in the total costs of intermediate inputs by the firm in the initial year, as suggested by one of the referees, and obtain similar results (see related discussion of baseline results of Table 5 in Section 5.1.1 "Main Results" and the supplementary table in the online appendix).

${ }^{26}$ This measure isolates pure changes in tariffs rather than the changes in input bundles (Ge, Lai and Zhu, 2011) by fixing the total number of imported varieties over the sample period.

${ }^{27}$ We also compute this tariff measure at HS2 level by assigning the average tariff across all the imported inputs in a given HS2 category to all products exported by the same firm within the same HS2 category and it yields the similar results. Those results are available upon request. 
this one generates the smallest sample size as it loses those exported products that have no imported inputs in the same HS4 category.

\subsection{Productivity}

To control for changes in firm productivity, we estimate various measures of productivity, including revenue-based total factor productivity (TFP), physical TFP, and value added per worker. ${ }^{28}$ We also report results using firm size and alternative quantity-based proxy for firm-product level productivity. Our results are robust across productivity measures.

Our primary TFP measure is revenue TFP using the method of Olley-Pakes (hereafter O-P) (Olley and Pakes, 1996) that has been augmented to account for additional firmlevel decisions.For instance, we allow a firm's trade status in the TFP realization, as in Amiti and Konings (2007), by including two trade-status dummy variables-an export dummy (equal to one for exports and zero otherwise) and an import dummy (equal to one for imports and zero otherwise). We also inclu de a WTO dummy (i.e., one for a year since 2002 and zero for before) in the O-P estimation as the accession to WTO represents a positive demand shock for China's exports.

In estimating revenue TFP, we measure output using value-added, ${ }^{29}$ and deflate firms' inputs (e.g., capital) and value added, using the input price deflators and output price deflators from Brandt, Van Biesebroeck and Zhang (2012). ${ }^{30}$ We construct the real investment variable via the perpetual inventory method. For the depreciation rate we use each firm's real depreciation rate provided by the NBSC firm-production database. Besides TFP estimated using the O-P method, our results are robust to various approaches in estimating revenue TFP, including the OLS method and the Ackerberg-Caves-Frazer augmented O-P and L-P (Levinsohn and Petrin, 2003) methods (Ackerberg, Caves and Frazer, 2006).

Because revenue TFP estimated using sales or value added deflated by industrylevel producer price index can create an omitted-variable bias (see detailed explanation in De Loecker and Goldberg (2014)), we also report results using physical TFP, firmproduct export quantity as proxy for firm-product-level productivity, and other variables of efficiency or firm size, such as value added per worker, total sales or total employment payment. Our main results are robust to all those quantity-based productivity measures

\footnotetext{
${ }^{28}$ We estimated production functions at the 2-digit CIC level. In total, there are 29 2-digit CIC industries.

${ }^{29}$ Our results are not sensitive to TFP measures estimated by total output with material input. The results are available upon request.

${ }^{30}$ The output deflators are constructed using "reference price"information from China's Statistical Yearbooks, and the input deflators are constructed based on output deflators and China's national input-output table (2002). The data can be accessed via http://www.econ.kuleuven.be/public/N07057/CHINA/appendix/.
} 
and alternative measures of efficiency and firm size.

We estimate physical TFP using the method of De Loecker et al. (2016). While the details are presented inAppendix $\mathrm{C}$ in the online appendix, it is worth mentioning two specific features of the methodology. First, as in De Loecker et al. (2016) we assume that multi-product and single-product firms use the same technology so that we can focus on single-product firms to circumvent the problem of unobserved input allocations in multi-product firms. We merge the NBSC firm-level production data with another dataset on firms' output quantity which has the same firm identity code as the NBSC firm-level production database and provides output quantity at CPC 5-digit level (see a more detailed description of the output quantity data in Fan et al. (2017)). Our sample of single-product firms is about $25 \%$ of our previous sample of revenue TFP. ${ }^{31}$ Second, to solve the issue of omitted firm-specific input prices, we use the (unit value) output prices, market shares and export status to control for the omitted input prices in estimating the quantity-based TFP. Specifically, we follow De Loecker et al. (2016)'s approach to "control for unobserved input price variation across firms using information on observables, particularly (but not exclusively) output prices," based on the belief that output prices capture information about input prices which is a well documented fact in the quality-and-trade literature (e.g., Kugler and Verhoogen (2012), Manova and Zhang $(2012 a))$. Those results are reported in Section 5.1.2.

\section{Results}

In this section, we present the results of our empirical analyses. We begin with firmlevel export price responses to tariff reduction. After presenting the baseline results and robustness checks, we then consider firm-level input responses to tariff reduction. We conclude the section with evidence regarding firm-level extensive margin responses.

\subsection{Export Prices and Import Tariffs}

\subsubsection{Main Results}

We report the impact of tariff reductions on export price changes in Table 5 using our main measure of firm-specific tariff reduction (see detailed discussion in Section 4.2) and the baseline regression equation (14). ${ }^{32}$ The dependent variables are firm-product-country

\footnotetext{
${ }^{31}$ Nevertheless, the estimated physical TFP and revenue TFP is positively correlated. The correlation between revenue-based TFP and quantity-based TFP in our sample is $26.41 \%$.

${ }^{32}$ We also use an alternative weighting scheme for the main tariff measure where the weight is computed as the import share of product $h$ in the total costs of intermediate inputs by the firm in the initial year, as suggested by one of the referees, and obtain similar results (see Table A.1 in the online appendix).
} 
level price changes (see columns 1-3) and firm-product level price changes (see columns 4-6), respectively.

Table 5: Baseline Results: Effects of Tariff Reductions on Export Prices Depend on TFP

\begin{tabular}{|c|c|c|c|c|c|c|}
\hline & \multicolumn{6}{|c|}{ Dependent Variable: $\Delta \ln ($ price $)$} \\
\hline & \multicolumn{3}{|c|}{$\Delta \ln \left(p_{f h c}\right)$} & \multicolumn{3}{|c|}{$\Delta \ln \left(p_{f h}\right)$} \\
\hline & (1) & $(2)$ & (3) & (4) & $(5)$ & (6) \\
\hline$\Delta$ Duty & $\begin{array}{c}-0.343^{*} \\
(0.191)\end{array}$ & $\begin{array}{c}-2.496^{* * *} \\
(0.654)\end{array}$ & $\begin{array}{c}-2.457^{* * *} \\
(0.702)\end{array}$ & $\begin{array}{c}-0.543^{* *} \\
(0.234)\end{array}$ & $\begin{array}{c}-3.455^{* * *} \\
(0.869)\end{array}$ & $\begin{array}{c}-3.084^{* * *} \\
(0.930)\end{array}$ \\
\hline$\Delta$ Duty $\times \ln (\mathrm{TFP})$ & & $\begin{array}{c}0.490^{* * *} \\
(0.139)\end{array}$ & $\begin{array}{c}0.505^{* * *} \\
(0.150)\end{array}$ & & $\begin{array}{c}0.652^{* * *} \\
(0.188)\end{array}$ & $\begin{array}{c}0.592^{* * *} \\
(0.202)\end{array}$ \\
\hline$\Delta \ln (\mathrm{TFP})$ & & & $\begin{array}{l}0.021^{*} \\
(0.011)\end{array}$ & & & $\begin{array}{c}0.021 \\
(0.014)\end{array}$ \\
\hline$\Delta \ln ($ Capital/Labor) & & & $\begin{array}{c}0.020 \\
(0.013)\end{array}$ & & & $\begin{array}{l}0.037^{*} \\
(0.020)\end{array}$ \\
\hline$\Delta \ln ($ Labor $)$ & & & $\begin{array}{c}0.007 \\
(0.015)\end{array}$ & & & $\begin{array}{c}0.033 \\
(0.022)\end{array}$ \\
\hline$\Delta \ln$ (Wage) & & & $\begin{array}{c}0.004 \\
(0.018)\end{array}$ & & & $\begin{array}{c}0.016 \\
(0.022)\end{array}$ \\
\hline$\Delta \mathrm{HHI}$ & & & $\begin{array}{c}0.856^{* * *} \\
(0.239)\end{array}$ & & & $\begin{array}{c}0.432 \\
(0.306) \\
\end{array}$ \\
\hline Industry Fixed Effect & no & no & yes & no & no & yes \\
\hline Observations & 16,907 & 16,907 & 16,907 & 8,971 & 8,971 & 8,971 \\
\hline R-squared & 0.0004 & 0.002 & 0.017 & 0.001 & 0.004 & 0.019 \\
\hline \multicolumn{7}{|c|}{$\begin{array}{l}\text { Notes: }{ }^{* * *} \mathrm{p}<0.01,{ }^{* *} \mathrm{p}<0.05,{ }^{*} \mathrm{p}<0.1 \text {. Robust standard errors corrected for clustering } \\
\text { at the firm level in parentheses. The dependent variable in specifications }(1) \text { - }(3) \text { is the } \\
\text { (log) price change at the firm-HS6-country level, computed as the log price difference of the } \\
\text { same firm-HS6-country triplet from } 2001 \text { to } 2006 \text {. The dependent variable in specifications } \\
\text { (4)-(6) is the (log) price change at the firm-HS6 product level. All regressions include a } \\
\text { constant term. Herfindahl index }(H H I) \text { is computed at the 4-digit CIC industry in China. } \\
\text { Industry fixed effect is computed at } 2 \text {-digit CIC industry level. When we use initial levels } \\
\text { of TFP, capital-labor ratio, employment, wage payment, and Herfindahl index to replace } \\
\text { the changes in those firm-level and industry-level controls, the similar results obtain: the } \\
\text { coefficient of } \Delta \text { Duty is still significantly negative, and the coefficient for the interaction } \\
\text { term is still positive (the coefficients of the interaction terms for the firm-product-country } \\
\text { and firm-product regressions are } 0.203 \text { and } 0.302, \text { respectively). }\end{array}$} \\
\hline
\end{tabular}

We first discuss the results at firm-product-country level. Column 1 reports the coefficient estimate of regression of log changes in export prices on log changes in tariff reductions. The statistically significant and negative coefficient on tariff changes indicates that a reduction in import tariffs of 10 percentage points increases unit value export prices at firm-product-country level by $3.4 \%$. This result is consistent with Proposition 3 that tariff reductions induce an incumbent importer/exporter to raise its output prices. In columns 2 and 3, we add the interaction term of tariff change and initial productivity $(\Delta$ Duty $\times \log (\mathrm{TFP}))$, without and with firm- and industry-level controls and industry fixed effect, respectively. The positive, and statistically significant coefficients on the interaction term of tariff change and initial productivity suggest that initially less 
productive firms enjoy a larger raise in export prices during trade liberalization.

According to the coefficient estimates in column 2, a $10 \%$ reduction in import tariffs would raise export prices by approximately $3.9 \%$ for an average firm whose (log) productivity equals 4.3 ; while the same $10 \%$ tariff reduction would increase export prices by around $6.0 \%$ for a firm whose $(\log )$ productivity is $10 \%$ lower than the average firm. ${ }^{33}$ In other words, the effect of tariff reduction on export price increase is $53.8 \%$ greater on this less productive firm than that on the average firm. This result confirms the second prediction in Proposition 3 that the magnitude of the effect of tariff reductions on export prices is decreasing in a firm's productivity.

When we move to columns 4-6 for firm-HS6 product level regressions, similar results obtain: a reduction in import tariff induces firms to increase export prices, and this effect is more pronounced for low-productivity firms. ${ }^{34}$ The fact that the coefficient estimates on tariffs and interaction terms tend to be larger at the firm-HS6 level than at the firmHS6-country level suggests a composition effect: import tariff reductions induce Chinese firms to export to markets with strong demand for higher quality goods where higher prices can be charged, and this effect is more pronounced for less productive firms.

Besides using the interaction term to distinguish the differential effect of tariff reductions on export prices between less and more productive firms, we test Proposition 3 by adopting a discretized version of the TFP variable to loosen the linearity assumption:

$$
\begin{aligned}
\Delta \ln \left(p_{f h(c)}\right) & =\beta_{1} \Delta \operatorname{Duty}_{f}+\beta_{2}^{H} \Delta \text { Duty } y_{f} \times \text { High_TFP } P_{f}+\beta_{3} H i g h \_T F P_{f} \\
& +\beta_{4} \Delta \ln (T F P)_{f}+\boldsymbol{\beta}_{f} \Delta \boldsymbol{\chi}_{f}+\beta_{i} \Delta H H I_{i}+\varphi_{s}+\epsilon_{f h(c)}
\end{aligned}
$$

where $H i g h \_T F P_{f}$ is a firm-specific dummy variable that is equal to 1 if a firm belongs to the category of high-productivity firm and is 0 otherwise. ${ }^{35}$ The corresponding results at the firm-product-country and firm-product levels are reported in columns 1-4 and

\footnotetext{
${ }^{33}$ We also present the baseline regression results of Table 5 using the demeaned (log) productivity in Table A.2 where we demean $\ln (T F P)$ over the estimating sample before interacting it. In that way, the estimate on the interaction term is unaffected, but the estimate on the uninteracted term $\Delta$ Duty retains its interpretation that represents the effect of tariff reduction on an average firm. All coefficients on $\Delta$ Duty in Table A.2 are significantly negative at the firm-product level. At the firmproduct-country level, the coefficients on $\Delta$ Duty are also significantly negative with one exception that has $15 \%$ significance level. The negative coefficients on tariff change in Table A.2 imply that the average effect of tariff reduction on export price is indeed negative. In other words, a reduction in import tariffs on average would raise export prices.

${ }^{34} \mathrm{We}$ also run an F-test on key results for tariff and its interaction with TFP, since there exists a certain amount of collinearity, especially when coefficients are not independently significant. The results show that both coefficients of interest are statistically significant, at at least 1 percent significance level.

${ }^{35}$ In the main results as shown in Table 6, we define High_TFP $=1$ if a firm's TFP is above 75 percentile of all firms in the sample. We experimented with various thresholds, e.g., 90 percentile, 80 percentile, etc., and find similar results. Those results are available upon request. We further test the three-segment discretized version of TFP by dividing firms into three categories, namely high-, medium-, and low-productivity firms among which low-productivity firms are the omitted group, and also obtain similar results (see Table A.3 in the online appendix).
} 
Table 6: Breakout of the Effect of Tariff Reductions on Export Prices Using Discretized TFP

\begin{tabular}{|c|c|c|c|c|c|c|c|c|}
\hline & \multicolumn{8}{|c|}{ Dependent Variable: $\Delta \ln ($ price $)$} \\
\hline & \multicolumn{4}{|c|}{$\Delta \ln \left(p_{f h c}\right)$} & \multicolumn{4}{|c|}{$\Delta \ln \left(p_{f h}\right)$} \\
\hline & (1) & $(2)$ & $(3)$ & (4) & (5) & (6) & (7) & (8) \\
\hline$\Delta$ Duty & $\begin{array}{c}-0.494^{* *} \\
(0.207)\end{array}$ & $\begin{array}{l}-0.385^{*} \\
(0.208)\end{array}$ & $\begin{array}{c}-0.471^{* *} \\
(0.217)\end{array}$ & $\begin{array}{l}-0.387^{*} \\
(0.219)\end{array}$ & $\begin{array}{c}-0.823^{* * *} \\
(0.262)\end{array}$ & $\begin{array}{c}-0.736^{* * *} \\
(0.264)\end{array}$ & $\begin{array}{c}-0.780^{* * *} \\
(0.281)\end{array}$ & $\begin{array}{c}-0.715^{* *} \\
(0.287)\end{array}$ \\
\hline$\Delta$ Duty $\times H_{i g h \_T F P}$ & $\begin{array}{c}1.175^{* * *} \\
(0.352)\end{array}$ & $\begin{array}{c}0.875^{* *} \\
(0.354)\end{array}$ & $\begin{array}{l}1.048^{* *} \\
(0.512)\end{array}$ & $\begin{array}{l}0.883^{*} \\
(0.518)\end{array}$ & $\begin{array}{c}1.284^{* * *} \\
(0.415)\end{array}$ & $\begin{array}{c}1.102^{* * *} \\
(0.417)\end{array}$ & $\begin{array}{l}1.120^{* *} \\
(0.467)\end{array}$ & $\begin{array}{l}1.024^{* *} \\
(0.468)\end{array}$ \\
\hline High_TFP & & & $\begin{array}{l}-0.013 \\
(0.040)\end{array}$ & $\begin{array}{l}0.001 \\
(0.040)\end{array}$ & & & $\begin{array}{l}-0.019 \\
(0.043)\end{array}$ & $\begin{array}{l}-0.009 \\
(0.046)\end{array}$ \\
\hline$\Delta \ln (\mathrm{TFP})$ & & $\begin{array}{c}0.029^{* * *} \\
(0.010)\end{array}$ & & $\begin{array}{c}0.029 * * * \\
(0.010)\end{array}$ & & $\begin{array}{c}0.029^{* *} \\
(0.014)\end{array}$ & & $\begin{array}{r}0.029^{* *} \\
(0.014)\end{array}$ \\
\hline$\Delta \ln ($ Capital/Labor $)$ & & $\begin{array}{c}0.020 \\
(0.013)\end{array}$ & & $\begin{array}{c}0.020 \\
(0.013)\end{array}$ & & $\begin{array}{l}0.039^{*} \\
(0.020)\end{array}$ & & $\begin{array}{l}0.039^{*} \\
(0.020)\end{array}$ \\
\hline$\Delta \ln ($ Labor $)$ & & $\begin{array}{c}0.005 \\
(0.015)\end{array}$ & & $\begin{array}{c}0.005 \\
(0.015)\end{array}$ & & $\begin{array}{c}0.031 \\
(0.021)\end{array}$ & & $\begin{array}{c}0.031 \\
(0.022)\end{array}$ \\
\hline$\Delta \ln ($ Wage $)$ & & $\begin{array}{c}0.003 \\
(0.018)\end{array}$ & & $\begin{array}{c}0.003 \\
(0.018)\end{array}$ & & $\begin{array}{c}0.017 \\
(0.022)\end{array}$ & & $\begin{array}{c}0.016 \\
(0.022)\end{array}$ \\
\hline$\Delta \mathrm{HHI}$ & & $\begin{array}{c}0.827^{* * *} \\
(0.249)\end{array}$ & & $\begin{array}{c}0.826^{* * *} \\
(0.249)\end{array}$ & & $\begin{array}{c}0.404 \\
(0.315)\end{array}$ & & $\begin{array}{c}0.406 \\
(0.316)\end{array}$ \\
\hline Industry Fixed Effect & yes & yes & yes & yes & yes & yes & yes & yes \\
\hline Observations & 16907 & 16907 & 16907 & 16907 & 8971 & 8971 & 8971 & 8971 \\
\hline R-squared & 0.014 & 0.017 & 0.014 & 0.017 & 0.016 & 0.018 & 0.016 & 0.018 \\
\hline \multicolumn{9}{|c|}{$\begin{array}{l}\text { Notes: }{ }^{* * *} \mathrm{p}<0.01,{ }^{* *} \mathrm{p}<0.05,{ }^{*} \mathrm{p}<0.1 \text {. Robust standard errors corrected for clustering at the firm level in } \\
\text { parentheses. The low-productivity firms are the omitted group. The dependent variable in specifications (1)-(4) is the } \\
\text { (log) price change at the firm-HS6-country level, computed as the log price difference of the same firm-HS6-country } \\
\text { triplet from } 2001 \text { to } 2006 \text {. The dependent variable in specifications (5)-(8) is the (log) price change at the firm-HS6 } \\
\text { product level. Specifications (3)-(4) and (7)-(8) include the dummy variable High_TFP itself in levels; specifications } \\
(1)-(2) \text { and (5)-(6) do not include the dummy variable itself. All regressions include a constant term. Herfindahl } \\
\text { index }(H H I) \text { is computed at the 4-digit CIC industry in China. Industry fixed effect is computed at 2-digit CIC } \\
\text { industry level. }\end{array}$} \\
\hline
\end{tabular}

5-8 in Table 6, respectively, in which the odd columns exclude firm-level and industrylevel controls while the even columns include those controls. The estimated coefficients on $\triangle D$ uty $\times$ High_TFP in all specifications are significantly positive, suggesting that the effect of tariff reductions on export price increase for high-productivity firms is less pronounced than that for low-productivity firms. ${ }^{36}$ Note that the sum of the relevant coefficients $\left(\beta_{1}+\beta_{2}^{H}\right)$ is not statistically different from zero so one cannot conclude from these results that the highest TFP firms actually reduce their prices in response to an input tariff tariff cut. ${ }^{37}$ This implies that less productive firms are affected by tariff reduction and show an increase in their export prices, and this pattern attenuates as firm productivity rises.

According to Proposition 3, the difference in the responses to tariff reductions between low- and high-productivity firms should be more pronounced in industries with large

\footnotetext{
${ }^{36}$ The differential effect regarding firm productivity is further supported by regressions using separate samples for more and less productive firms (available upon request).

${ }^{37}$ In our model, the potential for quality upgrading is limitless as the range of the quality of inputs is unbounded. Were quality bounded from above, the most productive firms would respond to a trade liberalization by lowering the price of their output while firms below a certain productivity cutoff would increase their output price. The results here cannot distinguish between these subtle alternatives.
} 
scope for quality differentiation. We address the predicted slope heterogeneity using four approaches to categorize industry's scope for quality differentiation and report results in four panels in Table 7. In Panel A, under the reasonable assumption that differentiated goods present greater scope for quality differentiation than do homogeneous goods, we adopt Rauch (1999)'s classification to distinguish two types of products. ${ }^{38}$ In Panel B, we compute quality dispersion within each HS6 product as the residual from a demand equation using observed prices and market share data as in Khandelwal, Schott and Wei (2013) and Fan, Li and Yeaple (2015). ${ }^{39}$ Intuitively, conditional on price, higher market shares imply higher quality (Khandelwal, 2010). We use the median of quality variances of all goods to distinguish products with highly-dispersed quality as differentiated goods and those with less-dispersed quality as homogeneous goods. Finally, we use R\&D intensity as a proxy for the scope for quality differentiation within an industry (Kugler and Verhoogen, 2012). We use both U.S. and Chinese data on R\&D intensity and report in Panel C and Panel D, respectively. ${ }^{40}$

Columns 1-3 and columns 4-6 of Table 7 present firm-product-country level and firmproduct level results, respectively. The first column one reports the results using a subsample where the scope for quality differentiation is large (i.e., heterogeneous goods sample). The second column reports the results obtained from the subsample where the scope for quality differentiation is small (i.e., homogeneous goods sample). The third reports results based on a set of interactions for the whole sample, rather than splitting the sample in two, where the dummy variable "Diff" (Differentiated) is equal to 1 if the product is classified as differentiated goods and zero otherwise using the aforementioned four approaches in all panels.

We first compare the subsample results. Table 7 shows that the effect of tariff reductions on price increase is more pronounced when the scope for quality differentiation is large (see the comparison between the subsample of heterogeneous goods and of homogeneous goods, i.e., columns 1 vs. 2 and columns 4 vs. 5). Also, the coefficients on

\footnotetext{
${ }^{38}$ In our main results, we treat goods traded on organized exchanges and reference-priced goods as homogeneous goods. An alternative classification that includes only organized-exchange goods to homogeneous goods and refers heterogeneous goods to both differentiated goods and reference-priced goods generates similar results (see Table A.4 in the online appendix). Now, the coefficients on the triple interaction term $\Delta$ Duty $\times \ln (\mathrm{TFP}) \times$ Diff are significantly positive in both firm-product level and firm-productcountry level results; the coefficients on the interaction term $\Delta$ Duty $\times$ Diff are significantly negative in both firm-product level and firm-product-country level results.

${ }^{39}$ For a more detailed discussion of quality estimation, see the later part of "(B.3) The test using estimated quality" in "Robustness II - Alternative Explanations" in Section 5.1.2.

${ }^{40}$ In Panel C, we adopt U.S. R\&D intensity based on industry-level information of R\&D from U.S. Federal Trade Commission (FTC) Line of Business Survey as in Kugler and Verhoogen (2012). To be more specific, we employ the measure constructed by Kugler and Verhoogen (2012) and concord to HS6 using the concordance form the UN Comtrade. Using U.S. R\&D intensity to examine the role of quality scope on Chinese firms' behavior may be better exempt from the potential issue of the endogeneity of R\&D than using Chinese R\&D intensity. In Panel D, we compute the R\&D intensity for each CIC 4-digit industry based on Chinese R\&D data from the annual surveys of NBSC manufacturing firms.
} 
Table 7: Effect of Tariff Reductions by the Scope for Quality Differentiation

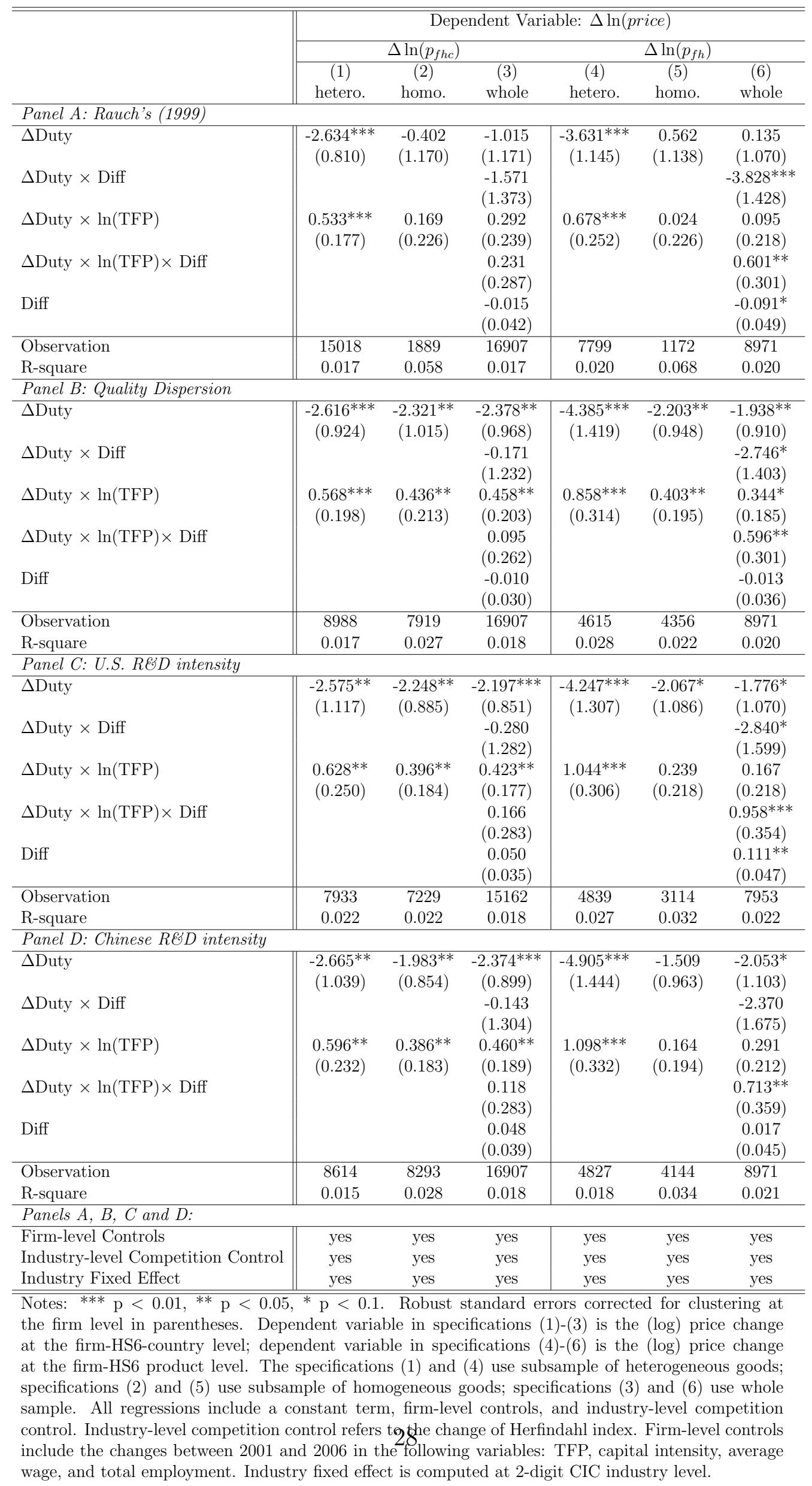


the interaction term $(\Delta$ Duty $\times \ln (\mathrm{TFP}))$ that indicate the difference between low- and high-productivity firms are positive and significant in heterogeneous goods sample in all specifications (see columns 1 and 4). In contrast, columns 2 and 5 show that in the sample where the scope for quality differentiation is small, all coefficients on tariff reduction $(\Delta$ Duty $)$ and the interaction term $(\Delta$ Duty $\times \ln (\mathrm{TFP}))$ are either insignificant or smaller in absolute magnitude.

The contrast in the size of the coefficients between homogeneous and differentiated goods is more noticeable at the firm-product level when comparing column 4 with column 5 than at the firm-product-country level. Apparently, the compositional shift among different destination markets is an important dimension of change in firm quality strategies. To be more specific, at the firm-product level, in Panels A, C, and D, only heterogeneous goods subsamples show significant response to tariff reduction conditional on initial productivity while this pattern is not statistically significant in homogeneous goods subsamples; in Panel B, the effect of tariff reduction conditional on TFP almost doubles in heterogeneous goods subsample, comparing with the one in homogeneous goods subsample. The comparison of those coefficients in the two types of subsamples are consistent with our previous discussion. ${ }^{41}$

Next, we study the results based on the whole sample using the interactions with the "Diff" dummy (see columns 3 and 6). This exercise can pin down whether there is indeed a statistically different effect of tariff reduction on export prices conditional on firm productivity in heterogeneous goods industries. According to Proposition 3 of the model, the difference in how high- and low-productivity firms respond to tariff reductions should differ based on whether the product is differentiated or homogeneous, with stronger effects observed for differentiated products. Thus, the variables of interest are the triple interaction term $\Delta$ Duty $\times \ln (\mathrm{TFP}) \times$ Diff and the interaction term $\Delta$ Duty $\times$ Diff.

Columns 3 and 6 show that the coefficients on the triple interaction term are positive in all specifications, and are all significant in firm-product level results in column 6 . The coefficients on $\Delta$ Duty $\times$ Diff at the firm-product level are all significantly negative, except for the one in the last panel where the significance level is within $20 \%$ when Chinese R\&D data are used. The fact that the results at the firm-product level are stronger than at the firm-product-country level is again consistent with the compositional effect that occurs when firms switch their destination markets (see more discussion about extensive margin later in Section 5.3). ${ }^{42}$

\footnotetext{
${ }^{41}$ See Proposition 3 for theoretical justifications of possible reasons why the coefficient would reverse the sign and the discussion after equation (14) in Section 4.1 for empirical implications.

${ }^{42}$ The results of two subsamples in Table 7 also reflect the role of compositional effect for industries in which the scope for quality differentiation is high when comparing coefficient estimates in column 1 with those in column 4, but this compositional effect does not occur in industries in which the scope for quality differentiation is small when comparing column 2 with column 5.
} 
The results in Table 7 confirm the role of quality differentiation as stated in Proposition 3: when the scope for quality differentiation becomes smaller, the effect of tariff reduction on price changes and the differential effect between less and more productive firms would become less pronounced or even become ambiguous.

In the online appendix, we report several sensitivity tests. First, we show that the results remain unchanged when we experiment with 2-year, 3-year, and 4-year lags in Table A.5. Second, to eliminate the concern that changes in destination country import tariffs might be affecting the results, we report in Table A.6 that adding export tariffs does not alter our main results. ${ }^{43}$ Third, we report the weighted regression results to alleviate the concern of heteroskedasticity in Table A.7 where various weighting schemes are used: Panels A, B, and C are weighted by the number of observations in each 2-digit CIC industry, the number of observations in each firm, and the export value of each firm, respectively. Table A.7 shows that the results are not driven by small exporters.

\subsubsection{Robustness for Main Results}

In this subsection, we show the robustness of our results from both statistical and mechanism perspectives. To show the statistical robustness of our results, we conduct four exercises. First, We show our results are robust to various measures of productivity (including physical TFP to remove the concern of revenue-based TFP, other quantitybased measures, labor productivity, and firm size). Second, we confirm the robustness of our results to alternative measures of tariff cuts (including other firm-specific or firmproduct-specific measures and the conventional industry-specific tariffs). Third, we use instrumental variable (IV hereafter) estimation to address the potential issue of the endogeneity of tariff reductions and obtain similar results. In addition, we show that our results are not biased toward big firms using the whole customs data without matching the data to the manufacturing firm survey.

From the mechanism perspective, we conduct three exercises to show that our results are not sensitive to other explanations. First, we conduct a placebo test to verify the model mechanism through imported intermediate inputs. Second, we present a battery of sensitivity tests to eliminate the concern that our results might be spuriously picking up the effect of other mechanisms (such as reduced policy uncertainty and currency appreciation) rather than the import tariff reduction effect through imported intermediate inputs. Lastly, we quality estimates to test the quality upgrading mechanism directly.

\section{A. Robustness I - Statistical}

(A.1) Alternative measures of productivity and firm size. - As our focus is the effect

\footnotetext{
${ }^{43}$ In columns 2, 4, and 6 of Table A.6 we also add the interaction term of export tariff and productivity, the results remain qualitatively the same.
} 
Table 8: Robustness: Alternative Measures of Quantity-Based Productivity

\begin{tabular}{|c|c|c|c|c|c|c|}
\hline & \multicolumn{6}{|c|}{ Dependent Variable: $\Delta \ln ($ price $)$} \\
\hline & \multicolumn{2}{|c|}{ Whole Sample } & \multicolumn{2}{|c|}{ Differentiated Goods } & \multicolumn{2}{|c|}{ Homogeneous Goods } \\
\hline & $\begin{array}{c}(1) \\
\Delta \ln \left(p_{f h c}\right)\end{array}$ & $\begin{array}{c}(2) \\
\Delta \ln \left(p_{f h}\right)\end{array}$ & $\begin{array}{c}(3) \\
\Delta \ln \left(p_{f h c}\right)\end{array}$ & $\begin{array}{c}(4) \\
\Delta \ln \left(p_{f h}\right)\end{array}$ & $\begin{array}{c}(5) \\
\Delta \ln \left(p_{f h c}\right)\end{array}$ & $\begin{array}{c}(6) \\
\Delta \ln \left(p_{f h}\right)\end{array}$ \\
\hline \multicolumn{7}{|l|}{ Panel A: Firm-level Physical TFP } \\
\hline$\Delta$ Duty & $\begin{array}{c}-0.959^{* *} \\
(0.436)\end{array}$ & $\begin{array}{c}-0.923^{*} \\
(0.511)\end{array}$ & $\begin{array}{c}-1.071^{* *} \\
(0.443)\end{array}$ & $\begin{array}{c}-0.983^{*} \\
(0.519)\end{array}$ & $\begin{array}{c}2.032 \\
(1.514)\end{array}$ & $\begin{array}{c}0.050 \\
(2.640)\end{array}$ \\
\hline$\Delta$ Duty $\times \ln (\mathrm{TFP})$ & $\begin{array}{l}0.693^{*} \\
(0.384)\end{array}$ & $\begin{array}{c}0.441 \\
(0.337)\end{array}$ & $\begin{array}{c}1.206^{* *} \\
(0.541)\end{array}$ & $\begin{array}{l}1.017^{*} \\
(0.530)\end{array}$ & $\begin{array}{c}0.009 \\
(0.396)\end{array}$ & $\begin{array}{c}0.223 \\
(0.438)\end{array}$ \\
\hline Observation & 4007 & 2326 & 3559 & 2105 & 448 & 221 \\
\hline R-square & 0.031 & 0.025 & 0.036 & 0.029 & 0.141 & 0.185 \\
\hline \multicolumn{7}{|c|}{ Panel B: Firm-product productivity proxy based on HS6 } \\
\hline$\Delta$ Duty & $\begin{array}{c}-1.279^{* *} \\
(0.621)\end{array}$ & $\begin{array}{c}-2.424^{* * * *} \\
(0.809)\end{array}$ & $\begin{array}{c}-1.591^{* *} \\
(0.681)\end{array}$ & $\begin{array}{c}-2.851^{* * *} \\
(0.895)\end{array}$ & $\begin{array}{c}0.982 \\
(1.071)\end{array}$ & $\begin{array}{c}1.362 \\
(1.344)\end{array}$ \\
\hline$\Delta$ Duty $\times \ln (\mathrm{TFP})$ & $\begin{array}{c}0.103^{* *} \\
(0.050)\end{array}$ & $\begin{array}{c}0.179 * * * \\
(0.062)\end{array}$ & $\begin{array}{c}0.127^{* *} \\
(0.057)\end{array}$ & $\begin{array}{c}0.204^{* * *} \\
(0.072)\end{array}$ & $\begin{array}{l}-0.042 \\
(0.070)\end{array}$ & $\begin{array}{l}-0.049 \\
(0.089)\end{array}$ \\
\hline Observation & 16907 & 8971 & 15018 & 7799 & 1889 & 1172 \\
\hline R-square & 0.015 & 0.018 & 0.015 & 0.019 & 0.058 & 0.068 \\
\hline \multicolumn{7}{|l|}{ Panels $A$ and $B$ : } \\
\hline Firm-level Controls & yes & yes & yes & yes & yes & yes \\
\hline Industry-level Competition Control & yes & yes & yes & yes & yes & yes \\
\hline Industry fixed effect Control & yes & yes & yes & yes & yes & yes \\
\hline
\end{tabular}

Notes: ${ }^{* * *} \mathrm{p}<0.01,{ }^{* *} \mathrm{p}<0.05,{ }^{*} \mathrm{p}<0.1$. Robust standard errors corrected for clustering at the firm level in parentheses. Dependent variable in specifications (1), (3), and (5) is the (log) price change at the firm-HS6-country level; dependent variable in specifications (2), (4), and (6) is the (log) price change at the firm-HS6 product level. All regressions include a constant term, firm-level controls, and industrylevel competition control. Industry-level competition control refers to the change of Herfindahl index. Firm-level controls include the changes between 2001 and 2006 in the following variables: TFP, capital intensity, average wage, and total employment. Industry fixed effect is computed at 2-digit CIC industry level. When we use firm-product productivity proxy based on HS4 product, the similar results as in Panel B obtain.

of initial productivity on firms' response to tariff reductions, it is important to show that our results are robust to different approaches of estimating firm productivity. Table 8 reports robustness checks using quantity-based productivity measures. Panel A presents results based on physical TFP (see Section 4.3 for the discussion on the measurement issues and estimation approach). ${ }^{44}$ The first two columns correspond to the whole sample, columns 3-4 use the subsample of differentiated goods, columns 5-6 refer to homogeneous goods, where the odd and even columns use firm-HS6-country and firm-HS6 level price change as dependent variable, respectively. ${ }^{45}$

\footnotetext{
${ }^{44}$ We also replicate the evidence of our key stylized fact using physical TFP to divide firms into lowand high-productivity firms and find similar patterns: the average (log) export price changes per firmHS6-country for low- and high-TFP firms are $20.27 \%$ and $12.12 \%$ in the whole sample, $21.04 \%$ and $14.35 \%$ in the differentiated goods sample, and $-2.20 \%$ and $-0.78 \%$ in the homogeneous goods sample, respectively.

${ }^{45}$ Here, the magnitude of the coefficient estimates is not always larger at more aggregated level, per-
} 
For all goods and for differentiated goods, the coefficients on tariff changes are significantly negative, and the coefficients on $\Delta$ Duty $\times \ln (\mathrm{TFP})$ are positive. The effect of tariff reductions for differentiated goods are always larger than the effect for all goods across all specifications, while for homogeneous goods the effect is insignificant. This pattern is consistent with the prediction of Proposition 3 that the effect of tariff reduction on price changes and the differential effect between less and more productive firms would become less pronounced when the scope for quality differentiation is smaller. Panel B of Table 8 reports results using firm-HS6 product level export quantity as rough proxy for firm-product level productivity, and all previous main results still hold. ${ }^{46}$

In addition, we use other variables, such as valued added per worker, total sales and total wage bill to replace firm productivity. ${ }^{47}$ Table A. 8 in the online appendix shows that when using these alternative proxies all coefficients on tariff changes are significantly negative and the ones on the interaction term $\Delta$ Duty $\times \ln (\mathrm{TFP})$ are positive for all goods and for differentiated goods. Furthermore, the effect of tariff reductions for differentiated goods is always greater than the effect for all goods across all specifications, while for homogeneous goods the effect is insignificant.

(A.2) Alternative measures of tariff cuts. - So far our discussion is based on the effect of firm-specific tariff reductions. This measure has the advantage of being theoretically justified and consistent with the intensive margin effect across firms. In Section 4.2 we also discussed various approaches to measure alternative tariff reductions and their features. We now show that our result is robust to other firm-specific, firm-product specific and industry-specific tariff reduction measures.

In Table 9, columns 1-2 refer to the first alternative measure of tariff cuts using fixed set of imported inputs, columns 3-4 adopt tariffs only of intermediate goods, and columns 5-6 use Manova and Zhang (2012b)'s method of computing the input within the same product category. Panel A reports the results in the whole sample, Panel B presents the results using the differentiated goods sample, and Panel $\mathrm{C}$ reports the results with the homogeneous goods sample. The firm-HS6-country level results are presented in columns 1,3 , and 5, while the firm-HS6 product level results are presented in columns 2, 4, and 6.

Table 9 shows that for all goods and for differentiated goods, the effect of tariff haps due to the sample size change since we only keep single-product firms when estimating physical productivity.

${ }^{46}$ Results in Panel B of Table 8 use firm-product level average export quantity in the sample period 2001-2006 as proxy for productivity. We also use the export quantity in the initial year 2001 as proxy and obtain similar results.

${ }^{47}$ Here, we use the total employment payment instead of the total employment number, because firm with different productivity pay different wages due to different levels of labor's effort based on our model. To drop outliers, we also delete the firms with the total employment payment below 1 percentile, around forty thousand dollars. 
Table 9: Robustness: Alternative Measures of Firm-Specific Tariff Cuts

\begin{tabular}{|c|c|c|c|c|c|c|}
\hline & \multicolumn{6}{|c|}{ "Dependent Variable: $\Delta \ln ($ price $)$} \\
\hline & \multicolumn{2}{|c|}{ Measure 1} & \multicolumn{2}{|c|}{ Measure 2} & \multicolumn{2}{|c|}{ Measure 3} \\
\hline & $\begin{array}{c}(1) \\
\Delta \ln \left(p_{f h c}\right)\end{array}$ & $\begin{array}{c}(2) \\
\Delta \ln \left(p_{f h}\right)\end{array}$ & $\begin{array}{c}(3) \\
\Delta \ln \left(p_{f h c}\right)\end{array}$ & $\begin{array}{c}(4) \\
\Delta \ln \left(p_{f h}\right)\end{array}$ & $\begin{array}{c}(5) \\
\Delta \ln \left(p_{f h c}\right)\end{array}$ & $\begin{array}{c}(6) \\
\Delta \ln \left(p_{f h}\right)\end{array}$ \\
\hline \multicolumn{7}{|l|}{ Panel A: Whole Sample } \\
\hline$\Delta$ Duty & $\begin{array}{c}-1.895^{* * *} \\
(0.601)\end{array}$ & $\begin{array}{c}-2.049^{* *} \\
(0.957)\end{array}$ & $\begin{array}{c}-2.298^{* * *} \\
(0.724)\end{array}$ & $\begin{array}{c}-2.698^{* * *} \\
(1.004)\end{array}$ & $\begin{array}{c}-2.982^{* * *} \\
(0.876)\end{array}$ & $\begin{array}{c}-3.809^{* * *} \\
(1.446)\end{array}$ \\
\hline$\Delta$ Duty $\times \ln (\mathrm{TFP})$ & $\begin{array}{c}0.421^{* * *} \\
(0.128)\end{array}$ & $\begin{array}{c}0.459^{* *} \\
(0.213)\end{array}$ & $\begin{array}{c}0.472^{* * *} \\
(0.154)\end{array}$ & $\begin{array}{c}0.526 * * \\
(0.215)\end{array}$ & $\begin{array}{c}0.669^{* * *} \\
(0.205) \\
\end{array}$ & $\begin{array}{c}0.852^{* * *} \\
(0.292)\end{array}$ \\
\hline Observation & 21922 & 11750 & 15229 & 8121 & 6629 & 2916 \\
\hline R-square & 0.013 & 0.015 & 0.018 & 0.0191 & 0.027 & 0.034 \\
\hline \multicolumn{7}{|l|}{ Panel B: Differentiated Goods } \\
\hline$\Delta$ Duty & $\begin{array}{c}-2.064^{* * *} \\
(0.672)\end{array}$ & $\begin{array}{c}-2.184^{* *} \\
(1.046)\end{array}$ & $\begin{array}{c}-2.539^{* * *} \\
(0.844)\end{array}$ & $\begin{array}{c}-3.183^{* * *} \\
(1.219)\end{array}$ & $\begin{array}{c}-3.270^{* * *} \\
(0.962)\end{array}$ & $\begin{array}{c}-4.123^{* * *} \\
(1.555)\end{array}$ \\
\hline$\Delta$ Duty $\times \ln (\mathrm{TFP})$ & $\begin{array}{c}0.475^{* * *} \\
(0.144)\end{array}$ & $\begin{array}{c}0.525^{* *} \\
(0.236)\end{array}$ & $\begin{array}{c}0.514^{* * *} \\
(0.184)\end{array}$ & $\begin{array}{c}0.606^{* *} \\
(0.271)\end{array}$ & $\begin{array}{c}0.721^{* * *} \\
(0.231) \\
\end{array}$ & $\begin{array}{c}0.947 * * * \\
(0.329)\end{array}$ \\
\hline Observation & 19630 & 10290 & 13426 & 7025 & 6217 & 2685 \\
\hline R-square & 0.012 & 0.015 & 0.019 & 0.020 & 0.027 & 0.035 \\
\hline \multicolumn{7}{|l|}{ Panel C: Homogeneous Goods } \\
\hline$\Delta$ Duty & $\begin{array}{l}-0.416 \\
(1.006)\end{array}$ & $\begin{array}{l}-0.343 \\
(1.518)\end{array}$ & $\begin{array}{c}0.228 \\
(1.365)\end{array}$ & $\begin{array}{c}1.891 \\
(1.601)\end{array}$ & $\begin{array}{c}2.728 \\
(3.229)\end{array}$ & $\begin{array}{c}-2.033 \\
(4.095)\end{array}$ \\
\hline$\Delta$ Duty $\times \ln ($ TFP $)$ & $\begin{array}{c}0.024 \\
(0.196)\end{array}$ & $\begin{array}{c}-0.040 \\
(0.321)\end{array}$ & $\begin{array}{c}0.074 \\
(0.247)\end{array}$ & $\begin{array}{c}-0.186 \\
(0.281)\end{array}$ & $\begin{array}{l}-0.365 \\
(0.626)\end{array}$ & $\begin{array}{c}0.388 \\
(0.770)\end{array}$ \\
\hline Observation & 2292 & 1460 & 1803 & 1096 & 412 & 231 \\
\hline R-square & 0.047 & 0.060 & 0.055 & 0.068 & 0.064 & 0.080 \\
\hline \multicolumn{7}{|l|}{ Panels $A, B$ and $C$ : } \\
\hline Firm-level Controls & yes & yes & yes & yes & yes & yes \\
\hline Industry-level Competition Control & yes & yes & yes & yes & yes & yes \\
\hline Industry fixed effect & yes & yes & yes & yes & yes & yes \\
\hline \multicolumn{7}{|c|}{$\begin{array}{l}\text { Notes: }{ }^{* *} \mathrm{p}<0.01,{ }^{*} \mathrm{p}<0.05,{ }^{*} \mathrm{p}<0.1 \text {. Robust standard errors corrected for clustering at the firm } \\
\text { level in parentheses. Measure } 1 \text { (see specifications } 1 \text { and } 2 \text { ) refers to the tariff reduction measure by fixing } \\
\text { the total number of imported varieties during the whole sample period; measure } 2 \text { (see specifications } 3 \\
\text { and } 4 \text { ) is the weighted firm-specific import tariff reductions of only intermediate goods; measure } 3 \text { (see } \\
\text { specifications } 5 \text { and } 6 \text { ) refers to Manova and Zhang }(2012 b \text { )'s method of computing the input within the } \\
\text { same product category. The sample size differs for different measures of tariff cuts: moving from measure } \\
1 \text { to measure } 2 \text { (based on the set of imported intermediates) and measure } 3 \text { (based on the inputs only } \\
\text { within the same product category) reduces the sample size. Dependent variable in specifications }(1),(3) \text {, } \\
\text { and (5) is the (log) price change at the firm-HS6-country level; dependent variable in specifications }(2) \text {, } \\
(4) \text {, and (6) is the (log) price change at the firm-HS6 product level. All regressions include a constant } \\
\text { term, firm-level controls, and industry-level competition control. Industry-level competition control refers } \\
\text { to the change of Herfindahl index. Firm-level controls include the changes between } 2001 \text { and } 2006 \text { in the } \\
\text { following variables: TFP, capital intensity, average wage, and total employment. Industry fixed effect is } \\
\text { computed at 2-digit CIC industry level. }\end{array}$} \\
\hline
\end{tabular}

reduction on export price and the difference between low- and high-productivity firms are all significant and consistent with our model predictions. The results of differentiated goods are stronger than the ones for all goods across all specifications, while the effect of interest is not significant for homogeneous goods. Since Measure 3 is firm-product 
specific, we also experiment with adding HS6 product fixed effect to further check the robustness and find similar results to those in columns 5 and 6 (see Table A.9 in the online appendix). ${ }^{48}$ These results corroborate Proposition 3.

Table 10: Robustness: Results of Industry Input and Output Tariffs

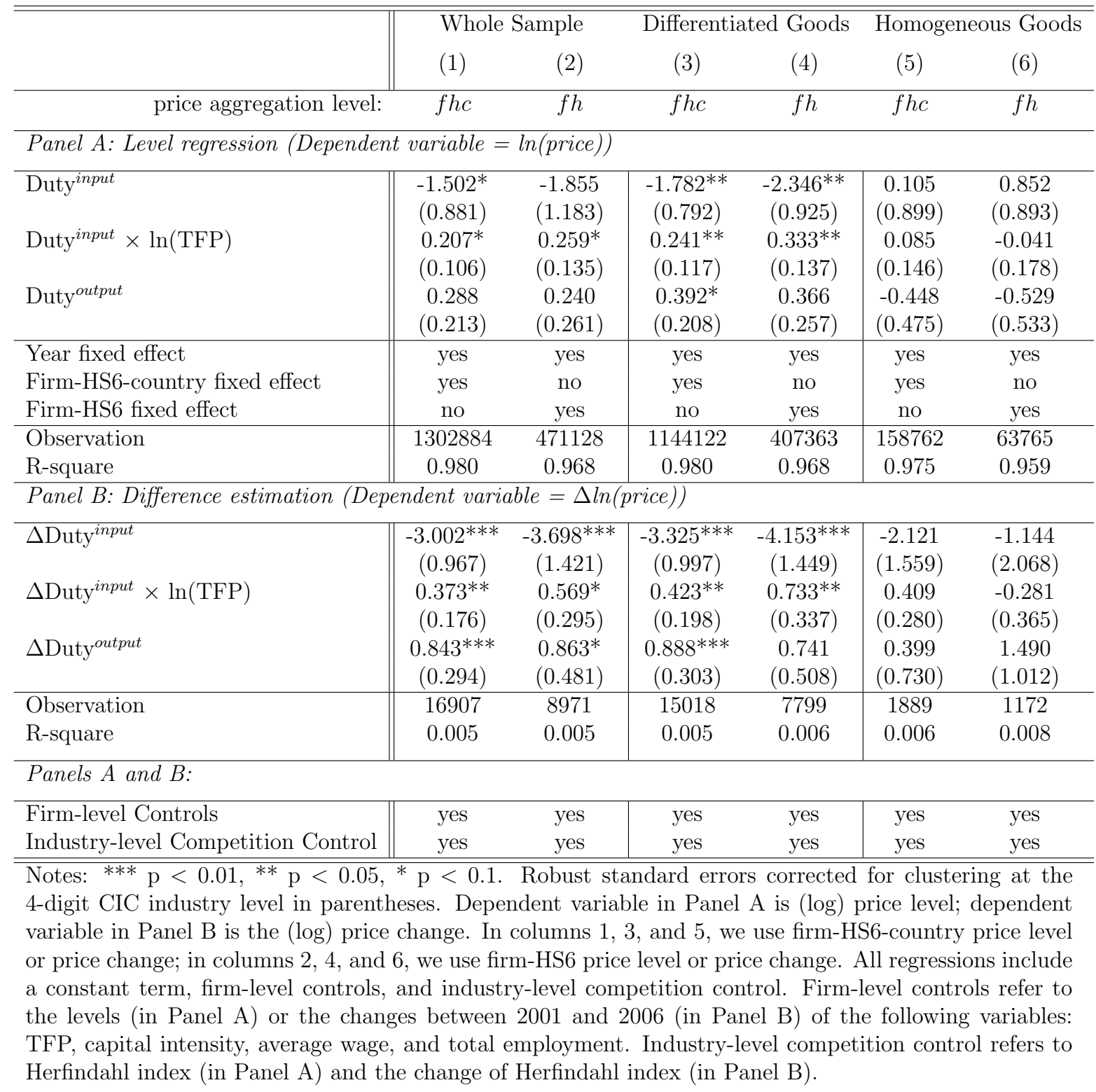

One might worry that the correlation between the reduction in import tariffs on intermediate inputs and tariff cuts on firms' outputs might cause the coefficient estimates to be polluted by competition effects (Amiti and Khandelwal, 2013). Moreover, as discussed in Section 4.2, while the firm-specific measures of tariff cuts have advantages, they may

\footnotetext{
${ }^{48}$ Adding firm fixed effect instead of HS6 product fixed effect in columns 5 and 6 would make coefficients become insignificant. The reason of insignificance when including firm fixed effect is that each firm only exports a small amount of products in the sample of using Measure 3 and, moreover, there is on average only 1.58 firm-product tariff lines (based on Measure 3) within each firm.
} 
miss the broader effect of tariff cuts on intermediate inputs when firms use domestically purchased intermediate inputs that are produced by other importing firms. We address these concerns by including output tariffs and input tariffs constructed using input-output tables. ${ }^{49}$

Table 10 reports results of both level regressions (see Panel A) and difference estimations (see Panel B). In Panel A, the dependent variable is (log) price at firm-HS6destination level in odd columns and (log) price at firm-HS6 level in even columns. To better capture the variation of export prices over time, we control for year fixed effects and firm-HS6(-country) fixed effect in level regressions. The coefficients on input tariff are mostly significant and negative, and the coefficients on the interaction term are always significantly positive, for the samples of all goods and differentiated goods, even after precisely controlling for firm-HS6(-destination) fixed effects. This pattern is more profound when using difference estimations in Panel B. To sum up, using industry-level input tariff does not alter our main results even after taking into account the effect of output tariffs.

So far, we have shown that our results are robust to alternative productivity and tariff measures using the subsamples of differentiated goods and of homogeneous goods. In addition, we check those robustness results using the triple interaction term $\Delta$ Duty $\times \ln (\mathrm{TFP}) \times$ Diff with the whole sample in Table A.10 for alternative measures of productivity and firmspecific tariff cuts and in Table A.11 for industry input and output tariff measures in the online appendix. We find that the coefficients on the triple interaction term are all positive and they are mostly significant at firm-product level, which further confirms the differential effect of tariff reduction between low- and high-productivity firms.

In addition, to assess the average effect of tariff reduction on export price change using alternative measures of productivity and tariff cuts, we demean (log) productivity before interacting it for the main specifications of Tables 8, 9, and 10. The results are reported in Table A.12 in the online appendix where columns 1-2 correspond to physical TFP measure and export quantity measure, columns 3-5 use the three alternative measures of tariff cuts, and column 6 corresponds to industry-specific tariff reductions. The significantly negative coefficients on tariff change in columns 1 and 2 indicate that the average effects of tariff reductions are negative and robust for alternative productivity measures. When using alternative tariff measures, the average effects also remain significantly negative for Measure 2 and industry-specific tariff (see columns 4 and 6). ${ }^{50}$

\footnotetext{
${ }^{49}$ We map the harmonized system (HS) 8-digit tariffs into the 3-digit Chinese Input-Output sectors (coded in 5-digit format). Our 3-digit output tariff, then, is the simple average of the tariffs in the HS 8-digit codes within each 3-digit IO industry code. To compute the input tariff, following Amiti and Konings (2007) we use an input cost weighted average of output tariffs where: $\tau_{i t}^{\text {input }}=\sum_{k} a_{k i} \tau_{k t}^{\text {output }}$ where $\tau_{k t}^{\text {output }}$ is the tariff on industry $k$ at time $t$, and $a_{k i}$ is the weight of industry $k$ in the input cost of industry $i$. Then we convert the input tariffs to CIC 4-digit industry level.

${ }^{50}$ When using Measure 1 and Measure 3 (see columns 3 and 5 of Table A.12), the average effects of
} 
(A.3) Endogeneity. - Now, we address the issue of the potential endogeneity of tariff changes, though we believe that tariff changes are arguably exogenous from the individual firm's perspective. Using industry-specific input tariffs alleviates the concern of the endogeneity of tariff cuts, but does not eliminate the concern. To address this issue, we re-estimate the baseline specification using past tariff levels as instruments for changes in tariffs as is commonly done in the literature (e.g., Goldberg and Pavcnik, 2005; Amiti and Konings, 2007). The idea is that the past tariffs are strongly correlated with the current changes in tariffs, but the past tariffs are uncorrelated with the error term or any other determinants of the dependent variable in the baseline regressions. Because the results of instrument are not qualitatively different, they are reported in Table A.13 in the online appendix in order to conserve space.

(A.4) Large sample test using whole customs data. - So far, our results are based on a merged sample that combines both the NBSC firm production data and the customs data. As the NBSC dataset contains only large firms, selection bias is a potential concern. This problem is not unique to our data: in developing countries and low-income countries a large proportion of firms may not be part of conventionally available datasets (see McCaig and Pavcnik $(2014,2015)$ for related evidence in Vietnam). Since our focus is on incumbent firms who are already exporters/importers, the left end of the firm distribution that contains the smallest firms is beyond the scope of this paper. Nonetheless, to alleviate the concern of sample selection bias, we present results using the whole customs data that covers the universe of all firms that either export or import through Chinese customs. As we cannot estimate TFP for lack of NBSC firm production data, we employ total export value as proxy for firm productivity and include HS2-product fixed effects. As the results are strongly consistent with our benchmark results, especially at the firm-product level, we present them in Table A.14 in the online appendix. We also replicate key stylized facts using whole customs data (see Table A.15 in the online appendix) and find that the key stylized facts still hold.

\section{B. Robustness II - Alternative Explanations}

(B.1) Placebo test using processing trade. - Our previous results were based on ordinary trade firms that pay import tariffs to import intermediate inputs. Processing firms were excluded because they are not subject to tariffs. As a placebo we replicate our baseline regressions using processing trade firms as a comparison group. ${ }^{51}$ Since our model

tariff reductions are still negative though insignificant.

${ }^{51} \mathrm{~A}$ firm cannot freely choose between ordinary trade and processing trade: its choice of trade regime is often constrained by financing situation. Profits, profit-to-sales ratios, and value added are higher for firms that conduct more ordinary relative to processing trade, while processing trade firms must face some constraint that prevents them from doing ordinary trade (Manova and Yu, 2016). Thus, even though processing firms can benefit from import tariff exempt, firms may not necessarily want to engage more in processing trade as it is a low value-added trade regime in the context of global production chain. This is also reflected in the steady share of processing exports in total exports over time that is around 55\% (Kee and Tang, 2016). This eliminates the concern that firms purposely conduct more processing 
highlights the channel through the improved access to imported intermediate inputs, we expect that processing trade firms do not respond significantly to tariff reductions and certainly there is no difference of the response between low- and high-productivity processing firms. Table A.16 in the online appendix reports the results using processing trade sample and confirms our expectation: All coefficients on tariff reductions and interaction terms are statistically insignificant.

(B.2) Sensitivity to other mechanisms. - One may concern that there are other mechanisms through which trade liberalization affects low- and high-productivity firms differently regarding their export price changes. Those potential mechanisms include reduced uncertainty that restraints Chinese firms' ability to export to certain markets, especially those high-income countries where demand for high quality goods is strong, and appreciation of Chinese currency.

Policy uncertainty. - Prior to its accession to the WTO, China was vulnerable to the sudden loss of MFN status in its trade relations with the United States, where such status required annual congressional action to maintain. Pierce and Schott (2013) have shown that this vulnerability depressed Chinese exports to the U.S., particularly in industries where non-MFN tariffs were very high. To role out the potential for this mechanism to drive our results, we remove the U.S. from our sample and reestimated our main equations. The resulting estimates for all goods, differentiated goods, and homogeneous goods are shown in columns 1, 4, and 7 in Table A.17 in the online appendix, respectively.

Currency appreciation. - As China's currency, Reminbi (RMB), has appreciated since July 2005, one may be also concerned that the price increase is partially due to the appreciation of RMB. It is possible that a stronger RMB reduces firms' costs to purchase imported inputs with local currency, and thus provides firms more incentive to switch to better inputs. To test the sensitivity of our results to RMB appreciation, we use the data during the period before the appreciation to test whether export prices indeed increase without currency appreciation. As the RMB appreciated in late 2005, we dropped data of 2005 and 2006, and conduct the long-difference estimation for the period between 2001 and 2004 in columns 2,5 and 8 for firm-HS6-country level price change $\left(\Delta \ln p_{f h c}\right)$ and columns 3, 6, and 9 for firm-HS6 level price change $\left(\Delta \ln p_{f h}\right)$ in Table A.17, respectively.

(B.3) The test using estimated quality. - It is not easy to directly measure quality, but we can infer "effective quality" (quality as it enters consumer's utility) from observed prices and market shares. We estimate "quality" of exported product $h$ shipped to destination country $c$ by firm $f$ in year $t, q_{f h c t}$, according to demand equation (1) in the model, using an OLS regression as in Khandelwal, Schott and Wei (2013) and Fan,

trade in order to avoid paying import tariff. 
Li and Yeaple (2015), via the following empirical demand equation in our model:

$$
\ln \left(x_{f h c t}\right)+\sigma \ln \left(p_{f h c t}\right)=\varphi_{h}+\varphi_{c t}+\epsilon_{f h c t}
$$

where $x_{f h c t}$ denotes the demand for a particular firm's export of product $h$ in destination country $c$ in year $t, p_{f h c t}$ is the price the firm charges that equals the price that consumers face, $\sigma$ is the elasticity of substitution across products, the country-year fixed effect $\varphi_{c t}$ collects the destination-year specific information including price index and expenditure at destination markets, and the product fixed effect $\varphi_{h}$ captures the information on prices and demand across product categories due to the inherent characteristics of products. We allow the elasticity of substitution to vary across industries $\left(\sigma_{i}\right)$ using the estimates of Broda and Weinstein (2006) to estimate quality. ${ }^{52}$ Then estimated quality is $\ln \left(\hat{q}_{f h c t}\right)=$ $\hat{\epsilon}_{f h c t}$, i.e., the residual from equation (15). ${ }^{53}$

The results using estimated quality as dependent variable are reported in Table A.18 in the online appendix. The results present a similar pattern as in our main results in which price changes are the dependent variable. In the whole sample of all goods and the sample of differentiated goods, tariff reductions significantly induce firms to upgrade quality of their products, and this quality upgrading pattern is more profound for lowproductivity firms as shown by the significantly positive coefficients on the interaction term. This pattern does not appear in the homogeneous goods sample.

(B.4) Controlling for Mark-Up Changes. - To further verify quality upgrading by firm's access to higher quality inputs, we check whether the effect of tariff reduction on price increase along the intensive margin still exists after controlling markup variation. To this end, we include change in market share in our estimation to control for the change in markup (see Amiti, Itskhoki and Konings (forthcoming) and Fan, Li and Yeaple (2015)). In specifications (1), (3) and (5) of Table A.19 in the online appendix, we add change in firm's market share as control variable to test impact of tariff reduction on $\Delta \ln p_{f h c}$, for all goods, differentiated goods and homogeneous goods, respectively. In accordance, coefficients on tariff reductions are significantly negative, while coefficients on interaction terms $(\Delta$ Duty $\times \log (\mathrm{TFP}))$ are significantly positive for all goods and differentiated goods. As for homogeneous goods, all effects are, however, insignificant. This alleviates the concern that our results reflect markup variation rather than quality adjustments along the intensive margin. To address the potential endogeneity of market

\footnotetext{
${ }^{52}$ Using the existing values of estimated $\sigma$ from the literature is a common approach used in the prior studies (e.g., Khandelwal, Schott and Wei, 2013). Broda and Weinstein (2006) estimate the elasticity of substitution for disaggregated categories and report that the average and median elasticity is 7.5 and 2.8 , respectively. We use their estimates aggregated to HS 2-digit level and merge with our sample. In addition, to avoid parameterizing $\sigma_{i}$ based on the existing values given in the literature, we also estimate quality using IV estimation and our results remain robust. To save space, the results based on estimated quality using IV estimation are not reported here, but available upon request.

${ }^{53}$ Here $\hat{q}_{f h c t} \equiv q_{f h c t}^{\eta}$. In other words, the estimated quality $\hat{q}$ is corresponding to $q^{\eta}$.
} 
share change, we employ initial tariff levels in 2001 (see columns 2, 4 and 6) facing all other firms in the same 4-digit CIC industry to instrument market share change for each individual firm. Again, the effect of tariff reductions on price increase across firm would not be affected by instrumenting for market share changes.

\subsection{Tariff Reduction and Input Upgrading}

In this section, we explore the input implications of our model. According to Proposition 4 , a reduction in import tariff would induce an incumbent exporter/importer to pay higher prices for both its primary and intermediate inputs. That is to say, an increase in export prices would go through two channels of input quality upgrading: the upgrade in the quality of imported intermediate inputs and an increase in the primary input quality involving better workers that require a higher wage. Moreover, this effect is smaller in absolute magnitude for more productive firms, and the differential effect between low- vs. high-productivity firms is most pronounced in industries in which the scope for quality differentiation is high. In the end of this section, we also explore the implication for input upgrading pattern at the extensive margin regarding the imported input share in total intermediate inputs.

Table 11 reports the regression results with changes in import prices as dependent variable at the firm-HS6-country level (see columns 1-4) and the firm-HS6 level (see columns $5-8) .{ }^{54}$ Our model suggests that the effect of tariff reductions on the import price increase would be more pronounced for low-productivity firms. As a result, the coefficients on the interaction term $\Delta$ Duty $\times \ln (\mathrm{TFP})$ would be positive and the coefficients on tariff change itself would be negative. The results using the whole sample (see columns 1 and 5 ) and the differentiated goods subsample (see columns 2 and 6) are all significant and consistent with our expectation. In particular, the differentiated goods subsample generates the largest response to tariff reductions, while the effect on homogeneous goods is insignificant. The significantly positive coefficients on $\Delta$ Duty $\times \ln ($ TFP $)$ for all goods and for differentiated goods indicate that the tariff reduction effect on import price increase is also stronger for less productive firms.

It is worth noting that the effect of the tariff reduction is stronger on the export prices for final outputs than on the import prices of inputs. ${ }^{55}$ There are several potential explanations. First, part of the quality upgrading story is due to innovation efforts on the part of the firm induced by lower marginal cost of production. That is, only part of quality

\footnotetext{
${ }^{54}$ The sample size of Table 11 for import prices at the firm-product-country level and the firm-product level is not much different. This suggests no compositional effect from the perspective of switching importing source countries within each firm-product dyad.

${ }^{55}$ The difference between the effect on import price vs. export price can be seen by comparing columns 1 and 5 in Table 11 for import prices vs. columns 3 and 6 in the baseline results of Table 5 for export prices.
} 
Table 11: Input Quality Upgrading (I): Import Price, Tariff Cuts, and Productivity

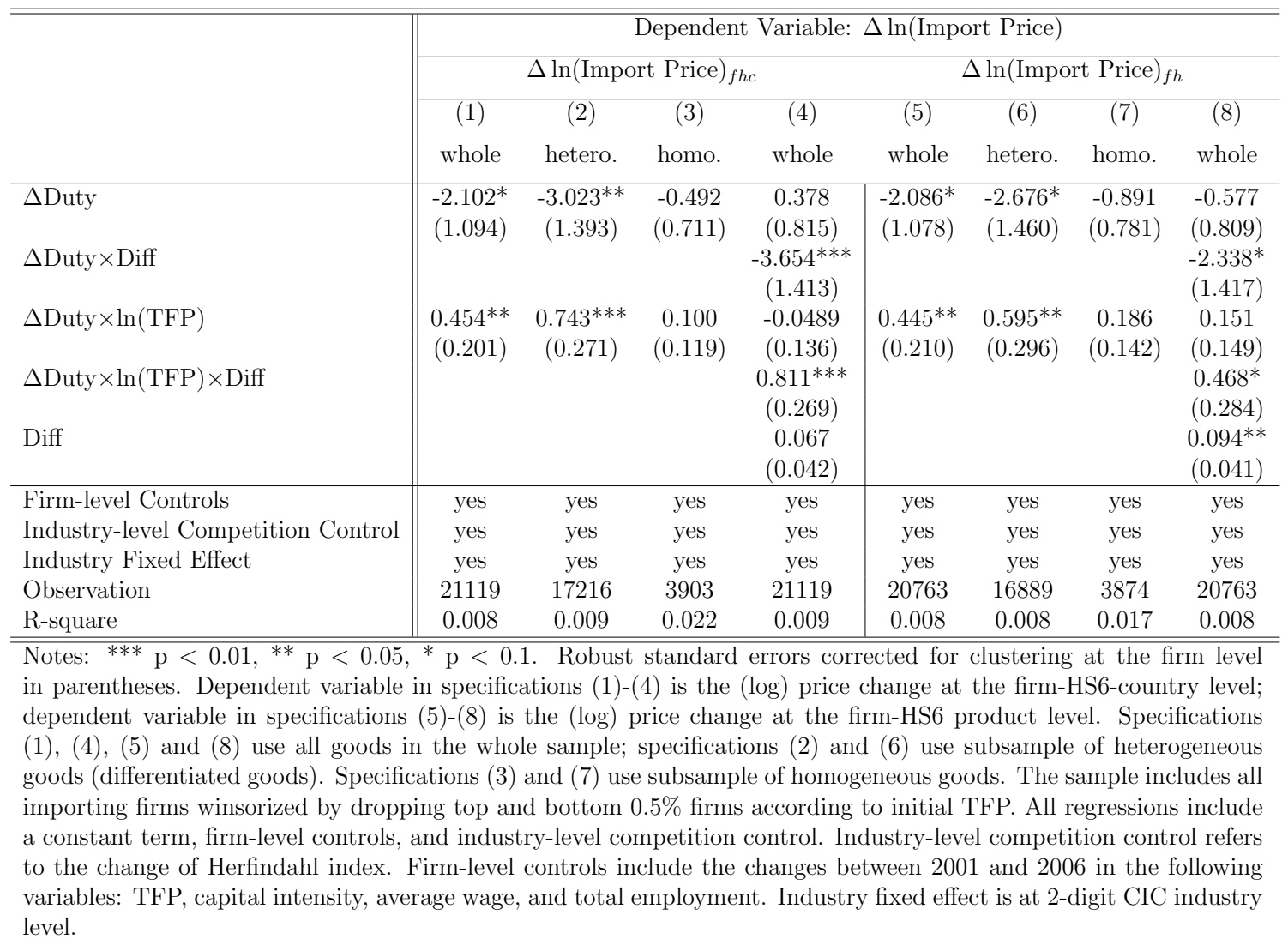

upgrading of output is due to quality upgrading of inputs. Second, the elasticities of input quality supply and output quality demand will in general be different. Third, as shown by (Amiti and Khandelwal, 2013) a tariff reduction that leads to greater competition in the home market is associated with an increase in export quality. The improved access to imported intermediate inputs would also induce an increase in total factor productivity or expanded export scope that would eventually relate to export quality upgrading. ${ }^{56}$ Finally, our price data is in unit values. Export unit values well capture export quality, while only a fraction of observed import unit value differences are attributed to import quality (Feenstra and Romalis, 2014).

Table 11 also reports results using triple interaction term $\Delta$ Duty $\times \ln (\mathrm{TFP}) \times$ Diff to further confirm the differential effect between low- and high-productivity firms conditional on quality scope. Indeed the coefficients on triple interaction terms are significantly positive while the coefficients on $\Delta$ Duty $\times$ Diff are significantly negative (see columns 4 and 8). These results are again consistent with Proposition 4 that in the industries where

\footnotetext{
${ }^{56}$ See, for example, Amiti and Konings (2007) on Indonesian firms, Kasahara and Rodrigue (2008) on Chilean firms, Goldberg et al. (2010) and Topalova and Khandelwal (2011) on Indian firms, Bas and Strauss-Kahn (2014) on French firms, Halpern, Koren and Szeidl (2015) on Hungarian firms, and Yu (2015) and Feng, Li and Swenson (2016) on Chinese firms.
} 
the scope for quality differentiation is large, trade liberalization has a greater effect on import price increase, especially for less productive firms.

Table 12: Input Quality Upgrading (II): Wage Upgrading, Tariff Cuts, and Productivity

\begin{tabular}{|c|c|c|c|c|}
\hline & \multicolumn{4}{|c|}{ "Dependent Variable: $\Delta \ln ($ Wage Payment) } \\
\hline & $\begin{array}{c}(1) \\
\text { whole }\end{array}$ & $\begin{array}{c}(2) \\
\text { hetero. }\end{array}$ & $\begin{array}{c}(3) \\
\text { homo. }\end{array}$ & $\begin{array}{c}(4) \\
\text { whole }\end{array}$ \\
\hline$\Delta$ Duty & $\begin{array}{c}-1.393^{*} \\
(0.717)\end{array}$ & $\begin{array}{c}-2.521^{* *} \\
(1.030)\end{array}$ & $\begin{array}{c}-0.579 \\
(0.848)\end{array}$ & $\begin{array}{l}-0.748 \\
(0.825)\end{array}$ \\
\hline$\Delta$ Duty $\times$ Diff & & & & $\begin{array}{l}-1.657 \\
(1.214)\end{array}$ \\
\hline$\Delta$ Duty $\times \ln (\mathrm{TFP})$ & $\begin{array}{c}0.291^{*} \\
(0.150)\end{array}$ & $\begin{array}{c}0.640^{* * * *} \\
(0.242)\end{array}$ & $\begin{array}{c}0.112 \\
(0.168)\end{array}$ & $\begin{array}{c}0.136 \\
(0.161)\end{array}$ \\
\hline$\Delta$ Duty $\times \ln (\mathrm{TFP}) \times$ Diff & & & & $\begin{array}{l}0.477^{*} \\
(0.268)\end{array}$ \\
\hline Diff & & & & $\begin{array}{c}0.030 \\
(0.031)\end{array}$ \\
\hline Firm-level Controls & yes & yes & yes & yes \\
\hline Industry-level Competition Control & yes & yes & yes & yes \\
\hline Industry Fixed Effect & yes & yes & yes & yes \\
\hline Observation & 4256 & 2980 & 1276 & 4256 \\
\hline R-square & 0.060 & 0.064 & 0.077 & 0.062 \\
\hline $\begin{array}{l}\text { Notes: }{ }^{* *} \mathrm{p}<0.01,{ }^{* *} \mathrm{p}<0.05,{ }^{*} \mathrm{f} \\
\text { clustering at the firm level in parent } \\
\text { payment change at the firm level. S } \\
\text { all firms; specification }(2) \text { uses hete } \\
\text { imported product is heterogeneous } \mathrm{g} \\
\text { uses homogeneous subsample in wh } \\
\text { geneous goods. All regressions inclu } \\
\text { industry-level competition control. } \\
\text { the change of Herfindahl index. Firr } \\
2001 \text { and } 2006 \text { in capital intensity al } \\
\text { computed at } 2 \text {-digit CIC industry le }\end{array}$ & $\begin{array}{l}0.1 . \mathrm{P} \\
\text { eses. D } \\
\text { cificati } \\
\text { geneou } \\
\text { ds (diff } \\
\text { a firm } \\
\text { a con } \\
\text { dustry } \\
\text { level co } \\
\text { total e }\end{array}$ & $\begin{array}{l}\text { oust stan } \\
\text { endent v } \\
\text { (1) and } \\
\text { ubsampl } \\
\text { entiated } \\
\text { core imp } \\
\text { int term, } \\
\text { vel comp } \\
\text { rols incly } \\
\text { ployment }\end{array}$ & $\begin{array}{l}\text { rd error } \\
\text { able is } \\
\text { ) use wl } \\
\text { n which } \\
\text { ods). Sp } \\
\text { ted pro } \\
\text { rm-level } \\
\text { ition co } \\
\text { the ch } \\
\text { ndustry }\end{array}$ & $\begin{array}{l}\text { rrected for } \\
\text { (log) wage } \\
\text { sample of } \\
\text { firm's core } \\
\text { ication (3) } \\
\text { t is homo- } \\
\text { atrols, and } \\
l \text { refers to } \\
\text { es between } \\
\text { ed effect is }\end{array}$ \\
\hline
\end{tabular}

Table 12 presents the results of regressing the change in firm-level wages on firmspecific tariff reductions and on the interaction terms to check the effect of trade liberalization on labor quality upgrading. Columns 1-3 use the whole sample of all firms, the subsample of firms that import differentiated goods, and the subsample of firms that import homogeneous goods, respectively. ${ }^{57}$ Import tariff reductions significantly raise wage payments, and this effect is more pronounced for low-productivity firms in the whole sample and in the heterogeneous subsample (see columns 1 and 2). The magnitude of tariff reduction effect is larger in column 2 than in column 1, while this effect is not

\footnotetext{
${ }^{57}$ Here we use the core imported product to determine whether a firm belongs to heterogeneous or homogeneous subsample: if a firm's largest imported product is differentiated goods, we categorize this firm into heterogeneous subsample; if a firm's largest imported product is homogeneous goods, we categorize this firm into homogeneous subsample. This approach is based on a belief of complementarity between primary inputs and intermediate inputs, e.g., more differentiated intermediate inputs may need relatively more skilled labor inputs to use.
} 
significant in the homogeneous subsample (see column 3). Moreover, column 4 reports the significantly positive coefficient on the triple interaction term, and the signs of coefficients of all other variables of interest are consistent with our expectation. These results confirm the model predictions in Proposition 4 that the trade liberalization induces firms with lower productivity to increase their payments for primary inputs more than those with higher productivity, and this differential effect is most pronounced in industries with large scope for quality differentiation.

In addition to examining the changes in intensive margin of inputs through import price and wage payment, we also explore the comparative statics of extensive margin of imports, i.e., how the share of imported inputs in total intermediate inputs evolves. As firms choose a higher quality of their output, they would substitute from domestic inputs towards imported inputs. As a result, we expect similar predictions as for the other propositions: more foreign sourcing by high-productivity firms, but a stronger increase following tariff reductions by low-productivity firms. We test these two predictions in Table A.20 in the online appendix where columns 1-3 regress imported inputs share on firm productivity using the data in initial year 2001 and columns 4-6 regress the changes in imported inputs share from 2001 to 2006 on tariff reduction and the interaction term $\Delta$ Duty $\times \ln (\mathrm{TFP})$. All results are significant and support the aforementioned two predictions.

\subsection{Evidence at Extensive Margin of Exports}

In this section, we turn to the extensive margin of exports. As discussed in the theory section, an immediate extension of our model with market penetration costs that are increasing in market demand can generate an extensive margin of market entry that is a function of input costs. Such an extension suggests that a tariff reduction on imported intermediates ought to affect the composition of destination markets of less productive firms by more than it affects the composition of destination markets of more productive firms.

To examine the pattern along the extensive margin, within the same firm-HS6 product (hereafter $f h$, for short), we distinguish three types of markets, namely, "continuing", "entry", and "exit" according to their status in the pre-liberalization period (2001) and post-liberalization period (2006). If a destination market for a $f h$ combination exists in both 2001 and 2006, it is defined as a "continuing" type; if it appears in 2006 but not in 2001, it is characterized as "entry" type; if it appears in 2001 but not in 2006, it is characterized as "exit" type. Then we compare the changes in (log) export prices and in (log) incomes (GDP per capita) of destination markets for different types of markets using a mean or median (see Table 13). 
Table 13: Changes at the Extensive Margin: Destination Market Types and Initial Productivity

\begin{tabular}{|c|c|c|c|c|c|c|}
\hline & \multicolumn{2}{|c|}{ All Markets } & \multicolumn{2}{|c|}{ Continuing Markets } & \multicolumn{2}{|c|}{ Entry vs. Exit } \\
\hline & $\begin{array}{c}\quad(1) \\
\leq 50 \text { th }\end{array}$ & $\begin{array}{c}(2) \\
>50 \operatorname{th}\end{array}$ & 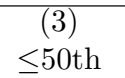 & $\begin{aligned} & (4) \\
> & 50 \text { th }\end{aligned}$ & $\begin{aligned} & (5) \\
\leq & 50 \mathrm{th}\end{aligned}$ & $\begin{aligned} & (6) \\
> & 50 \text { th }\end{aligned}$ \\
\hline \multicolumn{7}{|l|}{ Panel A: changes in export prices at firm-product level } \\
\hline Per Firm-product, median & $15.24 \%$ & $8.21 \%$ & $13.73 \%$ & $7.71 \%$ & $18.09 \%$ & $9.31 \%$ \\
\hline Per Firm-product, mean & $20.57 \%$ & $11.99 \%$ & $19.53 \%$ & $10.56 \%$ & $22.16 \%$ & $14.25 \%$ \\
\hline \multicolumn{7}{|l|}{ Panel B: changes in incomes of destination markets } \\
\hline \multicolumn{7}{|l|}{ Changes in Mean Incomes of Destination Markets: } \\
\hline Per Firm-product, median & $24.79 \%$ & $22.34 \%$ & $22.34 \%$ & $22.34 \%$ & $35.98 \%$ & $31.73 \%$ \\
\hline Per Firm-product, mean & $31.12 \%$ & $27.53 \%$ & $27.13 \%$ & $26.14 \%$ & $37.32 \%$ & $29.73 \%$ \\
\hline \multicolumn{7}{|l|}{ Changes in Median Incomes of Destination Markets: } \\
\hline Per Firm-product, median & $24.80 \%$ & $22.34 \%$ & $22.34 \%$ & $22.34 \%$ & $40.28 \%$ & $34.42 \%$ \\
\hline Per Firm-product, mean & $31.56 \%$ & $28.28 \%$ & $26.88 \%$ & $26.05 \%$ & $38.82 \%$ & $31.82 \%$ \\
\hline
\end{tabular}

In Table 13, we compute the following measures of changes in export prices (see Panel A) and changes in incomes of countries across destination markets (see Panel B) within the same firm-product: the price/income change for all markets and continuing markets, and the price/income change for markets of "entry" versus markets of "exit". 58 Within each firm-product, the price change for "entry-exit" is computed by the average price of each firm-product across all its newly added markets (markets of entry) in 2006 minus the average price across all its dropped markets (markets of exit) in 2001. As for changes in incomes of destination markets, we take either the mean or the median incomes across destinations within each firm-product in 2001 and 2006, and then compute the change over time for each type of market within the same firm-product. We present the mean and median price and income change for all markets, continuing markets, and switching markets (entry vs. exit) in columns 1-2, 3-4, and 5-6, respectively.

The first important message conveyed by Table 13 is that the quality upgrading pattern along extensive margin is related to firm productivity. To show this, we divide sample into low-productivity and high-productivity firms by median in each type of markets. For all three types of markets, the price increase for low-productivity firms is greater than that for high-productivity firms (see the odd columns vs. even columns). The average incomes of destination markets also present the pattern that less productive firms have greater increase than more productive firms with the only exception at continuing

\footnotetext{
${ }^{58}$ According to the literature (e.g., Manova and Zhang (2012a)), there is a positive correlation between product quality and income of destination markets, i.e., firms charge higher export prices in richer markets because they sell higher quality goods there. Hence, we study changes in incomes of destination markets as evidence at extensive margin.
} 
markets.

We then compare different types of markets in Table 13. We start with continuing markets (see columns 3 and 4 ) that reflect the intensive margin effect. The export price increases is greater for less productive firms than for more productive firms at continuing markets. When we move to the results for the sample of all markets in columns 1-2, the compositional shift at the extensive margin suggest that firms are able to enter more high-income markets where the demand for high quality goods is strong and so charge higher export prices, especially in the case of low-productivity firms (see column 1 vs. column 3). We provide more indirect evidence at the extensive margin through switching markets in the last two columns of Table 13, which shows that the price and income increase for low-productivity firms in switching markets (entry vs. exit) is of the greatest magnitude (see column 5 vs. other columns).

Table 14: Heterogeneity in the Effect of Tariff Reductions across Different Types of Markets

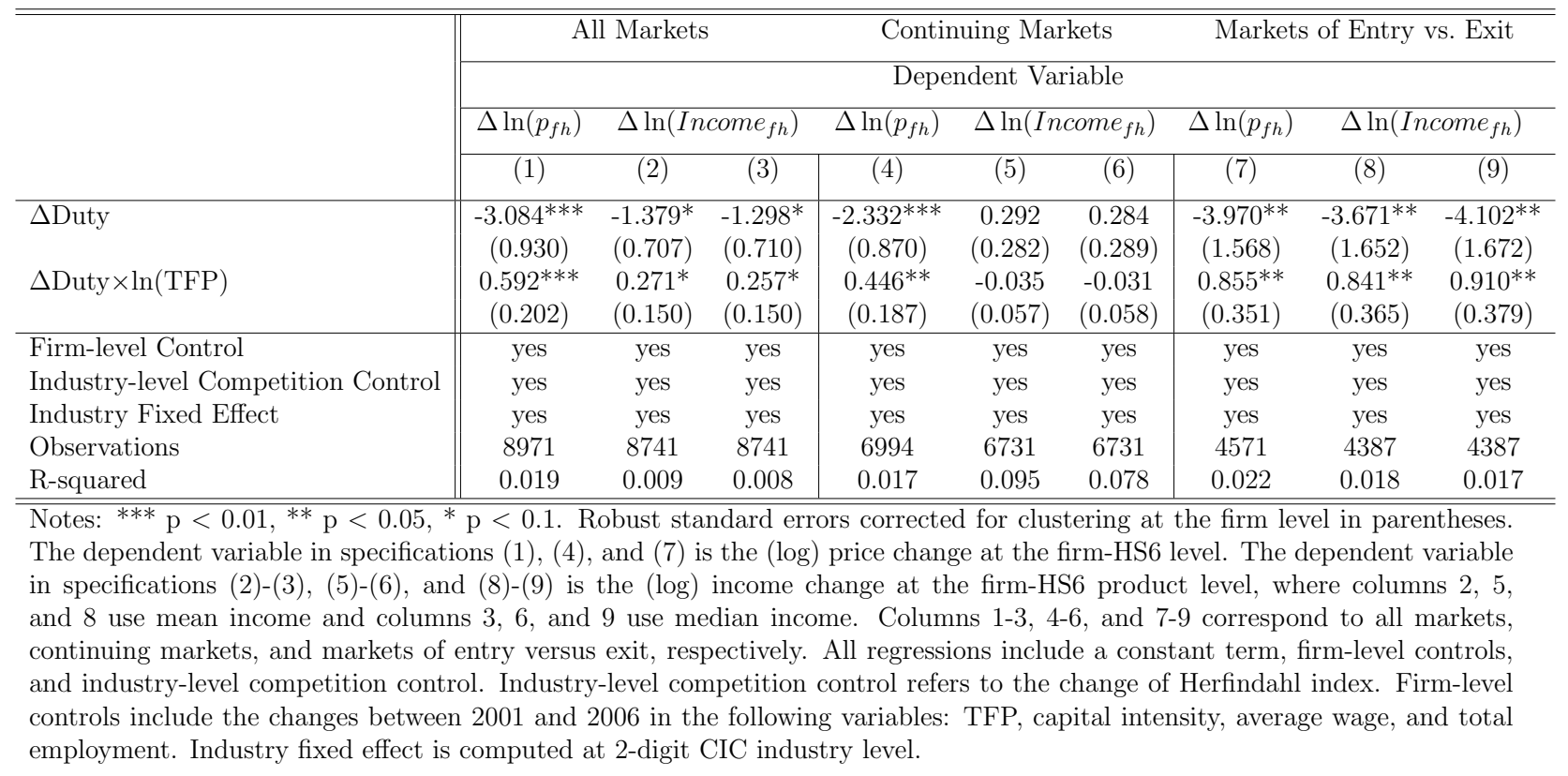

Finally, we replicate the baseline regressions using the price or income change for different types of markets as dependent variable and report results in Table 14. Columns 1-3, 4-6, and 7-9 correspond to all markets, continuing markets, and markets of entry vs. exit, respectively. Again, we start with continuing markets (intensive margin effect, see columns 4-6) that is the focus of our paper. At continuing markets, the price increase significantly depends on initial productivity and the coefficients on the interaction term are significant and consistent with the predicted sign (see column 4); while the income increase and its relation to productivity is not significant at continuing markets which is not surprising (see columns 5-6). The coefficients obtained from the "all markets" sample, shown in columns 1-3, indicate both a price increase and an income increase 
that arises due to the compositional effect. Lastly, the switching markets present the strongest pattern regarding the magnitude of coefficients (see columns 7-9 vs. columns 1-3 and 4-6). This indicates that incumbent firm-product pairs indeed switch from the lower income markets where demand for high quality goods is weak and products are sold at lower prices to higher income markets where demand for high quality goods is strong and products are sold at higher prices, and this pattern is more pronounced for low-productivity firms.

\section{Conclusion}

This paper studies the relationship between quality and productivity under trade liberalization and highlights the heterogeneous response across firms to import tariff reductions. We use highly disaggregated firm-product-level data and the shock of China's entry into the WTO to trace through the manner in which trade liberalization on intermediate inputs induced Chinese firms to upgrade their input and output quality. We find that quality upgrading is primarily achieved by the initially less successful Chinese firms. In other words, the chief beneficiaries of liberalized intermediate input tariffs are not the initially most productive firms but are instead the less productive firms that are operating in industries in which the scope for quality variation is the most pronounced. When initially more capable firms run into diminishing returns to quality upgrading, it is precisely those lower productivity firms that are most likely to upgrade the quality of their exports, increase the quality of their imported intermediates, and upgrade their workforces. They are also more aggressive in entering new, high income markets where demand for high quality goods is strong along the extensive margin. As a result, the gap between low and high productivity firms regarding their quality performance would be reduced under an import tariff reduction. In this sense, trade liberalization appears to have evened the playing field with respect to firm performance.

To explain these facts, we developed a simple heterogeneous-firm trade model that relates a firm's input and output quality choice to its imported intermediates and productivity. The model predicts that low productivity firms are induced to raise their output prices and quality more than high productivity firms do under a reduction in import tariffs. Meanwhile, they increase input prices more for both primary inputs and intermediate inputs than high productivity firms. In addition, at the extensive margin, low productivity firms expand destination markets by entering those with relatively strong demand for high-quality goods. Those tariff reduction effects are more pronounced in industries where the scope for quality differentiation is large.

Our finding has important policy implications that low productivity incumbent firms are potential winners from trade liberalization and this alleviates the concern that trade 
liberalization hurts small and less productive firms. There exists intriguing possibility that a high level of protection may favor firms that are particularly well suited for this environment.

\section{References}

Ackerberg, Daniel, Kevin Caves, and Garth Frazer. 2006. "Structural identification of production functions." University Library of Munich, Germany MPRA Paper 38349 .

Amiti, Mary, and Amit K. Khandelwal. 2013. "Import Competition and Quality Upgrading." The Review of Economics and Statistics, 95(2): 476-490.

Amiti, Mary, and Jozef Konings. 2007. "Trade Liberalization, Intermediate Inputs, and Productivity: Evidence from Indonesia." American Economic Review, 97(5): 16111638.

Amiti, Mary, Oleg Itskhoki, and Jozef Konings. forthcoming. "Importers, Exporters, and Exchange Rate Disconnect." American Economic Review.

Antràs, Pol, Teresa C. Fort, and Felix Tintelnot. 2017. "The Margins of Global Sourcing: Theory and Evidence from U.S. Firms." Harvard University OpenScholar Working Paper 154856.

Bas, Maria, and Vanessa Strauss-Kahn. 2014. "Does importing more inputs raise exports? Firm-level evidence from France." Review of World Economics, 150(2): 241275.

Bas, Maria, and Vanessa Strauss-Kahn. 2015. "Input-trade liberalization, export prices and quality upgrading." Journal of International Economics, 95(2): 250-262.

Brandt, Loren, Johannes Van Biesebroeck, and Yifan Zhang. 2012. "Creative Accounting or Creative Destruction? Firm-level Productivity Growth in Chinese Manufacturing." Journal of Development Economics, 97(2): 339-351.

Broda, Christian, and David E. Weinstein. 2006. "Globalization and the Gains From Variety." The Quarterly Journal of Economics, 121(2): 541-585.

Cai, Hongbin, and Qiao Liu. 2009. "Competition and Corporate Tax Avoidance: Evidence from Chinese Industrial Firms." Economic Journal, 119(537): 764-795.

Chatterjee, Arpita, Rafael Dix-Carneiro, and Jade Vichyanond. 2013. "Multiproduct Firms and Exchange Rate Fluctuations." American Economic Journal: Economic Policy, 5(2): 77-110. 
De Loecker, Jan, and Pinelopi Koujianou Goldberg. 2014. "Firm Performance in a Global Market." Annual Review of Economics, 6(1): 201-227.

De Loecker, Jan, Pinelopi K. Goldberg, Amit K. Khandelwal, and Nina Pavcnik. 2016. "Prices, Markups, and Trade Reform." Econometrica, 84(2): 445-510.

Fan, Haichao, Edwin L.-C. Lai, and Yao Amber Li. 2015. "Credit constraints, quality, and export prices: Theory and evidence from China." Journal of Comparative Economics, 43(2): 390 - 416.

Fan, Haichao, Xiang Gao, Yao Amber Li, and Tuan Anh Luong. 2017. "Trade liberalization and markups: Micro evidence from China." Journal of Comparative Economics.

Fan, Haichao, Yao Amber Li, and Stephen R. Yeaple. 2015. "Trade Liberalization, Quality, and Export Prices." Review of Economics and Statistics, 97(5): 1033-1051.

Feenstra, Robert C., and John Romalis. 2014. "International Prices and Endogenous Quality." The Quarterly Journal of Economics.

Feng, Ling, Zhiyuan Li, and Deborah L. Swenson. 2016. "The connection between imported intermediate inputs and exports: Evidence from Chinese firms." Journal of International Economics, 101(C): 86-101.

Ge, Ying, Huiwen Lai, and Susan Zhu. 2011. "Intermediates Import and Gains from Trade Liberalization." mimeo, University of International Business and Economics.

Goldberg, Pinelopi Koujianou, Amit Kumar Khandelwal, Nina Pavcnik, and Petia Topalova. 2010. "Imported Intermediate Inputs and Domestic Product Growth: Evidence from India." The Quarterly Journal of Economics, 125(4): 1727-1767.

Goldberg, Pinelopi Koujianou, and Nina Pavcnik. 2005. "Trade, wages, and the political economy of trade protection: evidence from the Colombian trade reforms." Journal of International Economics, 66(1): 75-105.

Hallak, Juan Carlos. 2006. "Product quality and the direction of trade." Journal of International Economics, 68(1): 238-265.

Halpern, László, Miklós Koren, and Adam Szeidl. 2015. "Imported Inputs and Productivity." American Economic Review, 105(12): 3660-3703.

Hummels, David, and Alexandre Skiba. 2004. "Shipping the Good Apples Out? An Empirical Confirmation of the Alchian-Allen Conjecture." Journal of Political Economy, 112(6): 1384-1402. 
Ju, Jiandong, Kang Shi, and Shang-Jin Wei. 2012. "Trade Reforms and Current Account Imbalances: When Does the General Equilibrium Effect Overturn a Partial Equilibrium Intuition?" National Bureau of Economic Research, Inc NBER Working Papers 18653.

Kasahara, Hiroyuki, and Joel Rodrigue. 2008. "Does the use of imported intermediates increase productivity? Plant-level evidence." Journal of Development Economics, 87(1): 106-118.

Kee, Hiau Looi, and Heiwai Tang. 2016. "Domestic Value Added in Exports: Theory and Firm Evidence from China." American Economic Review, 106(6): 1402-36.

Khandelwal, Amit. 2010. "The Long and Short (of) Quality Ladders." Review of Economic Studies, 77(4): 1450-1476.

Khandelwal, Amit K., Peter K. Schott, and Shang-Jin Wei. 2013. "Trade Liberalization and Embedded Institutional Reform: Evidence from Chinese Exporters." American Economic Review, 103(6): 2169-95.

Kugler, Maurice, and Eric Verhoogen. 2012. "Prices, Plant Size, and Product Quality." Review of Economic Studies, 79(1): 307-339.

Levinsohn, James, and Amil Petrin. 2003. "Estimating Production Functions Using Inputs to Control for Unobservables." The Review of Economic Studies, 70(2): pp. $317-341$.

Lu, Yi, and Linhui Yu. 2015. "Trade Liberalization and Markup Dispersion: Evidence from China's WTO Accession." American Economic Journal: Applied Economics, 7(4): 221-53.

Manova, Kalina, and Zhihong Yu. 2016. "How firms export: Processing vs. ordinary trade with financial frictions." Journal of International Economics, 100(C): 120-137.

Manova, Kalina, and Zhiwei Zhang. 2012a. "Export Prices Across Firms and Destinations." The Quarterly Journal of Economics, 127: 379-436.

Manova, Kalina, and Zhiwei Zhang. 2012b. "Multi-Product Firms and Product Quality." National Bureau of Economic Research, Inc NBER Working Papers 18637.

McCaig, Brian, and Nina Pavcnik. 2014. "Export Markets and Labor Allocation in a Low-income Country." National Bureau of Economic Research, Inc NBER Working Papers 20455.

McCaig, Brian, and Nina Pavcnik. 2015. "Informal Employment in a Growing and Globalizing Low-Income Country." American Economic Review, 105(5): 545-550. 
Melitz, Marc J. 2003. "The Impact of Trade on Intra-Industry Reallocations and Aggregate Industry Productivity." Econometrica, 71(6): 1695-1725.

Olley, G. Steven, and Ariel Pakes. 1996. "The Dynamics of Productivity in the Telecommunications Equipment Industry." Econometrica, 64(6): pp. 1263-1297.

Pierce, Justin, and Peter Schott. 2013. "The Surprisingly Swift Decline of U.S. Manufacturing Employment." Center for Economic Studies, U.S. Census Bureau Working Papers 13-59.

Rauch, James E. 1999. "Networks versus markets in international trade." Journal of International Economics, 48(1): 7-35.

Topalova, Petia, and Amit Khandelwal. 2011. "Trade Liberalization and Firm Productivity: The Case of India." The Review of Economics and Statistics, 93(3): 9951009.

Trefler, Daniel. 2004. "The Long and Short of the Canada-U. S. Free Trade Agreement." American Economic Review, 94(4): 870-895.

Verhoogen, Eric A. 2008. "Trade, Quality Upgrading, and Wage Inequality in the Mexican Manufacturing Sector." The Quarterly Journal of Economics, 123(2): 489530.

Yu, Miaojie. 2015. "Processing Trade, Tariff Reductions and Firm Productivity: Evidence from Chinese Firms." The Economic Journal, 125(585): 943-988. 


\section{The Online Appendix for: "On the Relationship Between Quality and Productivity: Evidence from China's Accession to the WTO"}

\section{A A Simple Micro foundation for Price Setting}

Consider an industry $i$. In this industry, a firm with productivity $\varphi$ produces output with quality $q$ according to the following production function for quality:

$$
q(\varphi)=g^{-1}\left[\varphi\left(\frac{e_{v}}{1-\mu_{i}}\right)^{1-\mu_{i}}\left(\frac{q_{i M}}{\mu_{i}}\right)^{\mu_{i}}\right]
$$

where $e_{v}$ is the final-good worker's effort (or the quality of labor inputs in producing final good), $q_{i M}$ is the quality of the composite intermediate inputs, $\mu_{i} \in(0,1)$.

The quality of composite intermediate input, $q_{i M}$, is costlessly assembled from a continuum of intermediates that are indexed by $m \in[0,1]$ according to the following function:

$$
q_{i M}=\min \left\{q_{i}(m) \mid \forall m\right\}
$$

where $q_{i}(m) \equiv q_{i m}$ is the quality of intermediate input $m$. The intermediate input market is perfect competition. Producing one unit of an intermediate input of quality $q_{i m}=a(m) e_{i m}$ depends on the intermediate-good worker's effort $e_{i m}$ and intermediategood producer's productivity $a(m)$. Plants face worker quality-wage schedules that are assumed to be upward-sloping and, in the interest of simplicity, linear:

$$
\begin{aligned}
e_{v} & =\kappa_{v} w_{v} \\
e_{i m} & =\kappa_{i m} w_{i m}
\end{aligned}
$$

where $w_{v}$ and $w_{i m}$ are the wages of final-good and intermediate-good worker on a particular production line and $\kappa_{v}$ and $\kappa_{i m}$ are positive constants.

For a cost minimizing firm, $q_{i m}=q_{i M}$ for all $m$. If the firm purchases intermediate $m$ with quality $q_{i m}$ locally, it pays the domestic unit price $c_{d}(m) q_{i M}=\frac{1}{\kappa_{i m} a(m)} q_{i M}$, where $c_{d}(m)=\frac{1}{\kappa_{i m} a(m)}$ denotes the cost to produce unit quality by domestic intermediate-good producer. If the firm imports the intermediate $m$ with quality $q_{i m}$, then it must first pay the unit price of $\tau c_{f}(m) q_{i M}$, where $\tau c_{f}(m)$ denotes the cost to produce unit quality by foreign intermediate-good producer and $\tau>1$ is one plus the tariff rate.

To be simplified, we assume that $c_{d}(m) \equiv c_{d}$ is a constant and $c_{f}(m)$ is strictly decreasing and continuous in $m$. Hence, foreign producers have a comparative advantage in high $m$ goods and domestic producers have a comparative advantage in low $m$ goods. 
We also assume that $\tau c_{f}(0)>c_{d}$ and $\tau c_{f}(1)<c_{d}$ so that there exists a cutoff intermediate that is not imported that is solution to

$$
\tau c_{f}(m)<c_{d}
$$

It follows that the marginal cost to produce the composite intermediate input with one unit of quality $q_{i M}$ satisfies:

$$
\widetilde{P}_{i M}(\tau)=\left(m^{*} c_{d}+\tau \int_{m^{*}}^{1} c_{f}(m) d m\right)
$$

Meanwhile, the marginal cost for one unit of effect $e_{v}$ is $\frac{1}{\kappa_{v}}$. Minimizing the production cost implies that the marginal cost of producing a variety of final good with quality $q$ by a firm with productivity $\varphi$ is $\frac{1}{\varphi}\left(\frac{1}{\kappa_{v}}\right)^{1-\mu_{i}}\left(\widetilde{P}_{i M}(\tau)\right)^{\mu_{i}} g(q)$. Hence, the payment for workers, domestic inputs and foreign intermediate input are:

$$
\begin{aligned}
w(q) & =\left(1-\mu_{i}\right)\left[\frac{1}{\varphi}\left(\frac{1}{\kappa_{v}}\right)^{1-\mu_{i}}\left(\widetilde{P}_{i M}(\tau)\right)^{\mu_{i}}\right] g(q) \\
p_{d} g(q) & =\frac{c_{d}}{\widetilde{P}_{i M}(\tau)} \mu_{i}\left[\frac{1}{\varphi}\left(\frac{1}{\kappa_{v}}\right)^{1-\mu_{i}}\left(\widetilde{P}_{i M}(\tau)\right)^{\mu_{i}}\right] g(q) \\
\tau p_{f}(m) g(q) & =\frac{\tau c_{f}(m)}{\widetilde{P}_{i M}(\tau)} \mu_{i}\left[\frac{1}{\varphi}\left(\frac{1}{\kappa_{v}}\right)^{1-\mu_{i}}\left(\widetilde{P}_{i M}(\tau)\right)^{\mu_{i}}\right] g(q)
\end{aligned}
$$

which provide the microfoundation for their functions in our model.

\section{B Alternative Explanation Using a General Model Setup}

Instead of production function (2), we assume that production function for a firm of productivity $\varphi$ producing quality level $q$ is:

$$
y(\varphi, q)=\min \left(\varphi^{\delta} S(q), \varphi M(q)\right)
$$

where $M(q)$ is a composite input of quality $q, S(q)$ is a composite of other inputs into production, and $\delta \in[0,1]$ measures the comparative advantage of more productive firms in efficiently using intermediate inputs. Here greater productivity will trigger scale effect, whereas asymmetric impact of productivity on input requirements generates lower intermediate input price sensitivity of more productive firms.

$S(q)$ could include any number of inputs such as managerial labor, after sale distribution, etc. Let the price schedule for $S(q)$ be $s w q^{\alpha}$, where $\alpha>0$ and $s>0$. This is similar as the additional fixed costs of distribution and handling output in our benchmark model. 
Different from our assumption, we generate it by allowing it is a function of productivity. This is to say, our benchmark model could be viewed as a special case with $\delta=0$.

As in our benchmark model, the composite intermediate input $M(q)$ is produced via a Leontief production function over a unit interval of individual intermediates, indexed by $m \in[0,1]$. A firm may source an intermediate input from both domestic market and abroad. Same as our benchmark model, the price of the composite intermediate input of quality $q$ is $P_{i M}(q ; \tau)=\widetilde{P}_{i M}(\tau) q^{\alpha}$. Now, the total cost of producing a unit of final output satisfies:

$$
C_{i}(q ; \varphi, \tau)=\left(\frac{s w}{\varphi^{\delta}}+\frac{\widetilde{P}_{M}(\tau)}{\varphi}\right) q^{\alpha}
$$

Moreover, we also assume that product design incurs fixed costs and these fixed costs depend on the number of attributes that the firm chooses to build into the variety, which is assumed to be $f q^{\beta}$.

The firm chooses its price, $p$, and its quality, $q$, to maximize its export profits of the firm, which are given by

$$
\pi(\varphi)=\max _{p, q}\left((p-C(q ; \varphi, \tau)) x(q, p, \omega)-f q^{\beta}\right)
$$

Solving for the first-order conditions for the choice of quality of outputs and inputs and the price of the final good, we find that the optimal quality choice is given by

$$
q=\left((\eta-\alpha(\sigma-1)) \frac{A}{\beta f}\left(\frac{s w}{\varphi^{\delta}}+\frac{\widetilde{P}_{M}(\tau)}{\varphi}\right)^{1-\sigma}\right)^{\frac{1}{\beta-\eta+\alpha(\sigma-1)}}
$$

where $A=\frac{1}{\sigma}\left(\frac{\sigma}{\sigma-1}\right)^{1-\sigma} \nu E P^{\sigma-1}$ is the mark-up adjusted demand level common to all firms in the same industry, and the optimal price is given by

$$
p=\frac{\sigma}{\sigma-1}\left((\eta-\alpha(\sigma-1)) \frac{A}{\beta f}\right)^{\frac{\alpha}{\beta-\eta+\alpha(\sigma-1)}}\left(\frac{s w}{\varphi^{\delta}}+\frac{\widetilde{P}_{M}(\tau)}{\varphi}\right)^{\frac{\beta-\eta}{\beta-\eta+\alpha(\sigma-1)}}
$$

Note that an interior solution requires that $\beta>\eta-\alpha(\sigma-1)>0$, which we assume holds henceforth.

Totally differentiating equations (A.8) and (A.9), we obtain

$$
\begin{aligned}
\frac{d q}{d \widetilde{P}_{M}(\tau)} \frac{\widetilde{P}_{M}(\tau)}{q} & =-\frac{\sigma-1}{\beta-\eta+\alpha(\sigma-1)} \frac{\widetilde{P}_{M}(\tau) / w}{s \varphi^{1-\delta}+\widetilde{P}_{M}(\tau) / w} \\
\frac{d p}{d \widetilde{P}_{M}(\tau)} \frac{\widetilde{P}_{M}(\tau)}{p} & =-\frac{\eta-\beta}{\beta-\eta+\alpha(\sigma-1)} \frac{\widetilde{P}_{M}(\tau) / w}{s \varphi^{1-\delta}+\widetilde{P}_{M}(\tau) / w}
\end{aligned}
$$


So the elasticity of quality and price with respect to the price of imported intermediates is decreasing in productivity as long as $\delta<1$. A tariff reduction on imported intermediates decrease the price of imported intermediates and hence raise the quality of inputs used within the firm. In addition, this impact on quality and price must be greater for less productive firms. The impact of tariff reductions on quality and price satisfy:

$$
\begin{aligned}
& \frac{d q}{q}=-\frac{\sigma-1}{\beta-\eta+\alpha(\sigma-1)} \frac{\widetilde{P}_{M}(\tau) / w}{s \varphi^{1-\delta}+\widetilde{P}_{M}(\tau) / w} \frac{\tau \int_{m^{*}}^{1} p_{f}(m) d m}{\int_{0}^{m^{*}} p_{d} d m+\tau \int_{m^{*}}^{1} p_{f}(m) d m} \frac{d \tau}{\tau}( \\
& \frac{d p}{p}=-\frac{\eta-\beta}{\beta-\eta+\alpha(\sigma-1)} \frac{\widetilde{P}_{M}(\tau) / w}{s \varphi^{1-\delta}+\widetilde{P}_{M}(\tau) / w} \frac{\tau \int_{m^{*}}^{1} p_{f}(m) d m}{\int_{0}^{m^{*}} p_{d} d m+\tau \int_{m^{*}}^{1} p_{f}(m) d m} \frac{d \tau}{\tau}\left(A^{\prime}\right.
\end{aligned}
$$

Hence, our propositions in our benchmark model still hold.

\section{Quantity-Based Production Function Estimation}

We rewrite production function as

$$
q_{f t}=\beta_{l} l_{f t}+\beta_{k} k_{f t}+\beta_{m} m_{f t}+\omega_{f t}+\varepsilon_{f t}
$$

where $l_{f t}, k_{f t}, m_{f t}$ is the vector of (log) physical inputs: labor, capital and materials, $\beta_{l}, \beta_{k}$ and $\beta_{m}$ are the production function coefficients to be estimated; $\omega_{f t}$ is firm-specific productivity; and $\varepsilon_{f t}$ is an i.i.d. error term.

We use the merged firm-level data, built upon the NBSC annual survey of manufacturing firms and another dataset from NBSC that contains physical quantity output of firms' main products during the same sample period in estimating physical TFP. Although this quantity output database provides the output quantity at 5-digit CPC level for each firm, we only have information on production inputs (e.g., employment, capital and material) at firm-level. As a result, we focus on single-product firms based on this merged sample.

Now this new sample provides the physical quantity of output $q_{f t}$ and the information on employment, which allows us to measure labor input $l_{f t}$ in physical quantity. However, capital $k_{f t}$ and material $m_{f t}$ inputs are only available in value terms; specifically, we use the value of fixed assets as a measure of $k_{f t}$ and the total value of intermediate materials as a measure of $m_{f t}$. To back out the physical quantity of $k_{f t}$ and $m_{f t}$, we deflate these values with the sector-specific price indices provided by Brandt, Van Biesebroeck and Zhang (2012). As a result, the true estimation specification of equation (A.14) is:

$$
q_{f t}=\beta_{l} l_{f t}+\beta_{k} \widetilde{k}_{f t}+\beta_{m} \widetilde{m}_{f t}-\left(\beta_{k} w_{f t}^{k}+\beta_{m} w_{f t}^{m}\right)+\omega_{f t}+\varepsilon_{f t}
$$


where $\widetilde{k}_{f t}, \widetilde{m}_{f t}$ denote the (observed) vector of deflated capital and material inputs, deflated by a sector-specific price index; $w_{f t}^{x}$ denotes the deviation of the unoberserved $(\log )$ firm-specific input price from the (log) industry-wide input price index. Hence, consistent estimation requires the proper control for unobserved firm productivity $\omega_{f t}$ and the omitted firm-specific input price $B_{t}\left(w_{f t}^{k}, w_{f t}^{m}, \beta_{k}, \beta_{m}\right)=-\left(\beta_{k} w_{f t}^{k}+\beta_{m} w_{f t}^{m}\right)$.

To control for omitted firm-specific input prices, we follow De Loecker et al. (2016) and $\mathrm{Lu}$ and $\mathrm{Yu}(2015)$ by assuming that firm-specific input prices are a function of output price $\left(p_{f t}\right)$, market share $\left(m s_{f t}\right)$, and exporter status $\left(e_{f t}\right)$, i.e., $w_{f t}^{x}=w_{t}\left(p_{f t}, m s_{f t}, e_{f t}\right)$ for $x=k$ or $m$. As a results, $B_{f t}$ becomes $B\left(\left(p_{f t}, m s_{f t}, e_{f t}\right), \delta\right)$, where $\delta$ depends on the parameters in $w_{t}(\cdot)$. To proxy productivity, Levinsohn and Petrin (2003) assume that $\widetilde{m}_{f t}=m_{t}\left(\omega_{f t}, l_{f t}, \widetilde{k}_{i t}, \mathbf{Z}_{f t}\right)$, where $\mathbf{Z}_{f t}$ is a vector of controls including output price $\left(p_{f t}\right)$, market share $\left(m s_{f t}\right)$, and exporter status $\left(e_{f t}\right)$, input tariff $\left(\tau_{f t}^{\text {input }}\right)$, output tariff $\left(\tau_{f t}^{\text {output }}\right)$, product dummies and region dummies.

In the first stage, we estimate the following equation:

$$
q_{f t}=\phi_{t}\left(l_{f t}, \widetilde{k}_{i t}, \widetilde{m}_{f t}, \mathbf{Z}_{f t}\right)+\varepsilon_{f t}
$$

We approximate the function with a third-order polynomial in all its elements, with the exception of product dummies and region dummies. We add the product dummies and region dummies linearly and yields an estimate of predicted output $\widehat{\phi}_{f t}$ by getting rid of unanticipated shocks and/or measurement error $\varepsilon_{f t}$. One can then express productivity $\omega_{f t}$ as a function of data and parameters. In particular, we have:

$$
\omega_{f t}=\widehat{\phi}_{f t}-\beta_{l} l_{f t}-\beta_{k} \widetilde{k}_{f t}-\beta_{m} \widetilde{m}_{f t}-B\left(\left(p_{f t}, m s_{f t}, e_{f t}\right), \delta\right)
$$

Meanwhile, to recover the parameter $\beta_{l}, \beta_{k}, \beta_{m}$ and parameter vector $\delta$ in the second stage, we consider the following law of motion for productivity:

$$
\omega_{f t}=g\left(\omega_{f t-1}, \tau_{f t-1}^{i n p u t}, \tau_{f t-1}^{i n p u t}, e_{f t-1}\right)+\xi_{f t}
$$

We form moments based on the innovation in the productivity shock $\xi_{f t}$, which satisfies:

$$
\xi_{f t}=\omega_{f t}-E\left(\omega_{f t} \mid \omega_{f t-1}, \tau_{f t-1}^{i n p u t}, \tau_{f t-1}^{\text {input }}, e_{f t-1}\right)
$$

The moments that identify the parameters are:

$$
E\left(\xi_{f t} \mathbf{Y}_{f t}\right)=0
$$

where $\mathbf{Y}_{f t}$ contains lagged labor, current capital, lag materials, as well as lag output prices, lagged market shares, lagged input/output tariff, lagged export status, and their 
appropriate interactions of inputs. Productivity is given by $\omega_{f t}=\widehat{\phi}_{f t}-\beta_{l} l_{f t}-\beta_{k} \widetilde{k}_{f t}-$ $\beta_{m} \widetilde{m}_{f t}-B\left(\left(p_{f t}, m s_{f t}, e_{f t}\right), \delta\right)$.

\section{Supplementary Figures and Tables}

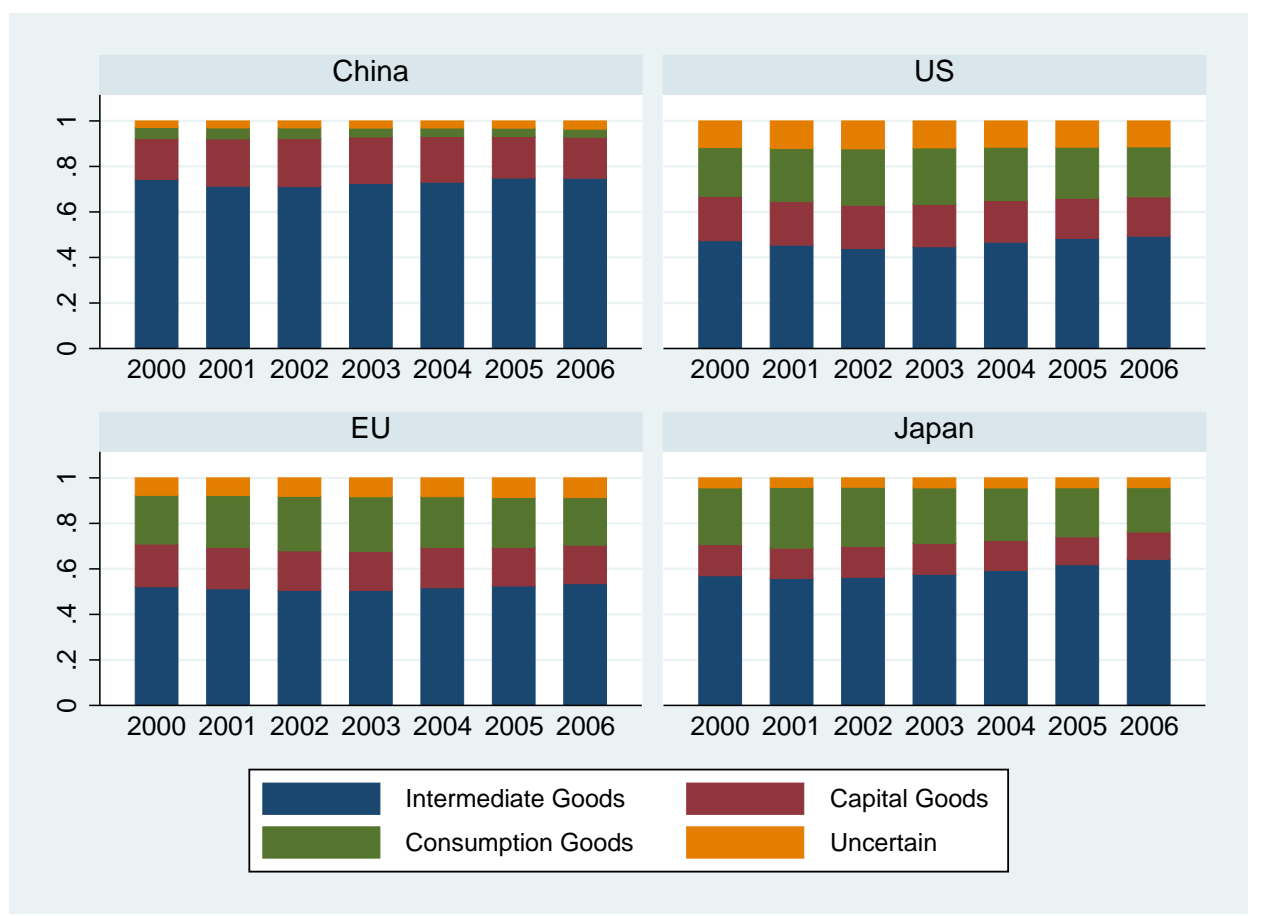

Figure A.1: Share of Four Categories of Goods in Total Imports

Notes: Bilateral trade data at HS6 product level from CEPII are grouped into four categories of products according to BEC (Broad Economic Categories) and then aggregated into the total import values of the captioned countries from the rest of the world. 

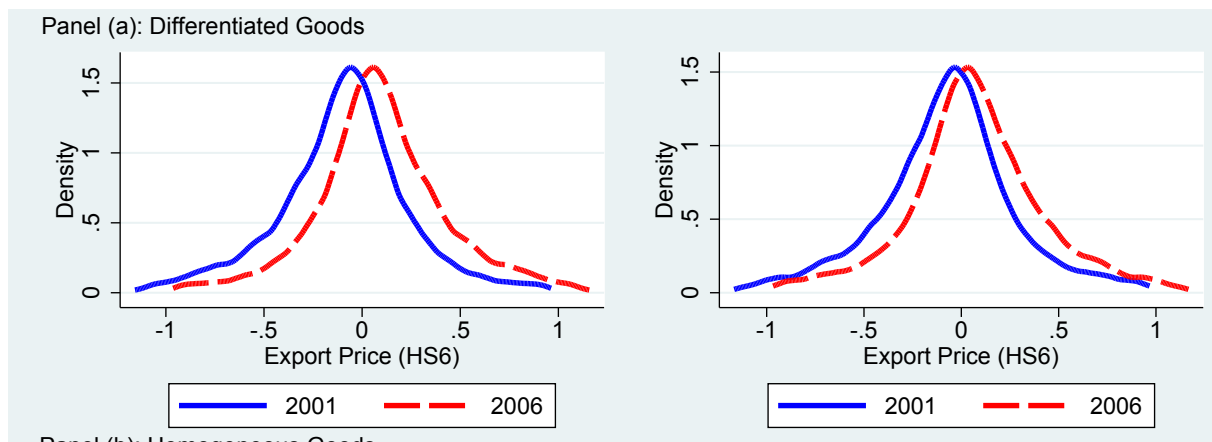

Panel (b): Homogeneous Goods
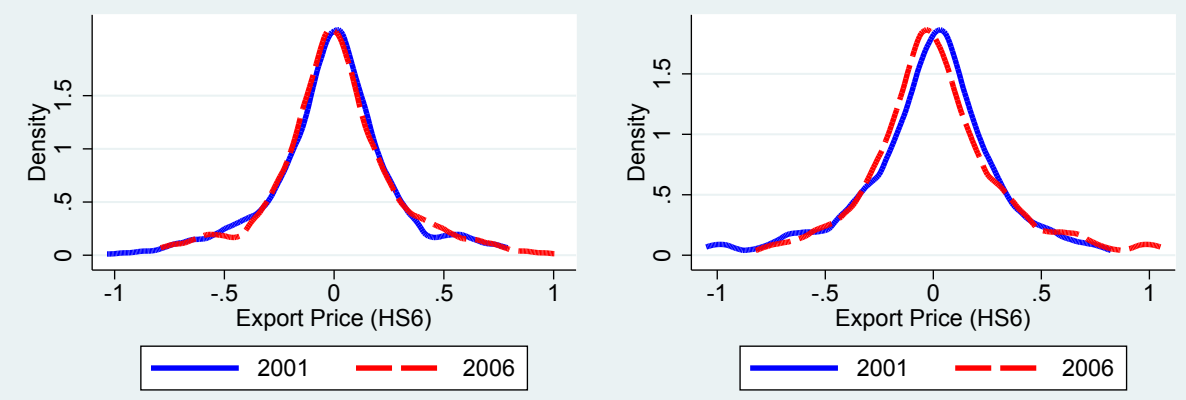

Figure A.2: Price Distributions for Differentiated Goods and Homogeneous Goods (HS6 products)

Notes: Prices for continuing firm-HS6 pairs are in logarithm. Panel (a) presents price distribution for differentiated goods (see the top panel) and Panel (b) presents price distribution for homogeneous goods (see the bottom panel). Graphs in the left panel refer to firms with lower initial productivity (i.e., productivity lower than the median) and graphs in the right panel refer to firms with higher initial productivity (i.e., productivity above the median). Price distributions are drawn by regressing export prices on firm-HS6 fixed effects and then plotting the residuals, as in De Loecker et al. (2016). 
Table A.1: Basic Results Using an Alternative Weighting Scheme of Main Tariff Measure

\begin{tabular}{|c|c|c|c|c|c|c|}
\hline & \multicolumn{6}{|c|}{ Dependent Variable: $\Delta \ln ($ price $)$} \\
\hline & \multicolumn{3}{|c|}{$\Delta \ln \left(p_{f h c}\right)$} & \multicolumn{3}{|c|}{$\Delta \ln \left(p_{f h}\right)$} \\
\hline & (1) & $(2)$ & (3) & (4) & $(5)$ & (6) \\
\hline$\Delta$ Duty & $\begin{array}{c}-7.602^{* *} \\
(3.864)\end{array}$ & $\begin{array}{c}-8.976^{* *} \\
(4.115)\end{array}$ & $\begin{array}{l}-7.715^{*} \\
(4.235)\end{array}$ & $\begin{array}{c}-15.215^{* * *} \\
(5.413)\end{array}$ & $\begin{array}{c}-16.074^{* * *} \\
(5.401)\end{array}$ & $\begin{array}{c}-16.516^{* * *} \\
(5.749)\end{array}$ \\
\hline$\triangle$ Duty $\times$ High_TFP & $\begin{array}{c}2.449^{* * *} \\
(0.881)\end{array}$ & $\begin{array}{c}2.608^{* * *} \\
(0.948)\end{array}$ & $\begin{array}{r}2.110^{* *} \\
(0.959)\end{array}$ & $\begin{array}{c}3.862^{* * *} \\
(1.201)\end{array}$ & $\begin{array}{c}3.803^{* * *} \\
(1.198)\end{array}$ & $\begin{array}{c}3.629^{* * *} \\
(1.225)\end{array}$ \\
\hline$\Delta \log (\mathrm{TFP})$ & & & $\begin{array}{c}0.034^{* * *} \\
(0.012)\end{array}$ & & & $\begin{array}{c}0.023 \\
(0.016)\end{array}$ \\
\hline$\Delta \log ($ Capital/Labor $)$ & & & $\begin{array}{c}0.021 \\
(0.016)\end{array}$ & & & $\begin{array}{c}0.039 \\
(0.024)\end{array}$ \\
\hline$\Delta \log ($ Labor $)$ & & & $\begin{array}{c}0.009 \\
(0.017)\end{array}$ & & & $\begin{array}{c}0.030 \\
(0.025)\end{array}$ \\
\hline$\Delta \log ($ Wage $)$ & & & $\begin{array}{c}0.007 \\
(0.021)\end{array}$ & & & $\begin{array}{l}0.019 \\
(0.026)\end{array}$ \\
\hline$\Delta$ Import Share & & & $\begin{array}{c}0.149 \\
(0.103)\end{array}$ & & & $\begin{array}{l}0.217 \\
(0.152)\end{array}$ \\
\hline$\Delta \mathrm{HHI}$ & & & $\begin{array}{c}0.801^{* * *} \\
(0.235)\end{array}$ & & & $\begin{array}{c}0.469 \\
(0.315)\end{array}$ \\
\hline Industry Fixed Effect & no & yes & yes & no & yes & yes \\
\hline Observations & 14082 & 14082 & 14082 & 7217 & 7217 & 7217 \\
\hline R-squared & 0.002 & 0.015 & 0.018 & 0.003 & 0.018 & 0.020 \\
\hline
\end{tabular}

Notes: ${ }^{* * *} \mathrm{p}<0.01,{ }^{* *} \mathrm{p}<0.05,{ }^{*} \mathrm{p}<0.1$. Robust standard errors corrected for clustering at the firm level in parentheses. The dependent variable in specifications (1)-(3) is the (log) price change at the firm-HS6-country level, computed as the log price difference of the same firm-HS6-country triplet from 2001 to 2006. The dependent variable in specifications (4)-(6) is the $(\log )$ price change at the firm-HS6 product level. All regressions include a constant term. Herfindahl index $(H H I)$ is computed at the 4-digit CIC industry in China. Industry fixed effect is computed at 2-digit CIC industry level. 
Table A.2: Effects of Tariff Reductions on Export Prices (Demean)

\begin{tabular}{|c|c|c|c|c|}
\hline & \multicolumn{4}{|c|}{ Dependent Variable: $\Delta \ln ($ price $)$} \\
\hline & \multicolumn{2}{|c|}{$\Delta \ln \left(p_{f h c}\right)$} & \multicolumn{2}{|c|}{$\Delta \ln \left(p_{f h}\right)$} \\
\hline & (1) & $(2)$ & $(3)$ & (4) \\
\hline$\Delta$ Duty & $\begin{array}{c}-0.399^{* *} \\
(0.199)\end{array}$ & $\begin{array}{l}-0.298 \\
(0.207)\end{array}$ & $\begin{array}{c}-0.719^{* * *} \\
(0.252)\end{array}$ & $\begin{array}{c}-0.600^{* *} \\
(0.252)\end{array}$ \\
\hline$\Delta$ Duty $\times \ln ($ TFP $)$ & $\begin{array}{c}0.490 * * * \\
(0.139)\end{array}$ & $\begin{array}{c}0.505^{* * *} \\
(0.150)\end{array}$ & $\begin{array}{c}0.652^{* * *} \\
(0.188)\end{array}$ & $\begin{array}{c}0.592^{* * * *} \\
(0.202)\end{array}$ \\
\hline$\Delta \ln (\mathrm{TFP})$ & & $\begin{array}{l}0.021^{*} \\
(0.011)\end{array}$ & & $\begin{array}{c}0.021 \\
(0.014)\end{array}$ \\
\hline$\Delta \ln ($ Capital/Labor $)$ & & $\begin{array}{c}0.020 \\
(0.013)\end{array}$ & & $\begin{array}{l}0.037^{*} \\
(0.020)\end{array}$ \\
\hline$\Delta \ln ($ Labor $)$ & & $\begin{array}{c}0.007 \\
(0.015)\end{array}$ & & $\begin{array}{c}0.033 \\
(0.022)\end{array}$ \\
\hline$\Delta \ln ($ Wage $)$ & & $\begin{array}{c}0.004 \\
(0.018)\end{array}$ & & $\begin{array}{c}0.016 \\
(0.022)\end{array}$ \\
\hline$\Delta \mathrm{HHI}$ & & $\begin{array}{c}0.856^{* * *} \\
(0.239) \\
\end{array}$ & & $\begin{array}{c}0.432 \\
(0.306)\end{array}$ \\
\hline Industry Fixed Effect & no & yes & no & yes \\
\hline Observations & 16907 & 16907 & 8971 & 8971 \\
\hline R-square & 0.002 & 0.017 & 0.004 & 0.019 \\
\hline
\end{tabular}

Notes: ${ }^{* * *} \mathrm{p}<0.01,{ }^{* *} \mathrm{p}<0.05,{ }^{*} \mathrm{p}<0.1$. Robust standard errors corrected for clustering at the firm level in parentheses. The dependent variable in specifications (1)-(2) is the (log) price change at the firmHS6-country level. The dependent variable in specifications (3)-(4) is the $(\log )$ price change at the firm-HS6 product level. We demean $(\log )$ TFP over the estimating sample before interacting it. All regressions include a constant term. Herfindahl index $(H H I)$ is computed at the 4-digit CIC industry in China. Industry fixed effect is computed at 2-digit CIC industry level. 
Table A.3: Breakout of the Effect of Tariff Reductions on Export Prices (Three-Segment of TFP)

\begin{tabular}{|c|c|c|c|c|c|c|c|c|}
\hline & \multicolumn{8}{|c|}{ Dependent Variable: $\Delta \ln ($ price $)$} \\
\hline & \multicolumn{4}{|c|}{$($ top $1 / 3) ;($ medium $1 / 3) ;($ bottom $1 / 3)$} & \multicolumn{4}{|c|}{$(\geq 75 \%) ;(\geq 25 \%$ and $\leq 75 \%) ;(\leq 25 \%)$} \\
\hline & \multicolumn{2}{|c|}{$\Delta \ln \left(p_{f h c}\right)$} & \multicolumn{2}{|c|}{$\Delta \ln \left(p_{f h}\right)$} & \multicolumn{2}{|c|}{$\Delta \ln \left(p_{f h c}\right)$} & \multicolumn{2}{|c|}{$\Delta \ln \left(p_{f h}\right)$} \\
\hline & (1) & $(2)$ & $(3)$ & $(4)$ & $(5)$ & (6) & $(7)$ & $(8)$ \\
\hline$\Delta$ Duty & $\begin{array}{c}-0.621^{*} \\
(0.329)\end{array}$ & $\begin{array}{c}-0.446 \\
(0.328)\end{array}$ & $\begin{array}{c}-0.991^{* * *} \\
(0.382)\end{array}$ & $\begin{array}{c}-0.789^{* *} \\
(0.386)\end{array}$ & $\begin{array}{c}-0.820^{* *} \\
(0.360)\end{array}$ & $\begin{array}{c}-0.637^{*} \\
(0.358)\end{array}$ & $\begin{array}{c}-1.700^{* * *} \\
(0.399)\end{array}$ & $\begin{array}{c}-1.519^{* * *} \\
(0.402)\end{array}$ \\
\hline$\triangle$ Duty $\times$ Medium_TFP & $\begin{array}{c}0.162 \\
(0.330)\end{array}$ & $\begin{array}{c}0.092 \\
(0.333)\end{array}$ & $\begin{array}{c}0.273 \\
(0.405)\end{array}$ & $\begin{array}{c}0.122 \\
(0.409)\end{array}$ & $\begin{array}{c}0.446 \\
(0.350)\end{array}$ & $\begin{array}{c}0.360 \\
(0.353)\end{array}$ & $\begin{array}{c}1.097^{* * *} * \\
(0.407)\end{array}$ & $\begin{array}{c}0.970^{* *} \\
(0.414)\end{array}$ \\
\hline$\Delta$ Duty $\times H_{i g h \_} T F P$ & $\begin{array}{c}0.926^{* *} \\
(0.370)\end{array}$ & $\begin{array}{c}0.623^{*} \\
(0.379)\end{array}$ & $\begin{array}{l}1.054^{* *} \\
(0.454)\end{array}$ & $\begin{array}{l}0.776^{*} \\
(0.468)\end{array}$ & $\begin{array}{c}1.197^{* * *} * \\
(0.419)\end{array}$ & $\begin{array}{c}0.872^{* *} \\
(0.428)\end{array}$ & $\begin{array}{c}2.042^{* * *} * \\
(0.493)\end{array}$ & $\begin{array}{c}1.809^{* * *} \\
(0.509)\end{array}$ \\
\hline$\Delta \ln (\mathrm{TFP})$ & & $\begin{array}{c}0.029^{* * *} \\
(0.011)\end{array}$ & & $\begin{array}{c}0.030^{* *} \\
(0.014)\end{array}$ & & $\begin{array}{c}0.028^{* *} \\
(0.011)\end{array}$ & & $\begin{array}{c}0.022 \\
(0.014)\end{array}$ \\
\hline$\Delta \ln ($ Capital/Labor $)$ & & $\begin{array}{c}0.021 \\
(0.013)\end{array}$ & & $\begin{array}{c}0.039^{*} \\
(0.020)\end{array}$ & & $\begin{array}{c}0.021 \\
(0.013)\end{array}$ & & $\begin{array}{c}0.040^{* *} \\
(0.020)\end{array}$ \\
\hline$\Delta \ln ($ Labor $)$ & & $\begin{array}{c}0.005 \\
(0.015)\end{array}$ & & $\begin{array}{c}0.030 \\
(0.022)\end{array}$ & & $\begin{array}{c}0.005 \\
(0.015)\end{array}$ & & $\begin{array}{c}0.034 \\
(0.021)\end{array}$ \\
\hline$\Delta \ln ($ Wage $)$ & & $\begin{array}{c}0.004 \\
(0.018)\end{array}$ & & $\begin{array}{c}0.017 \\
(0.022)\end{array}$ & & $\begin{array}{c}0.003 \\
(0.018)\end{array}$ & & $\begin{array}{c}0.015 \\
(0.022)\end{array}$ \\
\hline$\Delta \mathrm{HHI}$ & & $\begin{array}{c}0.846^{* * *} \\
(0.246)\end{array}$ & & $\begin{array}{c}0.414 \\
(0.313)\end{array}$ & & $\begin{array}{c}0.869^{* * *} \\
(0.241)\end{array}$ & & $\begin{array}{c}0.438 \\
(0.306)\end{array}$ \\
\hline Industry Fixed Effect & yes & yes & yes & yes & yes & yes & yes & yes \\
\hline Observations & 16907 & 16907 & 8971 & 8971 & 16907 & 16907 & 8971 & 8971 \\
\hline R-squared & 0.014 & 0.016 & 0.016 & 0.018 & 0.014 & 0.016 & 0.017 & 0.019 \\
\hline
\end{tabular}

Notes: ${ }^{* * *} \mathrm{p}<0.01,{ }^{* *} \mathrm{p}<0.05,{ }^{*} \mathrm{p}<0.1$. Robust standard errors corrected for clustering at the firm level in parentheses. Low-TFP firms are the omitted group. The dependent variable in specifications (1)-(2) and (5)-(6) is the $(\mathrm{log})$ price change at the firm-HS6-country level, computed as the log price difference of the same firm-HS6-country triplet from 2001 to 2006 . The dependent variable in specifications (3)-(4) and (7)-(8) is the $(\log )$ price change at the firm-HS6 product level. All regressions include a constant term. Herfindahl index $(H H I)$ is computed at the 4-digit CIC industry in China. Industry fixed effect is computed at 2-digit CIC industry level. In specifications (1)-(4), we use 33 percentile and 67 percentile as cutting points to divide firms into three groups-low-TFP (below 33 percentile), medium-TFP (between 33 and 67 percentile), and high-TFP (above 67 percentile) firms; in specifications (5)-(8), we use 25 and 75 percentile as cutting points and divide all firms into low-TFP (below 25 percentile), medium-TFP (between 25 and 75 percentile), and high-TFP firms (above 75 percentile). 
Table A.4: Effect of Tariff Reductions by the Scope for Quality Differentiation Using Alternative Classification Based on Rauch's (1999)

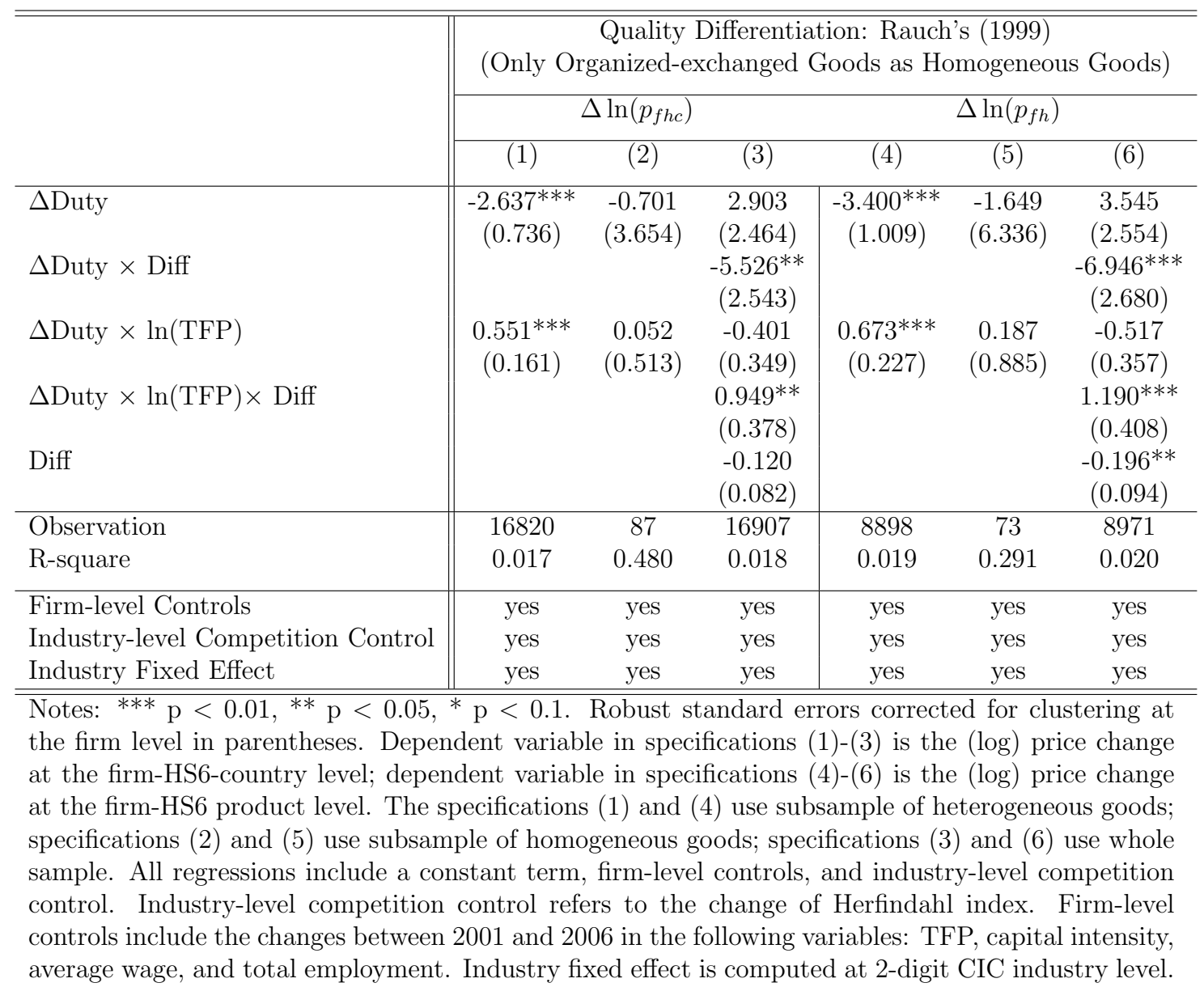


Table A.5: Impact of tariff reductions on export prices with different-period difference

\begin{tabular}{|c|c|c|c|c|c|c|c|c|c|}
\hline & \multicolumn{9}{|c|}{ Dependent Variable: $\Delta \ln ($ price $)$} \\
\hline & \multicolumn{3}{|c|}{ Whole Sample } & \multicolumn{3}{|c|}{ Differentiated Goods } & \multicolumn{3}{|c|}{ Homogeneous Goods } \\
\hline & 2-year & 3-year & 4-year & 2-year & 3-year & 4-year & 2-year & 3-year & 4-year \\
\hline & $(1)$ & $(2)$ & (3) & $(4)$ & $(5)$ & (6) & (7) & (8) & $(9)$ \\
\hline \multicolumn{10}{|c|}{ Panel A: dependent variable $=\Delta \log \left(p_{f h c}\right)$} \\
\hline$\Delta$ Duty & $\begin{array}{c}-0.966^{* *} \\
(0.397)\end{array}$ & $\begin{array}{c}-1.196^{* *} \\
(0.495)\end{array}$ & $\begin{array}{c}-1.486^{* *} \\
(0.602)\end{array}$ & $\begin{array}{c}-1.073^{* *} \\
(0.436)\end{array}$ & $\begin{array}{c}-1.419^{* *} \\
(0.559)\end{array}$ & $\begin{array}{c}-1.452^{* *} \\
(0.646)\end{array}$ & $\begin{array}{l}-0.185 \\
(0.822)\end{array}$ & $\begin{array}{c}0.048 \\
(0.805)\end{array}$ & $\begin{array}{l}-1.495 \\
(1.225)\end{array}$ \\
\hline$\Delta$ Duty $\times \ln ($ TFP $)$ & $\begin{array}{c}0.191^{* *} \\
(0.084)\end{array}$ & $\begin{array}{c}0.261^{* *} \\
(0.112)\end{array}$ & $\begin{array}{c}0.303^{* *} \\
(0.134)\end{array}$ & $\begin{array}{c}0.213^{* *} \\
(0.092)\end{array}$ & $\begin{array}{c}0.313^{* *} \\
(0.128)\end{array}$ & $\begin{array}{c}0.291^{* *} \\
(0.145)\end{array}$ & $\begin{array}{c}0.042 \\
(0.161)\end{array}$ & $\begin{array}{c}0.008 \\
(0.152)\end{array}$ & $\begin{array}{c}0.369 \\
(0.253)\end{array}$ \\
\hline Observation & 158495 & 79736 & 37351 & 140227 & 70389 & 33041 & 18268 & 9347 & 4310 \\
\hline R-square & 0.004 & 0.006 & 0.010 & 0.003 & 0.005 & 0.008 & 0.008 & 0.021 & 0.036 \\
\hline \multicolumn{10}{|c|}{ Panel B: dependent variable $=\Delta \log \left(p_{f h}\right)$} \\
\hline$\Delta$ Duty & $\begin{array}{c}-1.876^{* * *} \\
(0.540)\end{array}$ & $\begin{array}{c}-1.378^{* *} \\
(0.588)\end{array}$ & $\begin{array}{c}-1.875^{* *} \\
(0.800)\end{array}$ & $\begin{array}{c}-2.162^{* * *} \\
(0.655)\end{array}$ & $\begin{array}{c}-1.746^{* *} \\
(0.685)\end{array}$ & $\begin{array}{c}-1.961^{* *} \\
(0.896)\end{array}$ & $\begin{array}{l}-0.846 \\
(0.633)\end{array}$ & $\begin{array}{c}1.073 \\
(1.004)\end{array}$ & $\begin{array}{l}-0.590 \\
(1.305)\end{array}$ \\
\hline$\Delta$ Duty $\times \ln (\mathrm{TFP})$ & $\begin{array}{c}0.381^{* * * *} \\
(0.113)\end{array}$ & $\begin{array}{c}0.263^{* *} \\
(0.130)\end{array}$ & $\begin{array}{c}0.361^{* *} \\
(0.174)\end{array}$ & $\begin{array}{c}0.452^{* * *} \\
(0.139)\end{array}$ & $\begin{array}{c}0.324^{* *} \\
(0.157)\end{array}$ & $\begin{array}{c}0.359^{*} \\
(0.196)\end{array}$ & $\begin{array}{c}0.139 \\
(0.116)\end{array}$ & $\begin{array}{l}-0.132 \\
(0.183)\end{array}$ & $\begin{array}{c}0.219 \\
(0.255)\end{array}$ \\
\hline Observation & 68983 & 37175 & 18455 & 59787 & 32088 & 15925 & 9196 & 5087 & 2530 \\
\hline R-square & 0.003 & 0.006 & 0.011 & 0.003 & 0.005 & 0.009 & 0.006 & 0.018 & 0.035 \\
\hline \multicolumn{10}{|l|}{ Panels $A$ and $B$ : } \\
\hline \multirow{3}{*}{$\begin{array}{l}\text { Firm-level Controls } \\
\text { Industry-level Competition Control } \\
\text { Industry Fixed Effect }\end{array}$} & yes & yes & yes & yes & yes & yes & yes & yes & yes \\
\hline & yes & yes & yes & yes & yes & yes & yes & yes & yes \\
\hline & yes & yes & yes & yes & yes & yes & yes & yes & yes \\
\hline \multicolumn{10}{|c|}{$\begin{array}{l}\text { Notes: }{ }^{* *} \mathrm{p}<0.01,{ }^{* *} \mathrm{p}<0.05,{ }^{*} \mathrm{p}<0.1 \text {. Robust standard errors corrected for clustering at the firm level in parentheses. } \\
\text { Columns }(1),(4),(7) \text { correspond to 2-year difference; columns }(2),(5),(8) \text { correspond to } 3 \text {-year difference; columns }(3),(6), \\
\text { (9) correspond to } 4 \text {-year difference. All regressions include a constant term, firm-level controls, and industry-level competition } \\
\text { control. Industry-level competition control refers to the change of Herfindahl index. Firm-level controls include the changes } \\
\text { between } 2001 \text { and } 2006 \text { in the following variables: TFP, capital intensity, average wage, and total employment. Industry fixed } \\
\text { effect is computed at 2-digit CIC industry level. }\end{array}$} \\
\hline
\end{tabular}


Table A.6: Effect of Export Tariff Reductions

\begin{tabular}{|c|c|c|c|c|c|c|}
\hline & \multicolumn{6}{|c|}{ "Dependent Variable: $\Delta \ln ($ price $)$} \\
\hline & \multicolumn{2}{|c|}{ Whole Sample } & \multicolumn{2}{|c|}{ Differentiated Goods } & \multicolumn{2}{|c|}{ Homogeneous Goods } \\
\hline & (1) & $(2)$ & (3) & (4) & $(5)$ & (6) \\
\hline \multicolumn{7}{|l|}{ Panel $A: \Delta \ln \left(p_{f h c}\right)$} \\
\hline$\Delta$ Duty & $\begin{array}{c}-2.758^{* * *} \\
(0.706)\end{array}$ & $\begin{array}{c}-2.661^{* * *} \\
(0.701)\end{array}$ & $\begin{array}{c}-3.025^{* * *} \\
(0.816)\end{array}$ & $\begin{array}{c}-2.936^{* * *} \\
(0.812)\end{array}$ & $\begin{array}{l}-0.519 \\
(1.174)\end{array}$ & $\begin{array}{l}-0.360 \\
(1.164)\end{array}$ \\
\hline$\Delta$ Duty $\times \ln (\mathrm{TFP})$ & $\begin{array}{c}0.558^{* * *} \\
(0.155)\end{array}$ & $\begin{array}{c}0.535^{* * *} \\
(0.153)\end{array}$ & $\begin{array}{c}0.607^{* * *} \\
(0.182)\end{array}$ & $\begin{array}{c}0.585^{* * *} \\
(0.181)\end{array}$ & $\begin{array}{c}0.173 \\
(0.219)\end{array}$ & $\begin{array}{c}0.139 \\
(0.214)\end{array}$ \\
\hline$\Delta$ (Export Duty) & $\begin{array}{c}0.281 \\
(0.208)\end{array}$ & $\begin{array}{l}-1.138 \\
(0.896)\end{array}$ & $\begin{array}{c}0.223 \\
(0.238)\end{array}$ & $\begin{array}{l}-1.039 \\
(0.963)\end{array}$ & $\begin{array}{c}0.443 \\
(0.351)\end{array}$ & $\begin{array}{l}-1.945 \\
(2.020)\end{array}$ \\
\hline$\Delta($ Export Duty $) \times \ln (\mathrm{TFP})$ & & $\begin{array}{c}0.320 \\
(0.211)\end{array}$ & & $\begin{array}{c}0.282 \\
(0.228)\end{array}$ & & $\begin{array}{c}0.553 \\
(0.432)\end{array}$ \\
\hline Observation & 15484 & 15484 & 13702 & 13702 & 1782 & 1782 \\
\hline R-square & .0183 & .0185 & .0186 & .0188 & .0594 & .0607 \\
\hline \multicolumn{7}{|l|}{ Panel B: $\Delta \ln \left(p_{f h}\right)$} \\
\hline$\Delta$ Duty & $\begin{array}{c}-3.075^{* * *} \\
(0.932)\end{array}$ & $\begin{array}{c}-2.988^{* * *} \\
(1.070)\end{array}$ & $\begin{array}{c}-3.628^{* * *} \\
(1.146)\end{array}$ & $\begin{array}{c}-3.482^{* *} \\
(1.463)\end{array}$ & $\begin{array}{c}0.616 \\
(1.147)\end{array}$ & $\begin{array}{c}0.341 \\
(1.238)\end{array}$ \\
\hline$\Delta$ Duty $\times \ln ($ TFP $)$ & $\begin{array}{c}0.591 * * * \\
(0.202)\end{array}$ & $\begin{array}{c}0.571^{* *} \\
(0.231)\end{array}$ & $\begin{array}{c}0.678^{* * *} \\
(0.253)\end{array}$ & $\begin{array}{c}0.644^{* *} \\
(0.322)\end{array}$ & $\begin{array}{c}0.016 \\
(0.229)\end{array}$ & $\begin{array}{c}0.072 \\
(0.258)\end{array}$ \\
\hline$\Delta$ (Export Duty) & $\begin{array}{l}-0.620 \\
(2.398)\end{array}$ & $\begin{array}{l}-1.343 \\
(5.743)\end{array}$ & $\begin{array}{l}-0.259 \\
(2.931)\end{array}$ & $\begin{array}{l}-1.325 \\
(7.472)\end{array}$ & $\begin{array}{l}-1.627 \\
(3.153)\end{array}$ & $\begin{array}{c}2.713 \\
(7.544)\end{array}$ \\
\hline$\Delta($ Export Duty $) \times \ln (\mathrm{TFP})$ & & $\begin{array}{c}0.168 \\
(1.159)\end{array}$ & & $\begin{array}{l}0.245 \\
(1.478)\end{array}$ & & $\begin{array}{l}-1.050 \\
(1.698)\end{array}$ \\
\hline Observation & 8971 & 8971 & 7799 & 7799 & 1172 & 1172 \\
\hline R-square & .0191 & .0191 & .0199 & .0199 & .068 & .0682 \\
\hline \multicolumn{7}{|l|}{ Panels $A$, and $B$ : } \\
\hline Firm-level Controls & yes & yes & yes & yes & yes & yes \\
\hline Industry-level Competition Control & yes & yes & yes & yes & yes & yes \\
\hline Industry Fixed Effect & yes & yes & yes & yes & yes & yes \\
\hline \multicolumn{7}{|c|}{$\begin{array}{l}\text { Notes: }{ }^{* * *} \mathrm{p}<0.01,{ }^{* *} \mathrm{p}<0.05,{ }^{*} \mathrm{p}<0.1 \text {. Robust standard errors corrected for clustering at the firm level } \\
\text { in parentheses. Compared with odd columns, we also add the interaction term between export duty change } \\
\text { and TFP in even columns. All regressions include a constant term, firm-level controls, and industry-level } \\
\text { competition control. Industry-level competition control refers to the change of Herfindahl index. Firm-level } \\
\text { controls include the changes between } 2001 \text { and } 2006 \text { in the following variables: TFP, capital intensity, average } \\
\text { wage, and total employment. Industry fixed effect is computed at 2-digit CIC industry level. }\end{array}$} \\
\hline
\end{tabular}


Table A.7: Robustness: Weighted Regression Results

\begin{tabular}{|c|c|c|c|c|c|c|}
\hline & \multicolumn{6}{|c|}{ Dependent Variable: $\Delta \ln ($ price $)$} \\
\hline & \multicolumn{2}{|c|}{ Whole Sample } & \multicolumn{2}{|c|}{ Differentiated Goods } & \multicolumn{2}{|c|}{ Homogeneous Goods } \\
\hline & (1) & $(2)$ & $(3)$ & $(4)$ & $(5)$ & $(6)$ \\
\hline \multicolumn{7}{|c|}{ Panel A: Weighted by No. of Observations in 2-digit CIC Industry } \\
\hline$\Delta$ Duty & $\begin{array}{c}-2.887^{* * *} \\
(0.815)\end{array}$ & $\begin{array}{c}-3.539^{* * *} \\
(1.180)\end{array}$ & $\begin{array}{c}-3.011^{* * *} \\
(0.885)\end{array}$ & $\begin{array}{c}-3.819^{* * *} \\
(1.295)\end{array}$ & $\begin{array}{l}0.298 \\
(1.644)\end{array}$ & $\begin{array}{c}2.322 \\
(1.592)\end{array}$ \\
\hline$\Delta$ Duty $\times \ln (\mathrm{TFP})$ & $\begin{array}{c}0.528^{* * *} \\
(0.168)\end{array}$ & $\begin{array}{c}0.569 * * \\
(0.249)\end{array}$ & $\begin{array}{c}0.538^{* * *} \\
(0.187)\end{array}$ & $\begin{array}{c}0.591^{* *} \\
(0.282)\end{array}$ & $\begin{array}{c}0.051 \\
(0.298)\end{array}$ & $\begin{array}{l}-0.300 \\
(0.268)\end{array}$ \\
\hline Observation & 16907 & 8971 & 15018 & 7799 & 1889 & 1172 \\
\hline R-square & 0.018 & 0.021 & 0.017 & 0.022 & 0.048 & 0.055 \\
\hline \multicolumn{7}{|c|}{ Panel B: Weighted by No. of Observations in Each Firm } \\
\hline$\Delta$ Duty & $\begin{array}{c}-3.297^{* * *} \\
(1.054)\end{array}$ & $\begin{array}{c}-4.647^{* * *} \\
(1.444)\end{array}$ & $\begin{array}{c}-3.184^{* * *} \\
(1.121)\end{array}$ & $\begin{array}{c}-4.835^{* * *} \\
(1.590)\end{array}$ & $\begin{array}{l}-1.256 \\
(2.016)\end{array}$ & $\begin{array}{c}-1.066 \\
(2.324)\end{array}$ \\
\hline$\Delta$ Duty $\times \ln (\mathrm{TFP})$ & $\begin{array}{c}0.616^{* * *} \\
(0.220)\end{array}$ & $\begin{array}{c}0.847^{* * *} \\
(0.302)\end{array}$ & $\begin{array}{c}0.563^{* *} \\
(0.238)\end{array}$ & $\begin{array}{c}0.838^{* *} \\
(0.330)\end{array}$ & $\begin{array}{c}0.531 \\
(0.406) \\
\end{array}$ & $\begin{array}{c}0.465 \\
(0.477) \\
\end{array}$ \\
\hline Observation & 16907 & 8971 & 15018 & 7799 & 1889 & 1172 \\
\hline $\mathrm{R}$-square & 0.016 & 0.017 & 0.017 & 0.017 & 0.152 & 0.107 \\
\hline \multicolumn{7}{|c|}{ Panel C: Weighted by Export Values of Each Firm } \\
\hline$\Delta$ Duty & $\begin{array}{c}-2.427^{* * *} \\
(0.699)\end{array}$ & $\begin{array}{c}-3.216^{* * *} \\
(0.938)\end{array}$ & $\begin{array}{c}-2.611^{* * *} \\
(0.808)\end{array}$ & $\begin{array}{c}-3.790^{* * *} \\
(1.149)\end{array}$ & $\begin{array}{c}-0.233 \\
(1.167)\end{array}$ & $\begin{array}{c}0.891 \\
(1.155)\end{array}$ \\
\hline$\Delta$ Duty $\times \ln (\mathrm{TFP})$ & $\begin{array}{c}0.492^{* * *} \\
(0.148)\end{array}$ & $\begin{array}{c}0.618^{* * *} \\
(0.202)\end{array}$ & $\begin{array}{c}0.520^{* * *} \\
(0.175)\end{array}$ & $\begin{array}{c}0.709^{* * *} \\
(0.251)\end{array}$ & $\begin{array}{c}0.139 \\
(0.222)\end{array}$ & $\begin{array}{l}-0.028 \\
(0.228)\end{array}$ \\
\hline Observation & 16907 & 8971 & 15018 & 7799 & 1889 & 1172 \\
\hline $\mathrm{R}$-square & 0.018 & 0.020 & 0.018 & 0.021 & 0.060 & 0.080 \\
\hline \multicolumn{7}{|l|}{ Panels $A, B$ and $C$ : } \\
\hline Firm-level Controls & yes & yes & yes & yes & yes & yes \\
\hline Industry-level Competition Control & yes & yes & yes & yes & yes & yes \\
\hline
\end{tabular}

Notes: ${ }^{* * *} \mathrm{p}<0.01,{ }^{* *} \mathrm{p}<0.05,{ }^{*} \mathrm{p}<0.1$. Robust standard errors corrected for clustering at the firm level in parentheses. Dependent variable in specifications (1), (3), and (5) is the (log) price change at the firm-HS6-country level; dependent variable in specifications (2), (4), and (6) is the (log) price change at the firm-HS6 product level. All regressions include a constant term, firm-level controls, and industry-level competition control. Industry-level competition control refers to the change of Herfindahl index. Firm-level controls include the changes between 2001 and 2006 in the following variables: TFP, capital intensity, average wage, and total employment. The weights used in regressions are in logarithm, e.g., Panel $\mathrm{C}$ is weighted by $\ln$ (Export values of each firm). 
Table A.8: Robustness: Results with Alternative Measures of Productivity and Firm Size

\begin{tabular}{|c|c|c|c|c|c|c|}
\hline & \multicolumn{6}{|c|}{ Dependent Variable: $\Delta \ln ($ price $)$} \\
\hline & \multicolumn{2}{|c|}{ Whole Sample } & \multicolumn{2}{|c|}{ Differentiated Goods } & \multicolumn{2}{|c|}{ Homogeneous Goods } \\
\hline & (1) & $(2)$ & $(3)$ & $(4)$ & $(5)$ & $(6)$ \\
\hline \multicolumn{7}{|l|}{ Panel A: Using Value Added per Worker } \\
\hline$\Delta$ Duty & $\begin{array}{c}-2.724^{* * *} \\
(0.745)\end{array}$ & $\begin{array}{c}-2.958^{* * *} \\
(0.966)\end{array}$ & $\begin{array}{c}-2.944^{* * *} \\
(0.866)\end{array}$ & $\begin{array}{c}-3.271^{* * *} \\
(1.187)\end{array}$ & $\begin{array}{c}0.388 \\
(0.991)\end{array}$ & $\begin{array}{c}0.912 \\
(1.086)\end{array}$ \\
\hline$\Delta$ Duty $\times \ln ($ Value Added per Worker $)$ & $\begin{array}{c}0.649^{* * *} \\
(0.174)\end{array}$ & $\begin{array}{c}0.630^{* * *} \\
(0.223)\end{array}$ & $\begin{array}{c}0.717^{* * *} \\
(0.205)\end{array}$ & $\begin{array}{c}0.703^{* *} \\
(0.284)\end{array}$ & $\begin{array}{c}0.031 \\
(0.181)\end{array}$ & $\begin{array}{l}-0.037 \\
(0.199)\end{array}$ \\
\hline Observation & 16907 & 8971 & 15018 & 7799 & 1889 & 1172 \\
\hline R-square & 0.007 & 0.007 & 0.007 & 0.008 & 0.005 & 0.005 \\
\hline \multicolumn{7}{|l|}{ Panel B: Using Total Sales } \\
\hline$\Delta$ Duty & $\begin{array}{c}-3.473^{* * *} \\
(0.993)\end{array}$ & $\begin{array}{c}-4.646^{* * *} \\
(1.574)\end{array}$ & $\begin{array}{c}3.746^{* * *} \\
(1.171)\end{array}$ & $\begin{array}{c}-5.277^{* * *} \\
(1.937)\end{array}$ & $\begin{array}{c}2.060 \\
(1.926)\end{array}$ & $\begin{array}{l}3.522^{*} \\
(2.020)\end{array}$ \\
\hline$\Delta$ Duty $\times \ln ($ Total Sales $)$ & $\begin{array}{c}0.292^{* * *} \\
(0.087)\end{array}$ & $\begin{array}{c}0.371^{* * *} \\
(0.142)\end{array}$ & $\begin{array}{c}0.317^{* * *} \\
(0.106)\end{array}$ & $\begin{array}{c}0.422^{* *} \\
(0.180)\end{array}$ & $\begin{array}{c}-0.124 \\
(0.141)\end{array}$ & $\begin{array}{l}-0.220 \\
(0.146)\end{array}$ \\
\hline Observation & 16907 & 8971 & 15018 & 7799 & 1889 & 1172 \\
\hline R-square & 0.004 & 0.005 & 0.004 & 0.005 & 0.009 & 0.010 \\
\hline \multicolumn{7}{|l|}{ Panel C: Using Total Employment Payments } \\
\hline$\Delta$ Duty & $\begin{array}{c}-2.438^{* *} \\
(1.017)\end{array}$ & $\begin{array}{l}-2.573 \\
(1.647)\end{array}$ & $\begin{array}{c}-2.701^{* *} \\
(1.159)\end{array}$ & $\begin{array}{c}-3.053 \\
(1.856)\end{array}$ & $\begin{array}{c}1.316 \\
(2.126)\end{array}$ & $\begin{array}{c}3.064 \\
(2.416)\end{array}$ \\
\hline$\Delta$ Duty $\times \ln ($ Total Employment Payments $)$ & $\begin{array}{c}0.237^{* *} \\
(0.119)\end{array}$ & $\begin{array}{c}0.239 \\
(0.198)\end{array}$ & $\begin{array}{c}0.258^{*} \\
(0.137)\end{array}$ & $\begin{array}{c}0.275 \\
(0.224)\end{array}$ & $\begin{array}{c}-0.090 \\
(0.227)\end{array}$ & $\begin{array}{c}-0.272 \\
(0.264)\end{array}$ \\
\hline Observation & 16673 & 8846 & 14813 & 7699 & 1860 & 1147 \\
\hline R-square & 0.003 & 0.003 & 0.004 & 0.004 & 0.007 & 0.009 \\
\hline \multicolumn{7}{|l|}{ Panels $A, B$ and $C$ : } \\
\hline Firm-level Controls & yes & yes & yes & yes & yes & yes \\
\hline Industry-level Competition Control & yes & yes & yes & yes & yes & yes \\
\hline
\end{tabular}

Notes: ${ }^{* *} \mathrm{p}<0.01,{ }^{* *} \mathrm{p}<0.05,{ }^{*} \mathrm{p}<0.1$. Robust standard errors corrected for clustering at the firm level in parentheses. Dependent variable in specifications (1), (3), and (5) is the (log) price change at the firm-HS6-country level; dependent variable in specifications (2), (4), and (6) is the (log) price change at the firm-HS6 product level. All regressions include a constant term, firm-level controls, and industry-level competition control. Industry-level competition control refers to the change of Herfindahl index. Firm-level controls include the changes between 2001 and 2006 in the following variables: TFP, capital intensity, average wage, and total employment. 
Table A.9: Robustness: Alternative Tariff Reduction Measure 3 with Product Fixed Effect

\begin{tabular}{|c|c|c|c|c|c|c|}
\hline & \multicolumn{6}{|c|}{ Dependent Variable: $\Delta \ln ($ price $)$} \\
\hline & \multicolumn{2}{|c|}{ Whole Sample } & \multicolumn{2}{|c|}{ Differentiated Goods } & \multicolumn{2}{|c|}{ Homogeneous Goods } \\
\hline & $\begin{array}{c}\Delta \ln \left(p_{f h c}\right) \\
\text { (1) }\end{array}$ & $\begin{array}{c}\Delta \ln \left(p_{f h}\right) \\
(2)\end{array}$ & $\begin{array}{c}\Delta \ln \left(p_{f h c}\right) \\
(3)\end{array}$ & $\begin{array}{c}\Delta \ln \left(p_{f h}\right) \\
(4)\end{array}$ & $\begin{array}{c}\Delta \ln \left(p_{f h c}\right) \\
(5)\end{array}$ & $\begin{array}{c}\Delta \ln \left(p_{f h}\right) \\
(6)\end{array}$ \\
\hline$\Delta$ Duty & $\begin{array}{c}-2.643^{* *} \\
(1.293)\end{array}$ & $\begin{array}{c}-4.587^{* *} \\
(2.087)\end{array}$ & $\begin{array}{c}-2.808^{* *} \\
(1.333)\end{array}$ & $\begin{array}{c}-4.788^{* *} \\
(2.177)\end{array}$ & $\begin{array}{c}-6.780 \\
(9.908)\end{array}$ & $\begin{array}{c}-8.587 \\
(14.533)\end{array}$ \\
\hline$\Delta$ Duty $\times \ln (\mathrm{TFP})$ & $\begin{array}{c}0.476^{*} \\
(0.270)\end{array}$ & $\begin{array}{c}0.931^{* *} \\
(0.388)\end{array}$ & $\begin{array}{l}0.501^{*} \\
(0.276)\end{array}$ & $\begin{array}{c}1.000^{* *} \\
(0.410)\end{array}$ & $\begin{array}{c}-0.620 \\
(1.581)\end{array}$ & $\begin{array}{c}1.157 \\
(2.395)\end{array}$ \\
\hline Firm-level Controls & yes & yes & yes & yes & yes & yes \\
\hline Industry-level Competition Control & yes & yes & yes & yes & yes & yes \\
\hline Industry fixed effect & yes & yes & yes & yes & yes & yes \\
\hline HS6 fixed effect & yes & yes & yes & yes & yes & yes \\
\hline Observation & 6629 & 2916 & 6217 & 2685 & 412 & 231 \\
\hline R-square & 0.222 & 0.344 & 0.217 & 0.341 & 0.433 & 0.544 \\
\hline
\end{tabular}

Notes: ${ }^{* * *} \mathrm{p}<0.01,{ }^{* *} \mathrm{p}<0.05,{ }^{*} \mathrm{p}<0.1$. Robust standard errors corrected for clustering at the firm level in parentheses. Dependent variable in specifications (1), (3), and (5) is the (log) price change at the firm-HS6-country level; dependent variable in specifications (2), (4), and (6) is the (log) price change at the firm-HS6 product level. All regressions include a constant term, firm-level controls, and industry-level competition control. Industry-level competition control refers to the change of Herfindahl index. Firmlevel controls include the changes between 2001 and 2006 in the following variables: TFP, capital intensity, average wage, and total employment. Industry fixed effect is computed at 2-digit CIC industry level. 
Table A.10: Results Using Alternative Productivity and Firm-Specific Tariff Measures with Triple Interaction Term

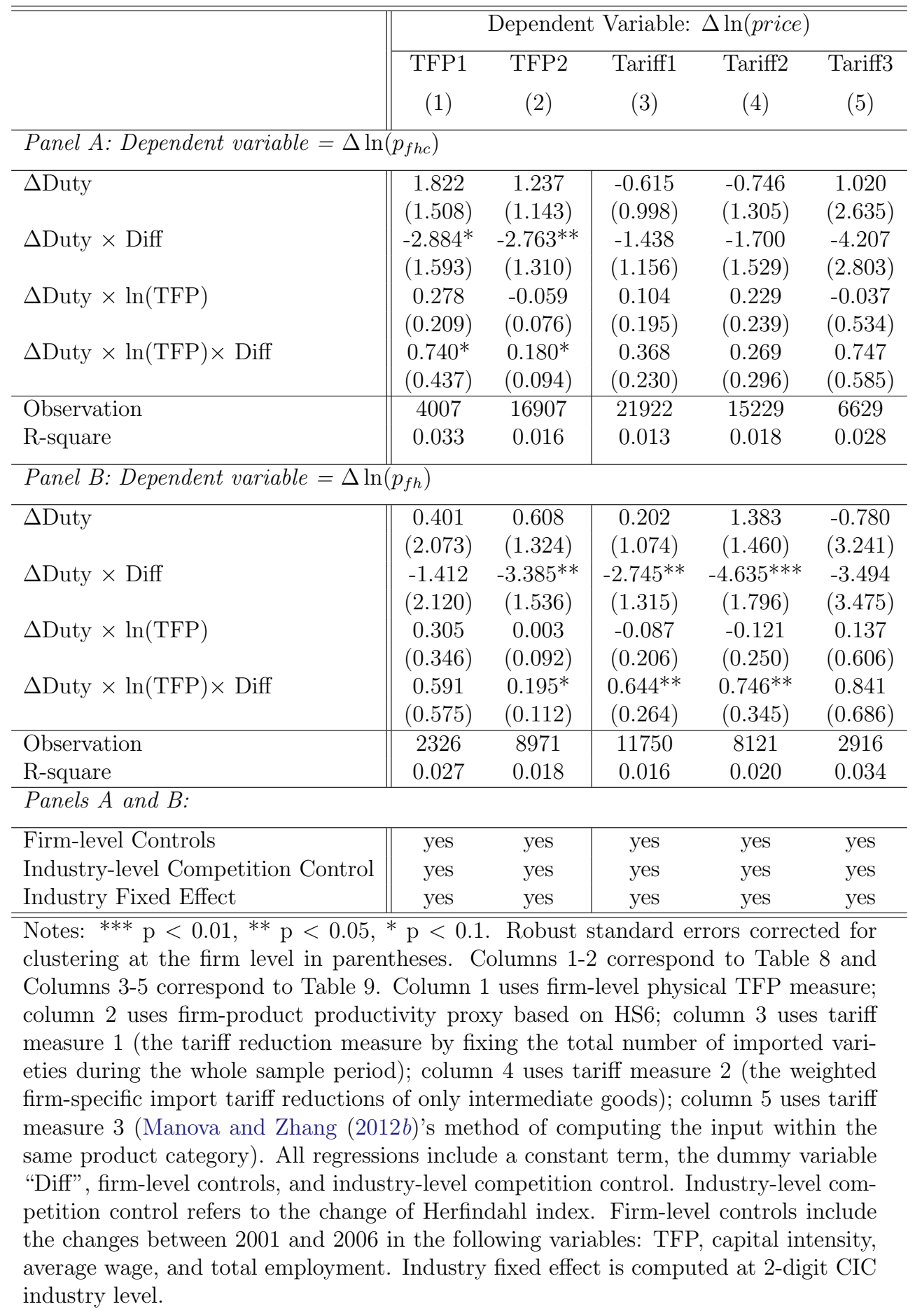


Table A.11: Results Using Industry Input and Output Tariffs with Triple Interaction Term

\begin{tabular}{|c|c|c|c|c|c|}
\hline & (1) & (2) & & $(3)$ & (4) \\
\hline Duty $^{\text {input }}$ & $\begin{array}{c}0.676 \\
(0.839)\end{array}$ & $\begin{array}{c}0.635 \\
(0.892)\end{array}$ & $\Delta$ Duty $^{\text {input }}$ & $\begin{array}{l}-1.216 \\
(1.361)\end{array}$ & $\begin{array}{l}-1.162 \\
(2.042)\end{array}$ \\
\hline Duty $^{\text {input }} \times$ Diff & $\begin{array}{c}-2.647^{* * *} \\
(0.806)\end{array}$ & $\begin{array}{c}-2.945^{* * *} \\
(0.774)\end{array}$ & $\Delta$ Duty $^{\text {input }} \times$ Diff & $\begin{array}{l}-2.199 \\
(1.659)\end{array}$ & $\begin{array}{l}-2.925 \\
(2.257)\end{array}$ \\
\hline Duty $^{\text {input }} \times \ln (\mathrm{TFP})$ & $\begin{array}{c}0.121 \\
(0.097)\end{array}$ & $\begin{array}{c}0.120 \\
(0.130)\end{array}$ & $\Delta$ Duty $^{\text {input }} \times \ln (\mathrm{TFP})$ & $\begin{array}{c}0.197 \\
(0.249)\end{array}$ & $\begin{array}{l}-0.267 \\
(0.320)\end{array}$ \\
\hline Duty $^{\text {input }} \times \ln (\mathrm{TFP}) \times$ Diff & $\begin{array}{c}0.125 \\
(0.082)\end{array}$ & $\begin{array}{l}0.181^{*} \\
(0.107)\end{array}$ & $\Delta$ Duty $^{\text {input }} \times \ln (\mathrm{TFP}) \times$ Diff & $\begin{array}{c}0.249 \\
(0.323)\end{array}$ & $\begin{array}{c}0.990^{* *} \\
(0.419)\end{array}$ \\
\hline Duty & $\begin{array}{l}-0.318 \\
(0.476)\end{array}$ & $\begin{array}{l}-0.412 \\
(0.508)\end{array}$ & $\Delta$ Duty $^{\text {output }}$ & $\begin{array}{c}0.360 \\
(0.716)\end{array}$ & $\begin{array}{c}1.396 \\
(1.056)\end{array}$ \\
\hline Duty $^{\text {output }} \times$ Diff & $\begin{array}{c}0.689 \\
(0.526) \\
\end{array}$ & $\begin{array}{c}0.739 \\
(0.579) \\
\end{array}$ & $\Delta$ Duty $^{\text {output }} \times$ Diff & $\begin{array}{c}0.524 \\
(0.776) \\
\end{array}$ & $\begin{array}{c}-0.661 \\
(1.168)\end{array}$ \\
\hline Firm-level Controls & yes & yes & Firm-level Controls & yes & yes \\
\hline Industry-level Competition Control & yes & yes & Industry-level Competition Control & yes & yes \\
\hline Year fixed effect & yes & yes & Year fixed effect & yes & yes \\
\hline Firm-HS6-country fixed effect & yes & no & Firm-HS6-country fixed effect & no & no \\
\hline Firm-HS6 fixed effect & no & yes & Firm-HS6 fixed effect & no & no \\
\hline Observation & 1302884 & 471128 & Observation & 16907 & 8971 \\
\hline R-square & 0.980 & 0.968 & R-square & 0.006 & 0.007 \\
\hline
\end{tabular}

Notes: ${ }^{* * *} \mathrm{p}<0.01,{ }^{* *} \mathrm{p}<0.05,{ }^{*} \mathrm{p}<0.1$. Robust standard errors corrected for clustering at the 4-digit CIC industry level in parentheses. Dependent variable in specifications (1)-(2) is (log) price level; dependent variable in specifications (3)-(4) is the (log) price change. In specifications (1) and (3), we use firm-HS6-country price level or price change; in specifications (2) and (4), we use firm-HS price level or price change. All regressions include a constant term, the dummy variable "Diff", firm-level controls, and industry-level competition control. Firm-level controls refer to the levels (in specifications 1-2) or the changes between 2001 and 2006 (in specifications 3-4) of the following variables: TFP, capital intensity, average wage, and total employment. Industry-level competition control refers to Herfindahl index (in specifications 1-2) and the change of Herfindahl index (in specifications 3-4). 
Table A.12: Effects of Tariff Reductions for Alternative Productivity and Tariff Measures (Demean)

\begin{tabular}{l||cc|cccc}
\hline \hline \multicolumn{1}{c||}{} & \multicolumn{6}{c}{ Dependent Variable: $\Delta \ln ($ price $)$} \\
\cline { 2 - 7 } & TFP1 & TFP2 & Tariff1 & Tariff2 & Tariff3 & Ind. Tariff \\
& $(1)$ & $(2)$ & $(3)$ & $(4)$ & $(5)$ & $(6)$ \\
\hline$\Delta$ Duty & $-0.994^{*}$ & $-0.602^{* *}$ & -0.107 & $-0.473^{*}$ & -0.201 & $-1.276^{* *}$ \\
& $(0.510)$ & $(0.260)$ & $(0.366)$ & $(0.258)$ & $(0.434)$ & $(0.571)$ \\
$\Delta$ Duty $\times \ln (\mathrm{TFP})$ & 0.441 & $0.179^{* * *}$ & $0.459^{* *}$ & $0.526^{* *}$ & $0.852^{* * *}$ & $0.569^{* *}$ \\
& $(0.337)$ & $(0.062)$ & $(0.213)$ & $(0.215)$ & $(0.292)$ & $(0.260)$ \\
$\Delta$ Duty ${ }^{\text {output }}$ & & & & & & $0.863^{* *}$ \\
& & & & & & $(0.385)$ \\
\hline Firm-level Controls & yes & yes & yes & yes & yes & yes \\
Industry-level Competition Control & yes & yes & yes & yes & yes & yes \\
Industry Fixed Effect & yes & yes & yes & yes & yes & no \\
Observation & 2326 & 8971 & 11750 & 8121 & 2916 & 8971 \\
R-square & 0.025 & 0.018 & 0.015 & 0.019 & 0.034 & 0.005 \\
\hline \hline
\end{tabular}

Notes: ${ }^{* * *} \mathrm{p}<0.01,{ }^{*} \mathrm{p}<0.05,{ }^{*} \mathrm{p}<0.1$. Robust standard errors corrected for clustering at the firm level in parentheses. Columns 1-2 correspond to Table 8; columns 3-5 correspond to Table 9; column 6 corresponds to Table 10. Column 1 uses firm-level physical TFP measure; column 2 uses firm-product productivity proxy based on HS6; column 3 uses tariff measure 1 (the tariff reduction measure by fixing the total number of imported varieties during the whole sample period); column 4 uses tariff measure 2 (the weighted firm-specific import tariff reductions of only intermediate goods); column 5 uses tariff measure 3 (Manova and Zhang (2012b)'s method of computing the input within the same product category); column 6 uses industry input tariff. Dependent variable is export price change at the firm-HS6 product level. The results at the firm-product-country level are similar yet less significant but remain the expected signs. All regressions include a constant term, firm-level controls, and industry-level competition control. Industry-level competition control refers to the change of Herfindahl index. Firm-level controls include the changes between 2001 and 2006 in the following variables: TFP, capital intensity, average wage, and total employment. 
Table A.13: Results Using Instrumental Variable Estimation

\begin{tabular}{|c|c|c|c|c|c|c|}
\hline & \multicolumn{6}{|c|}{ Instrumental Variable Estimation } \\
\hline & \multicolumn{2}{|c|}{ Whole Sample } & \multicolumn{2}{|c|}{ Differentiated Goods } & \multicolumn{2}{|c|}{ Homogeneous Goods } \\
\hline & (1) & $(2)$ & $(3)$ & $(4)$ & $(5)$ & $(6)$ \\
\hline \multicolumn{7}{|l|}{ Panel A: instrumented by Duty 1997} \\
\hline$\Delta$ Duty & $\begin{array}{c}-3.289^{* * *} \\
(0.660)\end{array}$ & $\begin{array}{c}-2.689^{* * *} \\
(0.901)\end{array}$ & $\begin{array}{c}-3.602^{* * *} \\
(0.736)\end{array}$ & $\begin{array}{c}-3.180 \text { *** } \\
(1.059)\end{array}$ & $\begin{array}{l}-0.075 \\
(1.467)\end{array}$ & $\begin{array}{c}0.518 \\
(1.534)\end{array}$ \\
\hline$\Delta$ Duty $\times \ln (\mathrm{TFP})$ & $\begin{array}{c}0.662^{* * *} \\
(0.138)\end{array}$ & $\begin{array}{c}0.486^{* * *} \\
(0.184)\end{array}$ & $\begin{array}{c}0.658^{* * *} \\
(0.154)\end{array}$ & $\begin{array}{c}0.480 * * \\
(0.220)\end{array}$ & $\begin{array}{c}0.319 \\
(0.357)\end{array}$ & $\begin{array}{c}0.169 \\
(0.358)\end{array}$ \\
\hline Kleibergen-Paap rk LM $\chi^{2}$ statistic & 606.391 & 272.258 & 1319.881 & 784.757 & 38.486 & 12.526 \\
\hline Kleibergen-Paap rk Wald F statistic & 828.463 & 420.565 & 983.191 & 639.515 & 174.685 & 48.582 \\
\hline Observation & 16907 & 8971 & 15018 & 7799 & 1889 & 1172 \\
\hline R-square & 0.017 & 0.019 & 0.017 & 0.019 & 0.052 & 0.066 \\
\hline Prob $>\mathrm{F}$ & 0.000 & 0.000 & 0.000 & 0.000 & 0.000 & 0.000 \\
\hline \multicolumn{7}{|l|}{ Panel B: instrumented by Duty $y_{2001}$} \\
\hline$\Delta$ Duty & $\begin{array}{c}-2.972^{* * * *} \\
(0.611)\end{array}$ & $\begin{array}{c}-2.297^{* * *} \\
(0.830)\end{array}$ & $\begin{array}{c}-3.114^{* * *} \\
(0.681)\end{array}$ & $\begin{array}{c}-2.596^{* * *} \\
(0.979)\end{array}$ & $\begin{array}{c}-0.292 \\
(1.377)\end{array}$ & $\begin{array}{c}0.498 \\
(1.466)\end{array}$ \\
\hline$\Delta$ Duty $\times \ln (\mathrm{TFP})$ & $\begin{array}{c}0.609^{* * *} \\
(0.129)\end{array}$ & $\begin{array}{c}0.458^{* * *} \\
(0.172)\end{array}$ & $\begin{array}{c}0.600^{* * *} \\
(0.145)\end{array}$ & $\begin{array}{c}0.458^{* *} \\
(0.207)\end{array}$ & $\begin{array}{c}0.287 \\
(0.299)\end{array}$ & $\begin{array}{c}0.125 \\
(0.308)\end{array}$ \\
\hline Kleibergen-Paap rk LM $\chi^{2}$ statistic & 282.798 & 160.806 & 222.205 & 124.279 & 154.251 & 29.792 \\
\hline Kleibergen-Paap rk Wald F statistic & 1084.806 & 669.492 & 896.163 & 554.004 & 402.790 & 103.083 \\
\hline Observation & 16907 & 8971 & 15018 & 7799 & 1889 & 1172 \\
\hline R-square & 0.017 & 0.019 & 0.017 & 0.020 & 0.056 & 0.067 \\
\hline Prob $>\mathrm{F}$ & 0.000 & 0.000 & 0.000 & 0.000 & 0.000 & 0.000 \\
\hline \multicolumn{7}{|l|}{ Panels $A$ and $B:$} \\
\hline Firm-level Controls & yes & yes & yes & yes & yes & yes \\
\hline Industry-level Competition Control & yes & yes & yes & yes & yes & yes \\
\hline Industry Fixed Effect & yes & yes & yes & yes & yes & yes \\
\hline
\end{tabular}

Notes: ${ }^{* * *} \mathrm{p}<0.01,{ }^{* *} \mathrm{p}<0.05,{ }^{*} \mathrm{p}<0.1$. Robust standard errors corrected in parentheses. Dependent variable in specifications (1), (3), and (5) is the (log) price change at the firm-HS6-country level; dependent variable in specifications (2), (4), and (6) is the (log) price change at the firm-HS6 product level. All regressions include a constant term, firm-level controls, and industry-level competition control. Industrylevel competition control refers to the change of Herfindahl index. Firm-level controls include the changes between 2001 and 2006 in the following variables: TFP, capital intensity, average wage, and total employment. Industry fixed effect is computed at 2-digit CIC industry level. 
Table A.14: Robustness: Results Using the Whole Customs Data

\begin{tabular}{|c|c|c|c|c|c|c|}
\hline & \multicolumn{6}{|c|}{ Dependent variable: $\Delta \ln ($ price $)$} \\
\hline & \multicolumn{2}{|c|}{ Whole Sample } & \multicolumn{2}{|c|}{ Differentiated Goods } & \multicolumn{2}{|c|}{ Homogeneous Goods } \\
\hline & (1) & $(2)$ & $(3)$ & (4) & $(5)$ & (6) \\
\hline$\Delta$ Duty & $\begin{array}{l}-0.949 \\
(0.639)\end{array}$ & $\begin{array}{c}-1.692^{* * *} \\
(0.613)\end{array}$ & $\begin{array}{c}-1.262^{*} \\
(0.763)\end{array}$ & $\begin{array}{c}-1.964^{* * *} \\
(0.722)\end{array}$ & $\begin{array}{c}0.911 \\
(1.422)\end{array}$ & $\begin{array}{l}-0.292 \\
(0.972)\end{array}$ \\
\hline$\Delta$ Duty $\times \ln ($ export value $)$ & $\begin{array}{c}0.063 \\
(0.044)\end{array}$ & $\begin{array}{c}0.107^{* *} \\
(0.043)\end{array}$ & $\begin{array}{c}0.078 \\
(0.054)\end{array}$ & $\begin{array}{c}0.124^{* *} \\
(0.050)\end{array}$ & $\begin{array}{l}-0.035 \\
(0.088)\end{array}$ & $\begin{array}{c}0.021 \\
(0.064)\end{array}$ \\
\hline Industry Fixed Effect & yes & yes & yes & yes & yes & yes \\
\hline Observation & 56282 & 36785 & 49375 & 32074 & 6907 & 4711 \\
\hline R-square & 0.010 & 0.008 & 0.008 & 0.007 & 0.018 & 0.017 \\
\hline
\end{tabular}

Notes: ${ }^{* * *} \mathrm{p}<0.01,{ }^{* *} \mathrm{p}<0.05,{ }^{*} \mathrm{p}<0.1$. Robust standard errors corrected for clustering at the firm level in parentheses. Dependent variable in specifications (1), (3), and (5) is the $(\log )$ price change at the firm-HS6-country level; dependent variable in specifications (2), (4), and (6) is the $(\log )$ price change at the firm-HS6 product level. All regressions include a constant term and the changes between 2001 and 2006 in TFP. Industry fixed effect is computed at the HS2 product level.

Table A.15: Change in Export Prices vs. Initial Productivity based on Whole Customs Data

\begin{tabular}{ccccc}
\hline \hline & \multicolumn{2}{c}{ Differentiated goods } & \multicolumn{2}{c}{ Homogeneous goods } \\
\cline { 2 - 5 } & $\begin{array}{c}(1) \\
\text { S }\end{array}$ & $\begin{array}{c}(2) \\
\text { (3) }\end{array}$ & $\begin{array}{c}(3) \\
\leq 50 \mathrm{th}\end{array}$ & $\begin{array}{c}(4) \\
>50 \mathrm{th}\end{array}$ \\
\hline $\begin{array}{c}\text { Change in Export Price (HS6-Country): } \\
\text { Per Firm-product-country, median }\end{array}$ & $11.88 \%$ & $10.21 \%$ & $-2.69 \%$ & $-0.20 \%$ \\
Per Firm-product-country, mean & $17.59 \%$ & $13.75 \%$ & $-2.24 \%$ & $3.18 \%$ \\
Change in Export Price (HS6): & & & & \\
Per Firm-product, median & $15.12 \%$ & $12.28 \%$ & $-0.17 \%$ & $2.37 \%$ \\
Per Firm-product, mean & $20.02 \%$ & $16.05 \%$ & $3.16 \%$ & $8.87 \%$ \\
\hline
\end{tabular}

Notes: $\leq 50$ th indicates the firms associated with lower initial productivity (i.e., the bottom 50th percentile); $>50$ th indicates the firms associated with higher initial productivity (i.e., the top 50th percentile). 
Table A.16: Robustness: Results Using Processing Trade Sample

\begin{tabular}{|c|c|c|c|c|c|c|}
\hline & \multicolumn{6}{|c|}{ Dependent variable: $\Delta \ln ($ price $)$} \\
\hline & \multicolumn{2}{|c|}{ Whole Sample } & \multicolumn{2}{|c|}{ Differentiated Goods } & \multicolumn{2}{|c|}{ Homogeneous Goods } \\
\hline & (1) & (2) & $(3)$ & $(4)$ & $(5)$ & (6) \\
\hline$\Delta$ Duty & $\begin{array}{l}-0.540 \\
(0.704)\end{array}$ & $\begin{array}{c}0.306 \\
(0.731)\end{array}$ & $\begin{array}{c}-0.509 \\
(0.741)\end{array}$ & $\begin{array}{c}0.223 \\
(0.779)\end{array}$ & $\begin{array}{l}-0.374 \\
(1.425)\end{array}$ & $\begin{array}{c}3.613^{* *} \\
(1.505)\end{array}$ \\
\hline$\Delta$ Duty $\times \ln (\mathrm{TFP})$ & $\begin{array}{c}0.055 \\
(0.155)\end{array}$ & $\begin{array}{c}-0.053 \\
(0.158)\end{array}$ & $\begin{array}{c}0.045 \\
(0.164)\end{array}$ & $\begin{array}{l}-0.039 \\
(0.171)\end{array}$ & $\begin{array}{c}0.138 \\
(0.268)\end{array}$ & $\begin{array}{c}-0.596^{* *} \\
(0.274)\end{array}$ \\
\hline Firm-level Controls & yes & yes & yes & yes & yes & yes \\
\hline Industry-level Competition Control & yes & yes & yes & yes & yes & yes \\
\hline Industry Fixed Effect & yes & yes & yes & yes & yes & yes \\
\hline Observation & 14596 & 6179 & 13784 & 5834 & 812 & 345 \\
\hline R-square & 0.026 & 0.015 & 0.025 & 0.013 & 0.109 & 0.164 \\
\hline
\end{tabular}

Notes: ${ }^{* * *} \mathrm{p}<0.01,{ }^{* *} \mathrm{p}<0.05,{ }^{*} \mathrm{p}<0.1$. Robust standard errors corrected for clustering at the firm level in parentheses.Dependent variable in specifications $(1),(3),(5)$ is the (log) price change at the firm-HS6-country level; dependent variable in specifications $(2),(4),(6)$ is the (log) price change at the firm-HS6 product level. All regressions include a constant term, firm-level controls, and industrylevel competition control. Industry-level competition control refers to the change of Herfindahl index. Firm-level controls include the changes between 2001 and 2006 in the following variables: TFP, capital intensity, average wage, and total employment. Industry fixed effect is computed at the CIC 2-digit industry level.

Table A.17: Sensitivity to Other Mechanisms

\begin{tabular}{|c|c|c|c|c|c|c|c|c|c|}
\hline & \multicolumn{9}{|c|}{ Dependent Variable: $\Delta \ln ($ price $)$} \\
\hline & \multicolumn{3}{|c|}{ Whole Sample } & \multicolumn{3}{|c|}{ Differentiated Goods } & \multicolumn{3}{|c|}{ Homogeneous Goods } \\
\hline & \multicolumn{2}{|c|}{$\Delta \ln \left(p_{f h c}\right)$} & \multirow{3}{*}{$\begin{array}{l}\frac{\Delta \ln \left(p_{f h}\right)}{(3)} \\
\text { ge rate }\end{array}$} & \multicolumn{2}{|c|}{$\Delta \ln \left(p_{f h c}\right)$} & \multirow{3}{*}{$\begin{array}{l}\frac{\Delta \ln \left(p_{f h}\right)}{(6)} \\
\text { ge rate }\end{array}$} & \multicolumn{2}{|c|}{$\Delta \ln \left(p_{f h c}\right)$} & \multirow{3}{*}{$\begin{array}{l}\frac{\Delta \ln \left(p_{f h}\right)}{(9)} \\
\text { nge rate }\end{array}$} \\
\hline & (1) & $(2)$ & & $(4)$ & $(5)$ & & $(7)$ & $(8)$ & \\
\hline & uncertainty & exchar & & uncertainty & exchan & & uncertainty & exchal & \\
\hline \multirow{4}{*}{$\begin{array}{l}\Delta \text { Duty } \\
\Delta \text { Duty } \times \ln (\mathrm{TFP})\end{array}$} & $-2.176^{* * *}$ & $-1.189^{* *}$ & $-1.628^{* *}$ & $-2.333^{* * *}$ & $-1.324^{* *}$ & $-1.988^{* *}$ & -0.459 & -0.861 & 0.795 \\
\hline & $(0.739)$ & $(0.530)$ & $(0.662)$ & $(0.862)$ & $(0.594)$ & $(0.804)$ & $(1.130)$ & $(1.010)$ & $(1.111)$ \\
\hline & $0.462^{* * *}$ & $0.261^{* *}$ & $0.288^{* *}$ & $0.494^{* * *}$ & $0.302^{* *}$ & $0.366^{* *}$ & 0.150 & 0.150 & -0.131 \\
\hline & $(0.158)$ & $(0.119)$ & $(0.142)$ & $(0.189)$ & $(0.135)$ & $(0.179)$ & $(0.209)$ & $(0.183)$ & $(0.179)$ \\
\hline \multirow{5}{*}{$\begin{array}{l}\text { Firm-level Controls } \\
\text { Industry-level Competition Control } \\
\text { Industry Fixed Effect } \\
\text { Observation } \\
\text { R-square }\end{array}$} & yes & yes & yes & yes & yes & yes & yes & yes & yes \\
\hline & yes & yes & yes & yes & yes & yes & yes & yes & yes \\
\hline & yes & yes & yes & yes & yes & yes & yes & yes & yes \\
\hline & 15086 & 18809 & 9253 & 13352 & 16468 & 7906 & 1734 & 2341 & 1347 \\
\hline & 0.020 & 0.007 & 0.007 & 0.021 & 0.006 & 0.007 & 0.050 & 0.038 & 0.037 \\
\hline \multicolumn{10}{|c|}{$\begin{array}{l}\text { Notes: } * * * \mathrm{p}<0.01,{ }^{* *} \mathrm{p}<0.05,{ }^{*} \mathrm{p}<0.1 \text {. Robust standard errors corrected for clustering at the firm level in parentheses.Dependent } \\
\text { variable in specifications }(1),(2),(4),(5),(7), \text { and }(8) \text { is the }(\log ) \text { price change at the firm-HS6-country level; dependent variable in } \\
\text { specifications }(3),(6) \text {, and }(9) \text { is the }(\mathrm{log}) \text { price change at the firm-HS6 product level. All regressions include a constant term, firm-level } \\
\text { controls, and industry-level competition control. Industry-level competition control refers to the change of Herfindahl index. Firm-level } \\
\text { controls include the changes between } 2001 \text { and } 2006 \text { in the following variables: TFP, capital intensity, average wage, and total employment. } \\
\text { Industry fixed effect is computed at 2-digit CIC industry level. }\end{array}$} \\
\hline
\end{tabular}


Table A.18: Effect of Tariff Reductions on Quality

\begin{tabular}{|c|c|c|c|c|c|c|c|c|c|}
\hline & \multicolumn{9}{|c|}{ Dependent Variable: the change in effective quality $\Delta \ln \left(\hat{q}_{f h c}\right)$} \\
\hline & \multicolumn{3}{|c|}{ Whole Sample } & \multicolumn{3}{|c|}{ Differentiated Goods } & \multicolumn{3}{|c|}{ Homogeneous Goods } \\
\hline & (1) & $(2)$ & (3) & (4) & (5) & (6) & (7) & (8) & (9) \\
\hline$\Delta$ Duty & $\begin{array}{c}-5.585^{* *} \\
(2.389)\end{array}$ & $\begin{array}{c}-29.729^{* * *} \\
(8.059)\end{array}$ & $\begin{array}{c}-20.113^{* *} \\
(8.060)\end{array}$ & $\begin{array}{c}-6.575^{* *} \\
(2.660)\end{array}$ & $\begin{array}{c}-31.679^{* * *} \\
(9.091)\end{array}$ & $\begin{array}{c}-21.336^{* *} \\
(9.430)\end{array}$ & $\begin{array}{c}4.857 \\
(3.903)\end{array}$ & $\begin{array}{c}-2.060 \\
(10.678)\end{array}$ & $\begin{array}{c}-1.049 \\
(11.061)\end{array}$ \\
\hline$\Delta$ Duty $\times \ln (\mathrm{TFP})$ & & $\begin{array}{c}5.498^{* * *} \\
(1.637)\end{array}$ & $\begin{array}{l}3.820^{* *} \\
(1.655)\end{array}$ & & $\begin{array}{c}5.819^{* * *} \\
(1.896)\end{array}$ & $\begin{array}{l}3.909^{* *} \\
(1.991)\end{array}$ & & $\begin{array}{c}1.377 \\
(1.950)\end{array}$ & $\begin{array}{c}1.035 \\
(1.945)\end{array}$ \\
\hline Firm-level Controls & no & no & yes & no & no & yes & no & no & yes \\
\hline Industry-level Competition Control & no & no & yes & no & no & yes & no & no & yes \\
\hline Industry fixed effect & no & no & yes & no & no & yes & no & no & yes \\
\hline Observation & 16907 & 16907 & 16907 & 15018 & 15018 & 15018 & 1889 & 1889 & 1889 \\
\hline R-square & 0.001 & 0.003 & 0.018 & 0.001 & 0.003 & 0.017 & 0.001 & 0.001 & 0.068 \\
\hline
\end{tabular}

Notes: ${ }^{* * *} \mathrm{p}<0.01,{ }^{*} \mathrm{p}<0.05,{ }^{*} \mathrm{p}<0.1$. Robust standard errors corrected for clustering at the firm level in parentheses. Dependent variable is the $(\log )$ effective quality change at the firm-HS6-country level. All regressions include a constant term, firm-level controls, and industry-level competition control. Industry-level competition control refers to the change of Herfindahl index. Firm-level controls include the changes between 2001 and 2006 in the following variables: TFP, capital intensity, average wage, and total employment. Industry fixed effect is computed at 2-digit CIC industry level.

Table A.19: Results with Controlling for Markup

\begin{tabular}{|c|c|c|c|c|c|c|}
\hline & \multicolumn{6}{|c|}{ Dependent Variable: $\Delta \ln ($ price $)$} \\
\hline & \multicolumn{2}{|c|}{ Whole Sample } & \multicolumn{2}{|c|}{ Differentiated Goods } & \multicolumn{2}{|c|}{ Homogeneous Goods } \\
\hline & (1) & $(2)$ & (3) & (4) & (5) & (6) \\
\hline$\Delta$ Duty & $\begin{array}{c}-2.432^{* * *} \\
(0.697)\end{array}$ & $\begin{array}{c}-2.200 * * * \\
(0.771)\end{array}$ & $\begin{array}{c}-2.588^{* * *} \\
(0.803)\end{array}$ & $\begin{array}{c}-2.220^{* *} \\
(0.892)\end{array}$ & $\begin{array}{l}-0.466 \\
(1.179)\end{array}$ & $\begin{array}{c}-4.634 \\
(10.600)\end{array}$ \\
\hline$\Delta$ Duty $\times \ln (\mathrm{TFP})$ & $\begin{array}{c}0.499^{* * *} \\
(0.149)\end{array}$ & $\begin{array}{c}0.446^{* * *} \\
(0.165)\end{array}$ & $\begin{array}{c}0.523^{* * *} \\
(0.176)\end{array}$ & $\begin{array}{c}0.444^{* *} \\
(0.194)\end{array}$ & $\begin{array}{c}0.180 \\
(0.229)\end{array}$ & $\begin{array}{c}0.900 \\
(1.862)\end{array}$ \\
\hline$\Delta$ Market share & $\begin{array}{c}0.124^{* * *} \\
(0.025)\end{array}$ & $\begin{array}{c}1.145 \\
(1.134)\end{array}$ & $\begin{array}{c}0.131^{* * *} \\
(0.027)\end{array}$ & $\begin{array}{c}1.094 \\
(0.959)\end{array}$ & $\begin{array}{c}0.047 \\
(0.046)\end{array}$ & $\begin{array}{c}3.104 \\
(7.462)\end{array}$ \\
\hline Firm-level Controls & yes & yes & yes & yes & yes & yes \\
\hline Industry-level Competition Control & yes & yes & yes & yes & yes & yes \\
\hline Industry fixed effect & yes & yes & yes & yes & yes & yes \\
\hline Observation & 16907 & 16907 & 15018 & 15018 & 1889 & 1889 \\
\hline R-square & 0.019 & 0.017 & 0.020 & 0.017 & 0.059 & 0.058 \\
\hline Kleibergen-Paap rk LM $\chi^{2}$ statistic & & 3.56 & & 4.82 & & 0.26 \\
\hline Kleibergen-Paap rk Wald F statistic & & 3.52 & & 4.79 & & 0.25 \\
\hline
\end{tabular}

Notes: $* * * \mathrm{p}<0.01,{ }^{*} \mathrm{p}<0.05, * \mathrm{p}<0.1$. Robust standard errors corrected for clustering at the firm level in parentheses. Dependent variable is the $(\log )$ price change at the firm-HS6-country level. All regressions include a constant term, firm-level controls, and industry-level competition control. Industry-level competition control refers to the change of Herfindahl index. Firm-level controls include the changes between 2001 and 2006 in the following variables: TFP, capital intensity, average wage, and total employment. Industry fixed effect is computed at 2-digit CIC industry level. 
Table A.20: Results on Imported Inputs Share

\begin{tabular}{|c|c|c|c|c|c|c|}
\hline & \multicolumn{3}{|c|}{ Imported Inputs Share } & \multicolumn{3}{|c|}{ Change in Imported Inputs Share } \\
\hline & (1) & $(2)$ & (3) & (4) & $(5)$ & (6) \\
\hline $\ln (\mathrm{TFP})$ & $\begin{array}{c}0.020^{* * *} \\
(0.003)\end{array}$ & $\begin{array}{c}0.033^{* * *} \\
(0.003)\end{array}$ & $\begin{array}{c}0.027^{* * *} \\
(0.004)\end{array}$ & & & \\
\hline$\Delta$ Duty & & & & $\begin{array}{c}-0.422^{* *} \\
(0.165)\end{array}$ & $\begin{array}{c}-0.530^{* * * *} \\
(0.180)\end{array}$ & $\begin{array}{c}-0.419^{* *} \\
(0.198)\end{array}$ \\
\hline$\Delta$ Duty $\times \ln (\mathrm{TFP})$ & & & & $\begin{array}{c}0.082^{* *} \\
(0.032)\end{array}$ & $\begin{array}{c}0.117^{* * *} \\
(0.037)\end{array}$ & $\begin{array}{c}0.093^{* *} \\
(0.040)\end{array}$ \\
\hline$\Delta \ln (\mathrm{TFP})$ & & & & & & $\begin{array}{c}0.006^{* *} \\
(0.003)\end{array}$ \\
\hline Other Firm-level Controls & no & no & yes & no & no & yes \\
\hline Industry-level Competition Control & no & no & yes & no & no & yes \\
\hline Industry Fixed Effect & no & yes & yes & no & yes & yes \\
\hline Cluster at Firm Level & yes & yes & yes & yes & yes & yes \\
\hline Observation & 4148 & 4148 & 4148 & 4148 & 4148 & 4148 \\
\hline R-square & 0.013 & 0.110 & 0.186 & 0.003 & 0.022 & 0.025 \\
\hline
\end{tabular}

Notes: ${ }^{* * *} \mathrm{p}<0.01,{ }^{* *} \mathrm{p}<0.05,{ }^{*} \mathrm{p}<0.1$. Robust standard errors corrected for clustering at the firm level in parentheses. Dependent variable in specifications 1-3 is the ratio of imported intermediate inputs in total intermediate inputs; dependent variable in specifications 4-6 is the change of the ratio of imported intermediate inputs. All regressions include a constant term, firm-level controls, and industry-level competition control. Firm-level controls refer to the levels (in Columns 1-3) or the changes (in Columns 4-6) of the following variables: TFP, capital intensity, average wage, and total employment. Industry-level competition control refers to Herfindahl index (in Columns 1-3) and the change of Herfindahl index (in Columns 4-6). 